\title{
Probabilistic Seismic Hazard Characterization and Design Parameters for the Pantex Plant
}

Prepared by

J. B. Savy

W. Foxall

D. L. Bernreuter

Hazards Mitigation Center

Lawrence Livermore National Laboratory

Prepared for

Mason \& Hanger Corporation 


\section{DISCLAIMER}

This document was prepared as an account of work sponsored by an agency of the United States Government. Neither the United States Government nor the University of California nor any of their employees, makes any warranty, express or implied, or assumes any legal liability or responsibility for the accuracy, completeness, or usefulness of any information, apparatus, product, or process disclosed, or represents that its use would not infringe privately owned rights. Reference herein to any specific commercial product, process, or service by trade name, trademark, manufacturer, or otherwise, does not necessarily constitute or imply its endorsement, recommendation, or favoring by the United States Government or the University of California. The views and opinions of authors expressed herein do not necessarily state or reflect those of the United States Government or the University of California and shall not be used for advertising or product endorsement purposes.

Work performed under the auspices of the U.S. Department of Energy by Lawrence Livermore National Laboratory under Contract W-7405-ENG-48. 


\section{Probabilistic Seismic Hazard Characterization and Design Parameters for the Pantex Plant}

Manuscript date: October 19, 1998

Prepared by

J. B. Savy

W. Foxall

D. L. Bernreuter

Lawrence Livermore National Laboratory

7000 East Avenue

Livermore, CA 94550

Prepared for

Mason \& Hanger Corporation 


\begin{abstract}
The Hazards Mitigation Center at Lawrence Livermore National Laboratory (LLNL) updated the seismic hazard and design parameters at the Pantex Plant. The probabilistic seismic hazard (PSH) estimates were first updated using the latest available data and knowledge from LLNL (1993, 1998), Frankel et al. (1996), and other relevant recent studies from several consulting companies. Special attention was given to account for the local seismicity and for the system of potentially active faults associated with the Amarillo-Wichita uplift. Aleatory (random) uncertainty was estimated from the available data and the epistemic (knowledge) uncertainty was taken from results of similar studies. Special attention was given to soil amplification factors for the site. Horizontal Peak Ground Acceleration (PGA) and 5\% damped uniform hazard spectra were calculated for six return periods (100 yr., 500 yr., 1000 yr., 2000 yr., 10,000 yr., and 100,000 yr.). The design parameters were calculated following DOE standards (DOE-STD-1022 to 1024). Response spectra for design or cvaluation of Pcrformance Catcgory 1 through 4 structures, systems, and components are provided.
\end{abstract}




\section{TABLE OF CONTENTS}

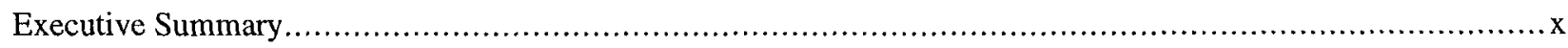

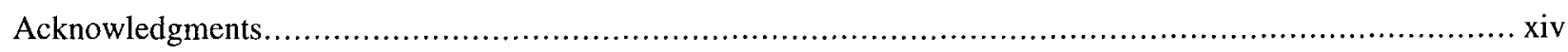

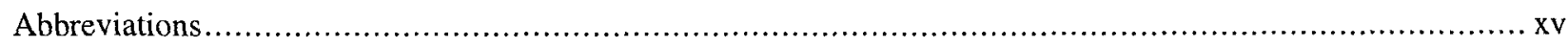

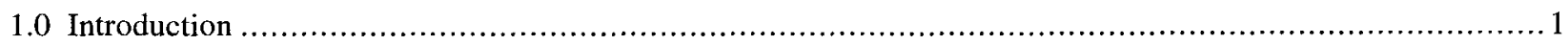

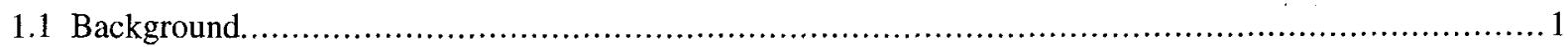

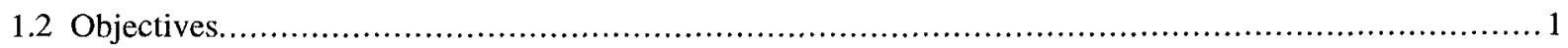

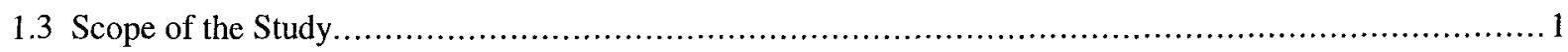

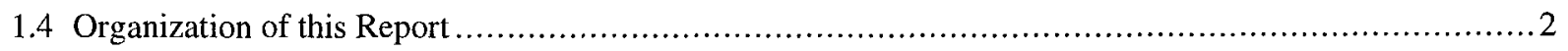

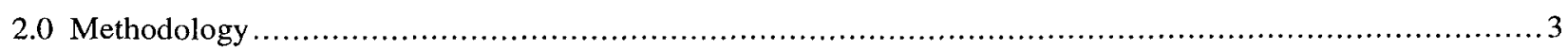

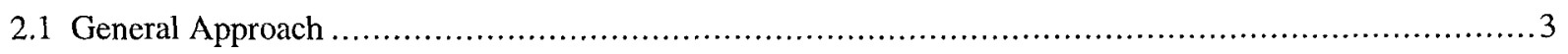

2.2 Seismic Hazard Characterization Model ............................................................................ 4

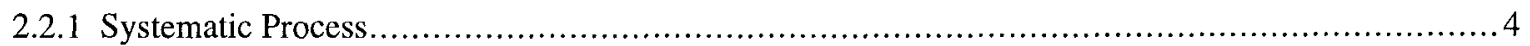

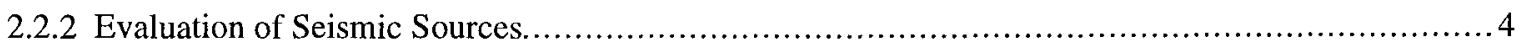

2.2.3 Evaluation of Earthquake Recurrence and Maximum Magnitude...................................... 5

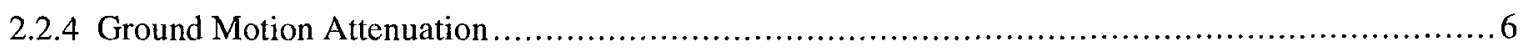

2.2.5 Mathematical Model to Calculatc Scismic Hazard....................................................... 6

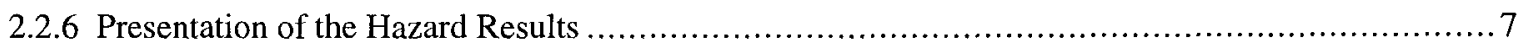

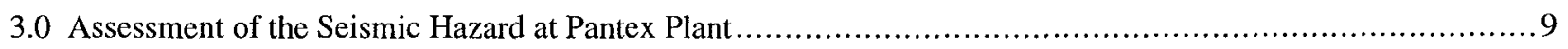

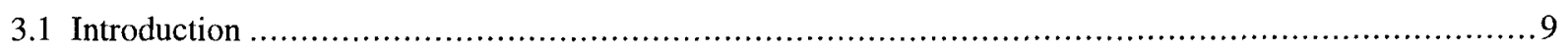

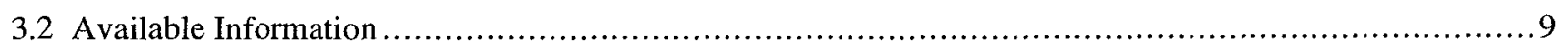

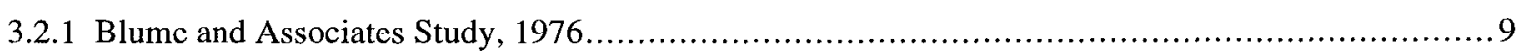

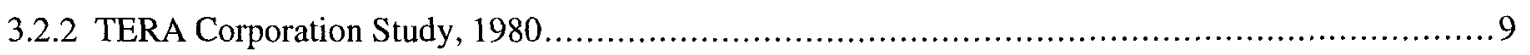

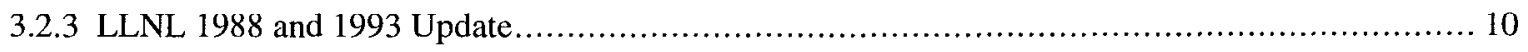

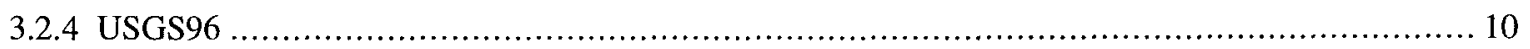

3.2.5 Pantex Environmental Information Document, September 1996 ........................................ 10

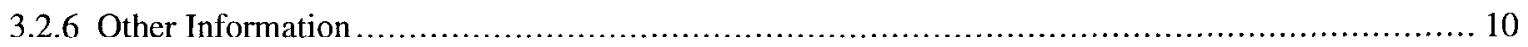

3.3 Description of the Hazards Model .......................................................................... 11

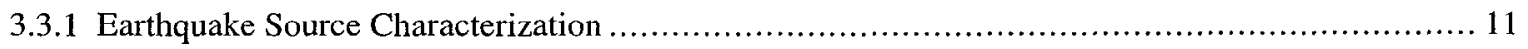

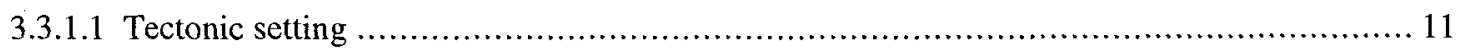

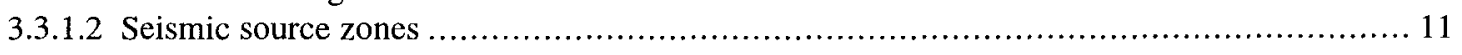

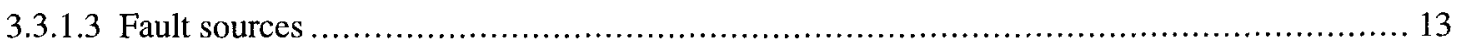

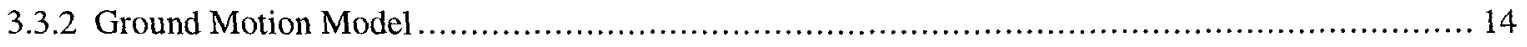

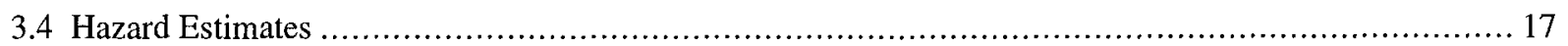

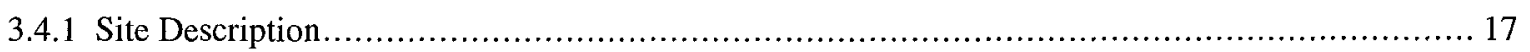

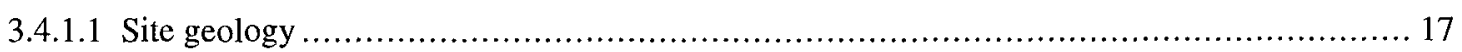

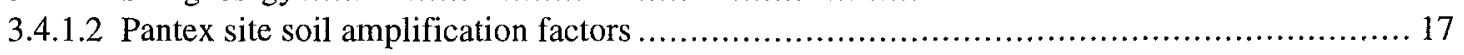

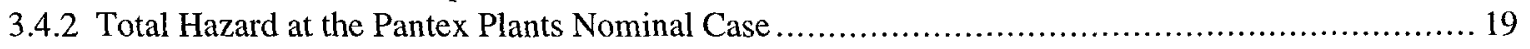

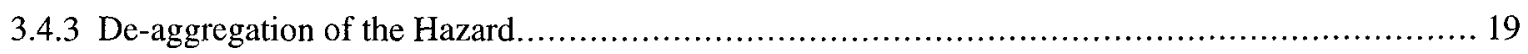


3.4.4 Sensitivity Analysis.

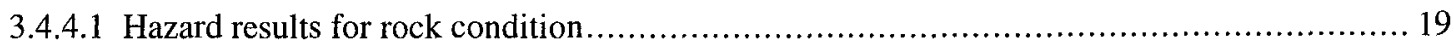

3.4.4.2 Probabilistic seismic hazard analysis with Atkinson-Boore (1995) ground motion model with the USGS B/C boundary amplification............................................... 20

3.4.4.3 Effect of the lower magnitude bound of integration.............................................. 20

3.4.4.4 Effect of considering only the area source zone located within approximately $40 \mathrm{~km}$ to

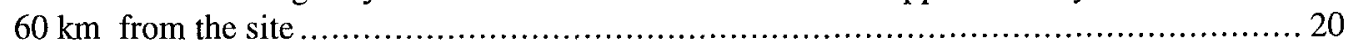

3.4.4.5 Sensitivity to the weight given to the extended Meers fault...................................... 20

3.4.4.6 Sensitivity to the location of the Amarillo-Wichita uplift boundary ............................... 21

3.4.4.7 Influence of the epistemic uncertainty in ground motion prediction on the uniform hazard

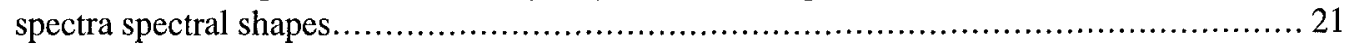

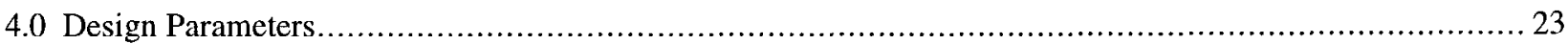

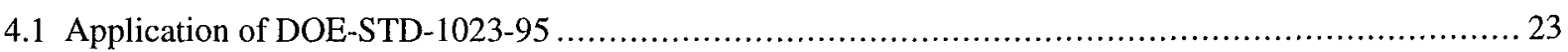

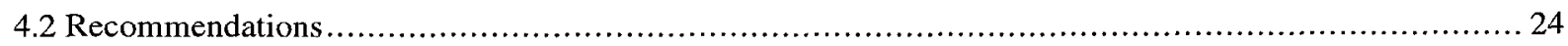

4.2.1 Recommendations on the Design Basis Peak Ground Acceleration and Spectra for Pantex Site..... 24

4.2.1.1 Mean hazard curve and design basis peak ground acceleration for Pantex soil .................. 24

4.2.1.2 Design basis response spectra for Pantex soil.................................................. 25

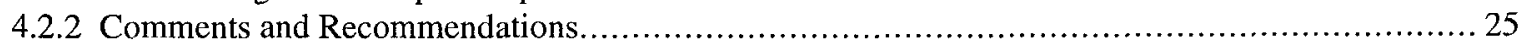

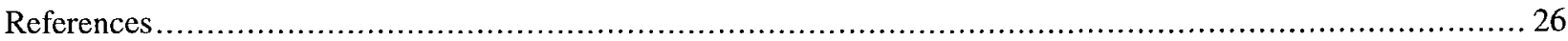

\section{LIST OF TABLES}

Tables....... 31

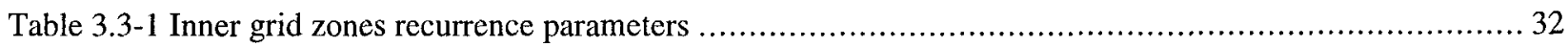

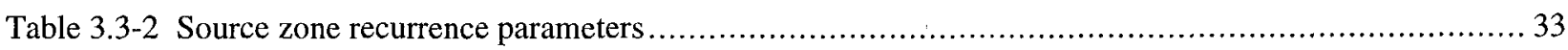

Table 3.3 3 Recurrence parameters for the Meers and Cheraw faults ............................................... 33

Table 3.3-4 Recurrence parameters for Rio Grande faults...................................................... 34

Table 3.3-5 Coefficient of the median LLNL93 composite model used for the study at Pantex Plant for rock ....... 35

Table 3.3-6 Coefficients of A/B95 model used in the sensitivity analysis for rock site conditions.................... 36

Table 3.3-7 Tabulation of PGA comparison between composite LLNL93 model, A/B95, USGS96 and TAS97

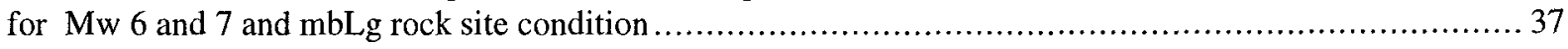

Table 3.3-8 Response spectral acceleration value comparisons for four ground motion models for two pairs of

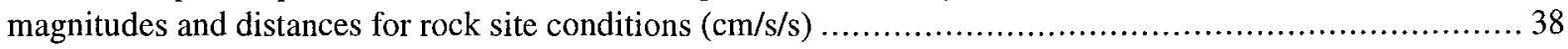

Table 3.4-1 Amplification factors used for the seismic hazard characterization of the Pantex site (EPRI 1993) ..... 39

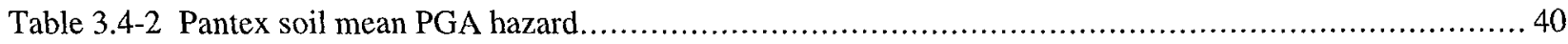

Table 3.4-3 Summary of controlling earthquakes for $500 \mathrm{yr}$., $2000 \mathrm{yr}$., 10,000 yr., return periods and for the average of $(1-2.5 \mathrm{~Hz})$ mean hazard and $(5-10 \mathrm{~Hz})$ mean hazard ............................................ 40

Table 3.4-4 B/C boundary (USGS96) soil amplification factors used in the calculation of the total hazard with

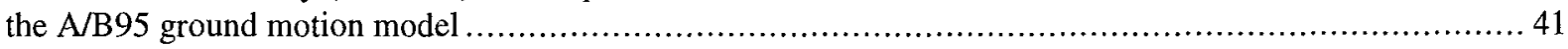

Table 3.4-5 Percent contributions of seismic sources to the total mean hazard in terms of PGA ...................... 41

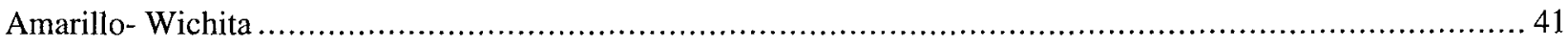

Table 4.2-1 5\%-damped design basis response spectra PGA values for Pantex soil.................................. 42

Table 4.2-2 Final design basis earthquake, 5\%-damped spectral velocities $(\mathrm{cm} / \mathrm{s})$ for the Pantex site, for PC1,

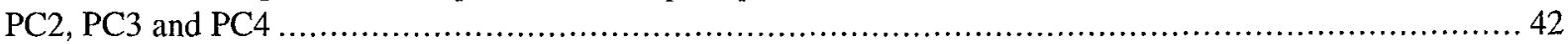

Table 4.2-3 Ratio of the final DBE to the UHS spectral velocity spectra........................................ 43 


\section{LIST OF FIGURES}

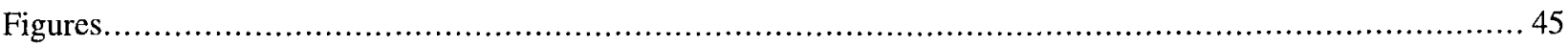

Figure 2.2-1 Basic steps of the methodology of assessing vibratory ground motion hazard.......................... 46

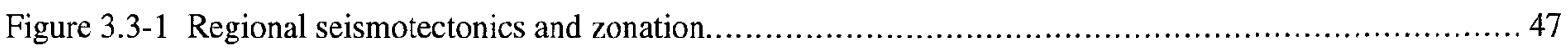

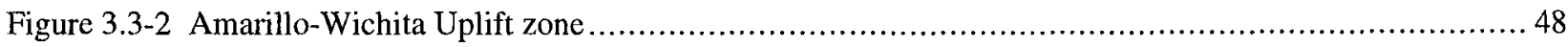

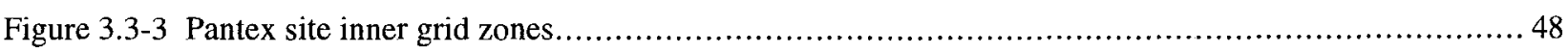

Figure 3.3-4 Comparison of median PGA estimates for $\mathrm{Mw}=5.0, \mathrm{mbLg}=5.5$ on rock........................... 49

Figure 3.3-5 Comparison of median PGA estimates for $\mathrm{Mw}=6.0, \mathrm{mbLg}=6.3$ on rock .......................... 49

Figure 3.3-6 Comparison of median PGA estimates for $\mathrm{Mw}=\mathrm{mbLg}=7.0$ on rock ................................. 50

Figure 3.3-7 Comparison of median spectral acceleration estimates for $10 \mathrm{~km}, \mathrm{Mw}=5.0, \mathrm{mbLg}=5.5$ on rock...... 50

Figure 3.3-8 Comparison of median acceleration spectral estimates for $20 \mathrm{~km}, \mathrm{Mw}=5.0, \mathrm{mbLg}=5.5$ on rock ...... 51

Figure 3.3-9 Comparison of median spectral acceleration estimates for $100 \mathrm{~km}, \mathrm{Mw}=5.0, \mathrm{mbLg}=5.5$ on rock .... 51

Figure 3.3-10 Comparison of median spectral acceleration estimates for $10 \mathrm{~km}, \mathrm{Mw}=6.0, \mathrm{mbLg}=6.3$ on rock ..... 52

Figure 3.3-11 Comparison of median spectral acceleration estimates for $20 \mathrm{~km}, \mathrm{Mw}=6.0, \mathrm{mbLg}=6.3$ on rock ..... 52

Figure 3.3-12 Comparison of median spectral acceleration estimates for $100 \mathrm{~km}, \mathrm{Mw}=6.0, \mathrm{mbLg}=6.3$ on rock .... 53

Figure 3.3-13 Comparison of median spectral acceleration estimates for $10 \mathrm{~km}, \mathrm{Mw}=\mathrm{mbLg}=7.0$ on rock ......... 53

Figure 3.3-14 Comparison of median spectral acceleration estimates for $20 \mathrm{~km}, \mathrm{Mw}=\mathrm{mbLg}=7.0$ on rock ......... 54

Figure 3.3-15 Comparison of median spectral acceleration estimates for $100 \mathrm{~km}, \mathrm{Mw}=\mathrm{mbLg}=7.0$ on rock ........54

Figure 3.4-1 15th, 50th, 85th percentiles and mean annual probability of exceedance of the PGA for the Pantex soil site, using the LLNL93 rock ground motion model and the EPRI93 amplification factor .................. 55

Figure 3.4-2 100-year return period 5\%-damped mean, 15 th, 50th and 85 th percentile uniform hazard response spectra for the Pantex site soil conditions using the LLNL93 rock ground motion model and EPRI93 amplification factors

Figure 3.4-3 500-year return period 5\%-damped mean, 15th, 50th and 85th percentile uniform hazard response spectra for the Pantex site soil conditions using the LLNL93 rock ground motion model and EPRI93 amplification factors

Figure 3.4-4 1,000-year return period 5\%-damped mean, 15th, 50th and 85th percentile uniform hazard response spectra for the Pantex site soil conditions using the LLNL93 rock ground motion model and EPRI93 amplification factors.

Figure 3.4-5 2,000-year return period 5\%-damped mean, 15th, 50th and 85th percentile uniform hazard response spectra for the Pantex site soil conditions using the LLNL93 rock ground motion model and EPRI93 amplification factors.

Figure 3.4-6 10,000-year return period 5\%-damped mean, 15th, 50th and 85th percentile uniform hazard response spectra for the Pantex site soil conditions using the LLNL93 rock ground motion model and EPRI93 amplification factors.

Figure 3.4-7 100,000-year return period 5\%-damped mean, 15th, 50th and 85th percentile uniform hazard response spectra for the Pantex site soil conditions using the LLNL93 rock ground motion model and

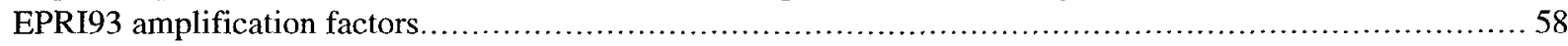

Figure 3.4-8 Mean hazard curve for Pantex rock site with LLNL93 ground motion model........................... 58

Figure 3.4-9 100-year return period 5\%-damped, mean, 15th, 50th and 85th percentiles UHS for Pantex rock site using the LLNL93 ground motion model. 


\section{LIST OF FIGURES, CONT'D.}

Figure 3.4-10 500-year return period 5\%-damped, mean, 15th, 50th and 85th percentiles UHS for Pantex rock site using the LLNL93 ground motion model.

Figure 3.4-11 1,000-year return period 5\%-damped, mean, 15th, 50th and 85th percentiles UHS for Pantex rock site using the LLNL93 ground motion model.

Figure 3.4-12 2,000-year return period 5\%-damped, mean, 15th, 50th and 85th percentiles UHS for Pantex rock site using the LLNL93 ground motion model.

Figure 3.4-13 10,000-year return period 5\%-damped, mean, 15th, 50th and 85th percentiles UHS for Pantex rock site using the LLNL93 ground motion model.

Figure 3.4-14 100,000-year return period 5\%-damped, mean, 15th, 50th and 85th percentiles UHS for Pantex rock site using the LLNL93 ground motion model

Figure 3.4-15 Total mean hazard curve with A/B95 ground motion rock model and USGS B/C boundary soil correction.

Figure 3.4-16 Mean UHS 5\%-damped response spectra with A/B95 ground motion model and USGS B/C boundary soil correction .....

Figure 3.4-17 Mean hazard for nominal case and extended Meers weight/10...... 63

Figure 3.4-18 Comparison of the mean hazard for nominal case, rates $/ 5$ in AWU and rate $\times 5$ in inner grid.

Figure 3.4-19 Median soil site response spectrum for each of the six controlling earthquakes (I.I.NI .93 ground motion model and the EPRI93 amplification factors).

Figure 3.4-20 Median soil site response spectrum for each of the six controlling earthquakes (A/B95 ground motion model and the EPRI93 amplification factors).

Figure 3.4-21 Median rock site response spectrum for each of the six controlling earthquakes (LLNL93 ground motion model)

Figure 3.4-22 Median rock site response spectrum for each of the six controlling earthquakes (A/B95 ground motion model)

Figure 3.4-23 Comparison of site amplification factors considered in this study for Pantex site. 66

Figure 3.4-24 Scaling of the LLNL93 controlling earthquakes response spectral shape to the spectral values of the 500-year return period UHS at $(1-2.5 \mathrm{~Hz})$ and $(5-10 \mathrm{~Hz})$.

Figure 3.4-25 Scaling of the LLNL93 controlling earthquakes response spectral shape to the spectral acceleration values of the 1,000-year return period UHS at $(1-2.5 \mathrm{~Hz})$ and $(5-10 \mathrm{~Hz})$...

Figure 3.4-26 Scaling of the LLNL93 controlling earthquakes response spectral acceleration shape to the spectral values of the 2,000-year return period UHS at $(1-2.5 \mathrm{~Hz})$ and $(5-10 \mathrm{~Hz})$.

Figure 3.4-27 Scaling of the LLNL93 controlling earthquakes response spectral acceleration shapes to the spectral values of the 10,000-year return period UHS at $(1-2.5 \mathrm{~Hz})$ and $(5-10 \mathrm{~Hz})$.

Figure 3.4-28 Comparison of spectral shapes between the LLNL93, Mw 6, 100-km distance model and the 10,000-year return period UHS shapes with full uncertainty labeled "Full UNC" and with no epistemic uncertainty in the ground motion models labeled "No UNC".

Figure 3.4-29 Comparison of spectral shapes between the LLNL93, Mw 6, 20-km distance model and the 10,000-year return period UHS shapes with full uncertainty labeled "Full UNC" and with no epistemic uncertainty in the ground motion model labeled "No UNC".

Figure 3.4-30 Comparison of spectral shapes between the LLNL93, Mw 5, 20-km distance model and the 10,000-year return period UHS shapes with full uncertainty labeled "Full UNC" and with no epistemic uncertainty in the ground motion model labeled "No UNC". 


\section{LIST OF FIGURES, CONT'D.}

Figure 4.1-1 Contributions of magnitude and distance bins to the avg. (1.0-2.5 Hz) 10,00-yr. mean hazard ........ 70

Figure 4.1-2 Contribution of the distance and magnitude bins to the avg. (5.0-10.0 Hz) 10,000-yr. mean hazard.. 70

Figure 4.1-3 Comparison of the UHS spectra and the (1-2.5Hz) scaled low-frequency scenario earthquake

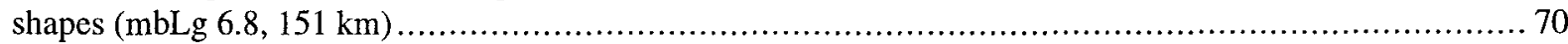

Figure 4.2-1 Final estimate of the mean, 15th, 50th, and 85th percentile hazard (annual probability of exceedance) at the Pantex soil site, with a linear PGA axis

Figure 4.2-2 Final estimate of the mean, 15th, 50th, and 85th percentile hazard (annual probability of

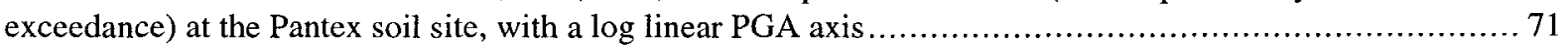

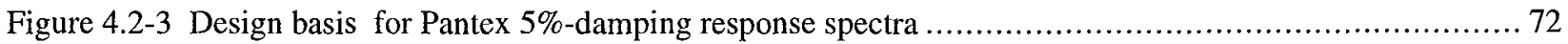

Figure 4.2-4 DBE response spectra for Pantex PC 1 (500 yr.) 0.5, 2.0, 5.0, 7.0 and 10.0\% damping................. 73

Figure 4.2-5 DBE response spectra for Pantex PC 2 (1000 yr.) 0.5, 2.0, 5.0, 7.0 and 10.0\% damping................ 74

Figure 4.2-6 DBE response spectra for Pantex PC 3 (2000 yr.) 0.5, 2.0, 5.0, 7.0 and 10.0\% damping............... 75

Figure 4.2-7 DBE response spectra for Pantex PC 4 (10,000 yr.) 0.5, 2.0, 5.0, 7.0 and 10.0\% damping ............. 76 


\section{EXECUTIVE SUMMARY}

All available applicable information has been incorporated into the probabilistic seismic hazard characterizations for the Pantex Plant. Numerous comparisons between current models have been conducted and sensitivity studies were carried out.

The following figures show the results of this study for use in evaluating structures, systems, and components at the Pantex Plant. The figures are numbered to correspond to the sections in which they are discussed.

Tablc 3.4-2 shows the Pantex soil mean PGA hazard. Table 4.2-2 shows the 5\% damped response spcctra values for the periods corresponding to the four performance categories $\mathrm{PC} 1,2,3$, and 4 . These values are recommended for design and evaluations of structures, systems, and components at the Pantex Plant.

With regard to horizontal peak ground acceleration, in the absence of site-specific data, it is recommended to use the standard $\mathrm{V}=2 / 3 \mathrm{H}$.

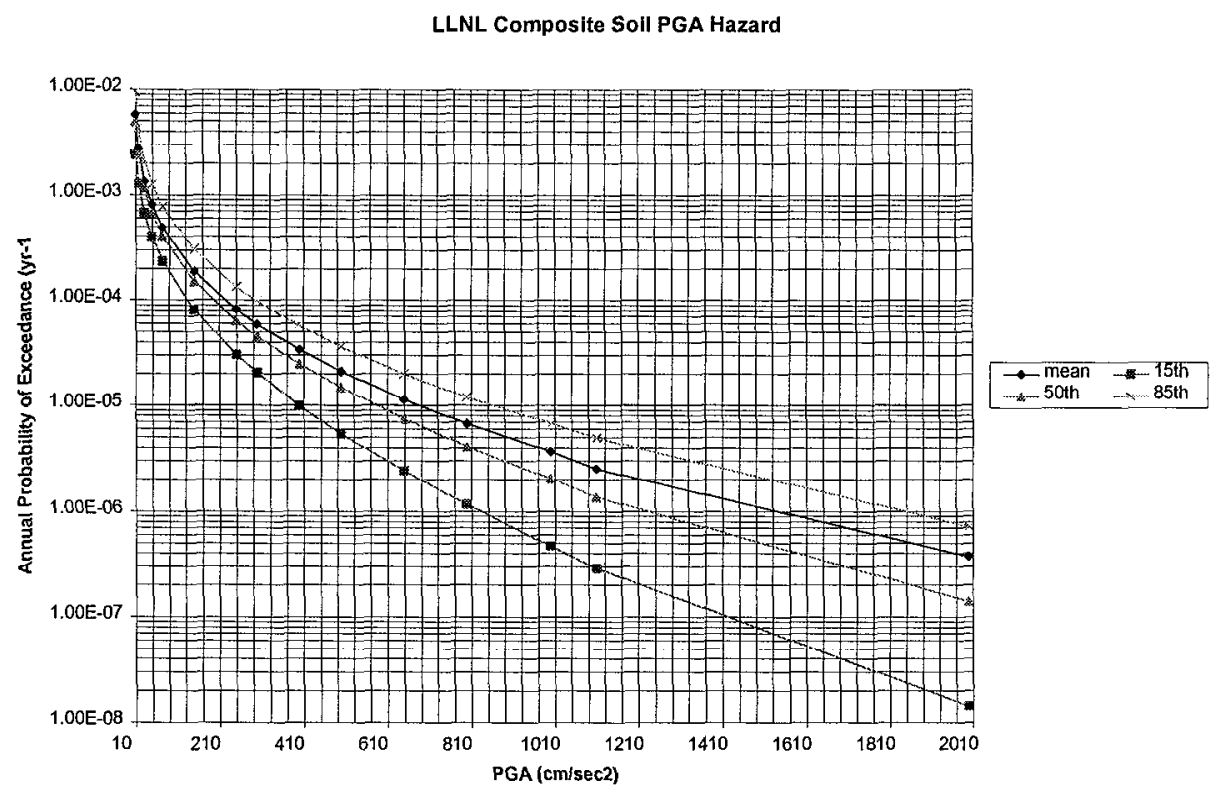

Figure 4.2-1 Final estimate of the mean, 15th, 50th, and 85th percentile hazard (annual probability of exceedance) at the Pantex soil site, with a linear PGA axis 
LL.NL Composite Soil PGA Hazard

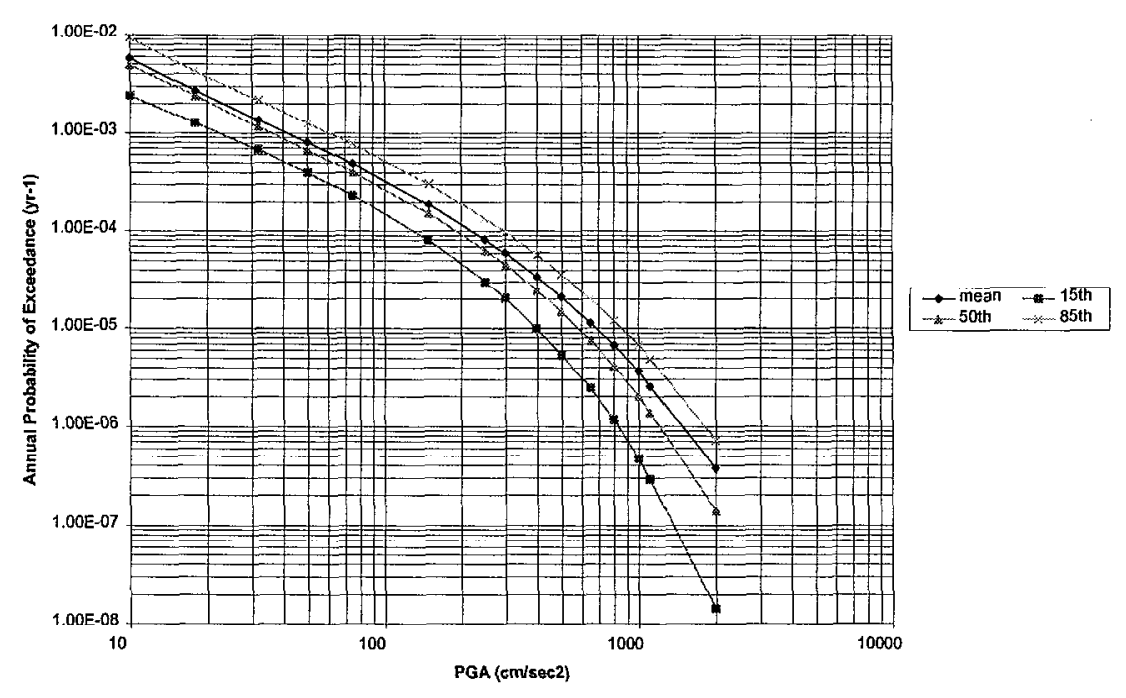

Figure 4.2-2 Final estimate of the mean, 15th, $50 \mathrm{th}$, and 85th percentile hazard (annual probability of exceedance) at the Pantex soil site, with a log linear PGA axis

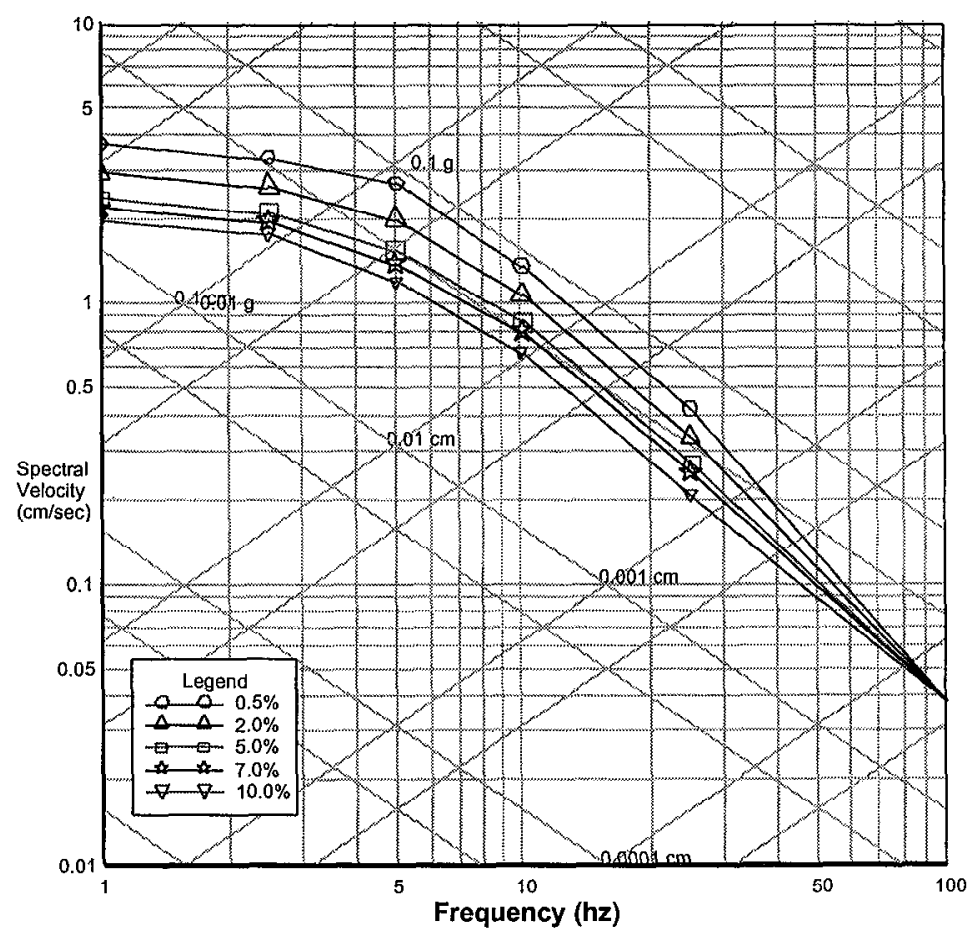

Figure 4.2-3 DBE response spectra for Pantex PC1 (500 yr) 0.5, 2.0, 5.0, 7.0 and 10.0\% damping 


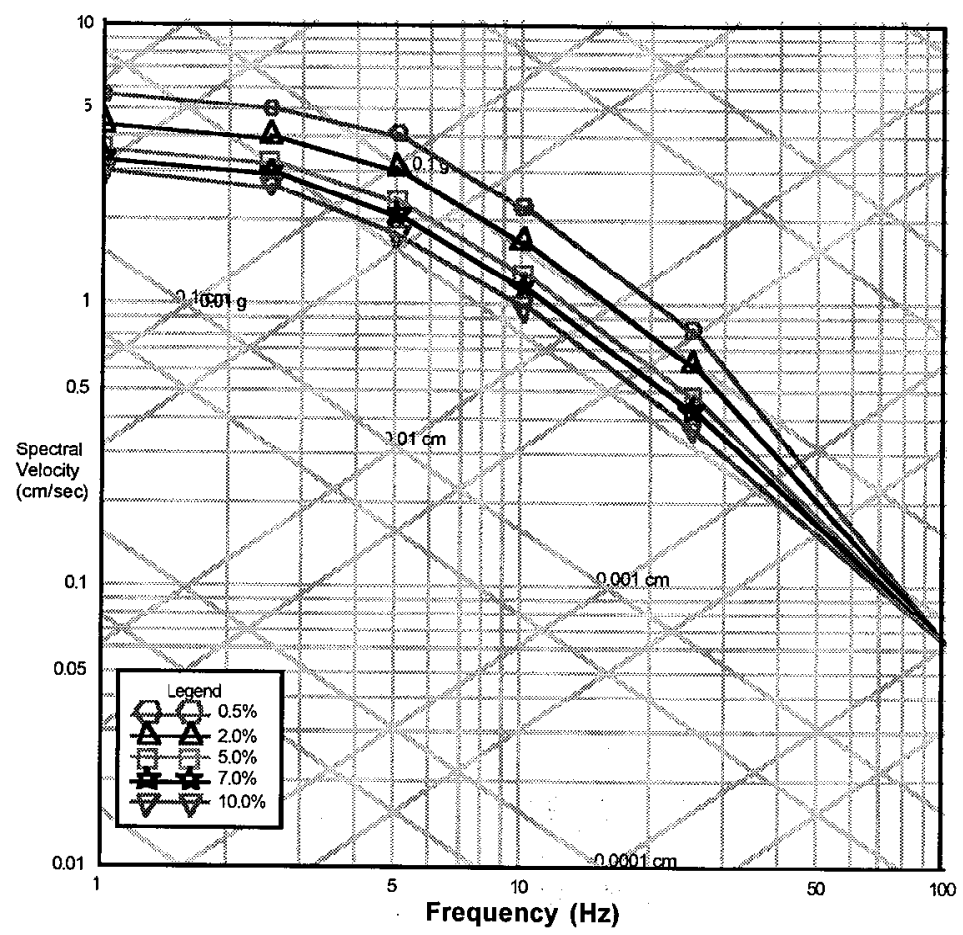

Figure 4.2-4 DBE response spectra for Pantex PC2 (1000 yr) 0.5, 2.0, 5.0, 7.0 and 10.0\% damping

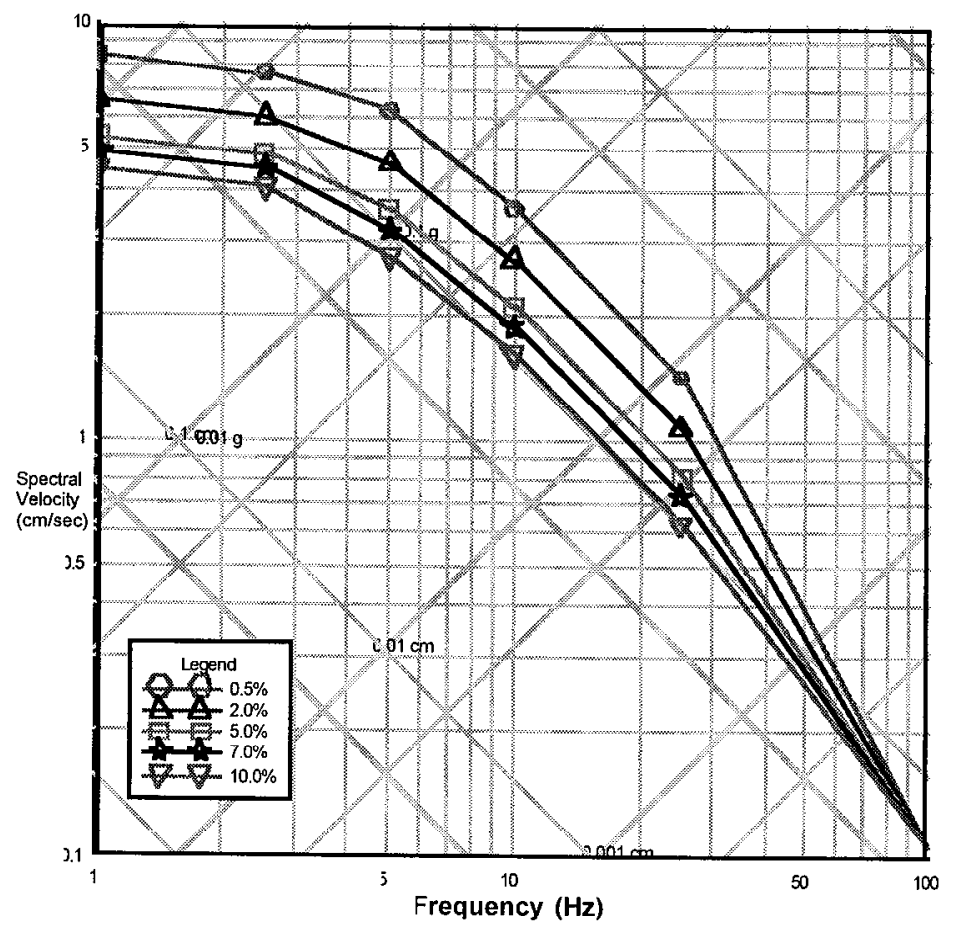

Figure 4.2-5 DBE response spectra for Pantex PC3 (2000 yr.) 0.5, 2.0, 5.0, 7.0 and 10.0\% damping 


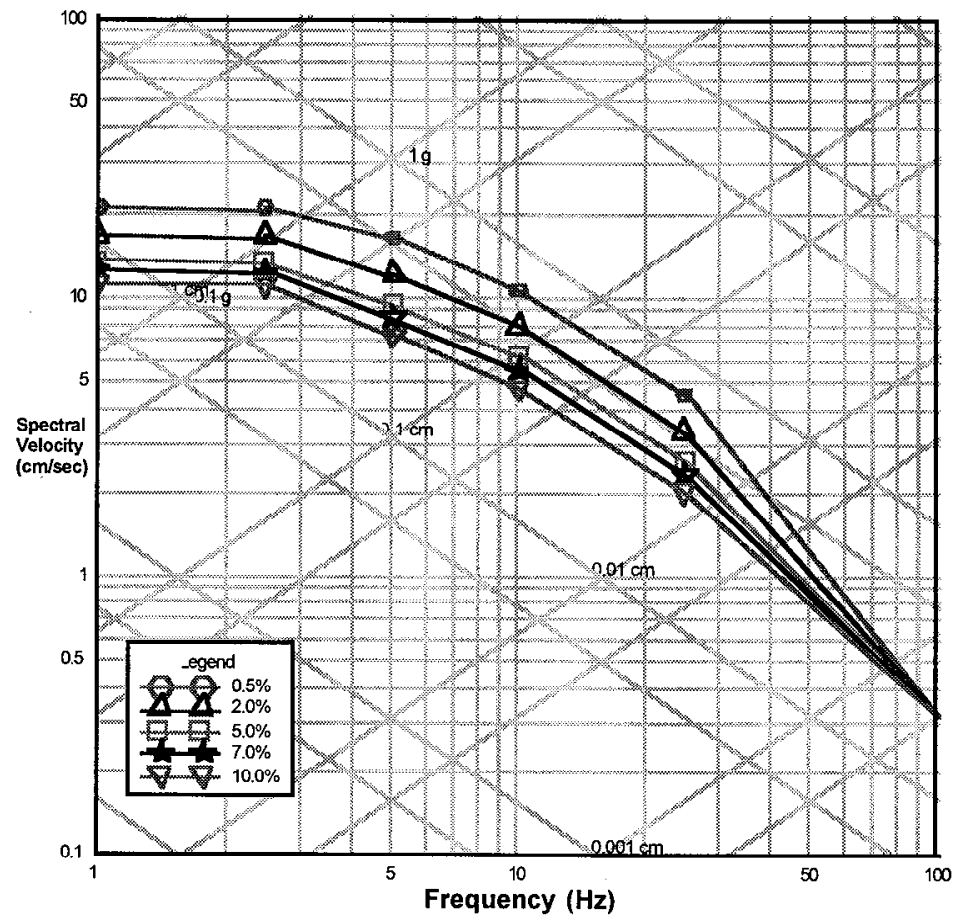

Figure 4.2-6 DBE response spectra for Pantex PC4 (10,000 yr.) 0.5, 2.0, 5.0, 7.0 and 10.0\% damping 


\section{ACKNOWLEDGMENTS}

The authors wish to acknowledge the support of numerous experts around the country who provided opinions and offered judgments on seismicity and ground motion modeling which were factored into this study. Their contributions have been referenced as personal communications.

Art Frankel and his team at the USGS in Colorado participated in a one-day workshop to discuss available seismic hazard modeling information affecting the Pantex site.

Charlie Green and Jeff Wang, Mason \& Hanger Corp., provided data available at the Pantex Plant and reviewed the draft version of the report.

Jeff Kimball, DOE/DP and Ivan Wong, Woodward-Clyde Federal Services under contract to Los Alamos National Laboratory, provided detailed comments on the modeling used in this analysis.

Mike Bohn, Sandia National Laboratory, provided overall comments on the methodology.

Richard Lee, Westinghouse Savannah River Company, worked with us for one week and assisted in developing soil amplification factors for the Pantex Site.

Bob Murray, Lawrence Livermore National Laboratory, was the project manager and assisted in report preparation and review.

Lyssa Campbell, Lawrence Livermore National Laboratory, edited the manuscript and helped format the final report.

Rosa Yamamoto, Lawrence Livermore National Laboratory, typed the manuscript and helped finalize the report. 


\section{ABBREVIATIONS}

AWU Amarillo-Wichita uplift

BP before present

CEUS central and eastern United States

CNA central North America

DBE design basis earthquake

DOE U.S. Department of Energy

DRS dynamic response spectrum

ENA eastern North America

EPRI Electric Power Research Institute

HMC Hazard Mitigation Center at LLNL

LLNL Lawrence Livermore National Laboratory

MHC Mason \& Hanger Corporation

NRC Nuclear Regulatory Commission

PGA peak ground acceleration

PSH probabilistic seismic hazard

PSHA probabilistic seismic hazard analysis

SRS Savannah River Site

SSHAC Senior Seismic Hazard Analysis Committee

TFI Technical Facilitator Integrator

UHS uniform hazard spectra

WUS western United States 


\section{PROBABILISTIC SEISMIC HAZARD CHARACTERIZATION AND DESIGN PARAMETERS FOR THE PANTEX PLANT}

\subsection{INTRODUCTION}

\subsection{Background}

The Hazard Mitigation Center (HMC) at Lawrence Livermore National Laboratory (LLNL) has been requested by Mason \& Hanger Corporation (MHC) to update the seismic design response parameters at the Pantex Plant. MHC is under contract to the U.S. Department of Energy (DOE) to operate the Pantex Plant near Amarillo, Texas. MHC is required to comply with DOE Order 5480.28 (now DOE Order 420.1), "Natural Phenomena Hazard Mitigation" and to use the DOE standard DOE-STD-1023-95, "Natural Phenomena Hazards Assessment Criteria." DOE Order 420.1 requires that the need for updating the site seismic hazard assessment be reviewed and updated if necessary, at least every 10 years. DOE-STD-1024-92 indicates that the approach used for the seismic hazard assessments summarized in UCRL-53582 (Coats et al. 1984), which is more than 10 years old, is out-of-date relative to the current state-of-the-art. Since the TERA Corporation seismic hazard curves no longer represent statc-of-the-art seismic hazard estimates, it is necessary to update the Pantex Plant seismic hazard and dynamic response spectrum curves. This assessment considers site-specific information discussed in DOE-STD-1022-94, "Natural Phenomena Hazards Site Characterization Criteria." In addition, Pantex Plant's site-specific Probabilistic Seismic Hazard Analysis (PSHA) has passed the 10-year review period, requiring MHC to employ a subcontractor with the expertise to perform this assessment. LLNL has been assigned this task and is using only readily available data from previous studies for the final estimation of the hazard, including

1 the latest eastern U.S. studies sponsored by the Nuclear Regulatory Commission (NRC) titled "Recommendations for Probabilistic Seismic Hazard Analysis: Guidance on Uncertainty and Use of Experts," (NUREG/CR-6372) and "Guidance for Performing Probabilistic Seismic Hazard Analysis for a Nuclear Plant Site: Example Application to the Southern United States" (Savy et al. 1998), and

2 the national hazard mapping studies sponsored by the U.S. Geological Survey (USGS) titled "National Seismic Hazards Maps: Documentation" (Frankel et al. 1996), from here called USGS96.

\subsection{Objectives}

The objective is to fully comply with the requirements of DOE Order 420.1. LLNL has developed a sitespecific probabilistic seismic hazard estimate and further upgraded the Pantex Dynamic Response Spectrum (DRS) curves to reflect the latest state-of-the-art methodology. This report describes the methodology and provides the seismic design parameters in the form of tables, charts, and graphs for the structural engineers.

\subsection{Scope of the Study}

The overall purpose of this study was to provide recommendations on the seismic design parameters for the Pantex site and the following information:

- Ground motion estimates for six values of the annual probability of exceedance; $10^{-2}, 2 \times 10^{-3}, 10^{3}$, $5 \times 10^{-4}, 10^{-4}$ and $10^{-5}$, for peak ground acceleration (PGA) and for response spectral values. These hazard events include the hazard levels associated with the performance categories PC1 $\left(2 \times 10^{-3}\right)$, PC2 $\left(10^{3}\right)$, PC3 $\left(5 \times 10^{-3}\right)$, and PC4 $\left(10^{-4}\right)$ defined in DOE-STD-1021-96. 
- Aggregation of the total mean hazard for PGA, (1-2.5 Hz) and (5-10 Hz), to calculate the rock motion controlling earthquake for determining Pantex site rock spectral shapes, and corrected shapes to account for the amplification characteristics of the Pantex site.

- Results of a seismicity analysis in which the Atkinson-Boore 1995 model titled, "Ground Motion Relations for Eastern North America," (from here called A/B95) is used with the site amplification factors at the USGS B/C boundary (USGS96).

This study makes use of the latest technology in the area of PSHA, and uses all available information on the geology, seismology, tectonics, and geological engineering from previous LLNL studies for the eastern U.S. and from other studies, including previous site-specific studies and regional studies such as USGS96.

Given the relatively low seismicity of the region of interest, it was felt that a moderately distant region of enhanced seismic activity, although not a dominant contributor to the total hazard, could have a nonnegligible effect at the Pantex Plant. Based on experience in other similar studies, it is well understood that for levels of hazards in the range of a few hundred years to a few thousand years, distant faults in the region of enhanced seismic activity would have a negligible effect on the Pantex Plant. For the range of values required for this study (up to 100,000 years and possibly 1 million years), it is obvious that distant faults could contribute to the hazard, especially in the lower frequency range. For that reason, we included faults within the Rio Grande rift in New Mexico as well as the Cheraw fault in eastern Colorado in the analysis.

This study uses all relevant site-specific information available for the PSHA. Since a great deal of construction has taken place at Pantex, some information is available on the stratigraphy. Although that information was not sufficient to make a detailed site-specific characterization, it allowed us to narrow the selection of spectral amplification factors. This enabled us to select a soil category for the site, consistent with previous Electric Power Research Institute (EPRI) studies for the eastern U.S.

\subsection{Organization of this Report}

This report includes four sections and a collection of tables and figures.

Section 1 gives background information and describes the study.

Section 2 describes the methodology for assessing seismic hazards.

Section 3 describes the seismic hazard assessment at the Pantex Plant.

Section 4 discusses the application of DOE-STD-1023-95 and the steps involved in development of the design criteria.

Table and figure caption numbers correspond to the section in which they are discussed. For example, Figure 3.4-1 is discussed in Section 3.4 of the report. 


\subsection{METHODOLOGY}

\subsection{General Approach}

A methodology to assess seismic hazards and uncertainty at Pantex Plant must provide technically sound results that meet the regulatory requirements, are amenable to regulatory review, and make appropriate use of site characterization data. To help meet these goals, the methodology incorporates attributes described below:

1) Experience Based. The methodology takes advantage of the experience gained from recent assessments of seismic hazards. Over the past decade, probabilistic methods have evolved into the generally preferred state-of-the-art for assessing vibratory ground motion at critical facilities. By incorporating recurrence information and input variability, these methods provide a more complete evaluation of hazard for risk-based design, long-term performance assessment, and regulatory review than do deterministic methods. Recent applications of probabilistic methodologies, associated lessons learned, and ongoing evaluations and integration of seismic hazard methodologies (e.g., the Senior Seismic Hazard Analysis Committee (SSHAC) study, jointly sponsored by the DOE, the NRC, and EPRI) provide the basis for the methodology described in this report.

2) Data-Driven. Development of inputs to the seismic hazards methodology and the associated input variability is based on site-specific data. The methodology is capable of incorporating all relevant available site-specific data, including information on earthquake recurrence. The methodology also allows seismic hazard assessments to be easily updated as new data become available.

3) Proper Uncertainty Treatment. The methodology provides an unbiased assessment of seismic hazards by incorporating and properly treating various types of input variability. These types of variability include uncertainty in data interpretations and randomness in the earthquake process. In comparison with typical deterministic methods, treating uncertainty in a probabilistic framework results in a more complete characterization of seismic hazards. The uncertainty is directly incorporated into the calculation of hazard, rather than qualitatively contributing to selection of a deterministic value. This facilitates regulatory decision-making and risk-based design. The methodology accommodates alternative relationships describing physical processes (e.g., earthquake occurrence); alternative values of parameters associated with those relationships (e.g., amount of fault dip, slip rates, and maximum magnitudes); and alternative interpretations based on site characterization data.

4) Flexible. The methodology accommodates a range of credible scientific interpretations, approaches, and data. Further, the methodology allows rational consideration of unlikely or highly uncertain scenarios. For example, the methodology accommodates the notion of seismic sources occurring in regions where faults are presently unmapped or unknown. This flexibility results from the probabilistic framework in which alternative input interpretations are explicitly incorporated.

5) Facilitate Sensitivity Analysis. The methodology is structured such that sensitivity analyses are facilitated. Such analyses identify important contributors to the hazard result and the relative importance of various data and interpretations. Similarly, they are used to highlight relationships or parameters for which differences in interpretation or data do not strongly influence the hazard at the site. Hence, the methodology aids in setting priorities for additional data collection and analysis efforts, so that the most important technical issues are addressed and reductions in uncertainty have the greatest impact.

To fulfill the above requirements, the present state-of-the-art approach (as described in the SSHAC report [NUREG/CR-6372]), uses the concept of the Technical Facilitator Integrator to rationally integrate the 
information from a group of experts. For limited-effort studies such as the one presented in this report, the requirements are fulfilled in a simplified approach. The trade-off between a full-fledged analysis of the type described in SSHAC and the one used here is not in the quality or credibility of the results, but rather in the total amount of uncertainty in the estimated hazard.

In this study, the LLNL analysis team's main challenge was to gain sufficient knowledge of existing interpretations of the data by the scientific community - and to use its experience from previous studies-to realistically represent the uncertainty that exists in the scientific community.

The LLNL team first collected all the information available at Pantex Plant on the characteristics of the site, the geology and tectonics of the region, and on existing hazard models (see Section 3). This information was used to formulate a set of seismic source maps and seismic source recurrences.

\subsection{Seismic Hazard Characterization Model}

\subsubsection{Systematic Process}

Five steps are involved in deriving the distribution of seismic hazard.

Step 1: Evaluation of Seismic Sources.

Determine the spatial distribution of seismic sources. In the region around the site, identify faults and volumetric zones that will be the sources of future seismic activity. Characterize the uncertainty in the spatial description of each source.

Step 2: Evaluation of Earthquake Recurrence and Maximum Magnitude.

For each seismic source, describe the rate of occurrence and relative size (e.g., magnitude, moment) distribution of future seismicity. In addition, evaluate the maximum magnitude for each source. Characterize the uncertainty in recurrence relations and in maximum magnitude.

Step 3: Ground Motion Attenuation.

For the site region, evaluate or determine relations that express how the amplitude of ground motion parameters varies with earthquake magnitude and source-to-site distance. Characterize the uncertainty in these ground motion/attenuation relations.

Step 4: Mathematical Model to Calculate Seismic Hazard.

Integrate over each combination of inputs determined in steps 1 through 3 to calculate a seismic hazard and plot a curve expressing the annual probability that a given value of ground motion will be exceeded. Carry out the integration for all combinations of inputs to incorporate the variability of input evaluation.

Step 5: Presentation of the Hazard Results.

Express the results of step 4 as a distribution of seismic hazard curves that can be represented by a mean curve and curves representing particular percentiles of the distribution.

Each of these steps is discussed below and shown schematically in Figure 2.2-1.

\subsubsection{Evaluation of Seismic Sources}

A seismic source represents a portion of the earth's crust with a potential to generate future earthquakes. Within a seismic source, the probability of earthquake occurrence and the size of the maximum magnitude are generally considered to be invariant. Seismic sources include faults with a potential to 
affect Pantex Plant. Seismic sources also depict volumetric zones in which future earthquakes may occur, but for which specific faults are not identified.

In identifying and characterizing seismic sources, the scale of features to be considered and the level of investigation varies with distance from the site. Because ground motion attenuates with distance as the distance to the site increases, earthquake size must increase to produce significant ground motion at the site. The size of earthquake that a feature can generate is related to its physical dimensions. Thus, as one gets farther from the site, larger faults are required for a significant ground motion potential to exist at the site.

Each seismic source is evaluated to provide its:

- spatial description, including variability in that description (two-dimensional zone of diffused seismicity or three-dimensional faults)

- probability of activity

- dependency on other seismic sources.

Alternate interpretations of the spatial description of a seismic source permitted by the available data are weighted according to their ability to explain the data. The spatial description of a seismic source includes an evaluation of the depth of earthquakes associated with the source.

For each source, a probability of activity is assessed, which expresses the probability that the source is seismogenic and is based on the evidence of its activity during the Quaternary period. Such assessments are based on available data, and take into account alternative tectonic interpretations, including the orientation of the stress field. Dependencies among seismic sources are also evaluated. For example, a seismic source interpretation based on a particular tectonic model may be inconsistent with a seismic source interpretation based on another tectonic model. Such sources would have a mutually exclusive dependency.

\subsubsection{Evaluation of Earthquake Recurrence and Maximum Magnitude}

Each seismic source is characterized by an earthquake recurrence relationship, a maximum magnitude, and the variability in these parameters. For recurrence, the relationship expresses the expected number of earthquakes per year of magnitudes greater than some minimum magnitude, $\mathrm{m}^{\circ}$. This distribution is developed from observed seismicity and geologic data. Since the level of seismicity in the region is low and the historical record is short (about 400 years), geologic data such as paleoseismic recurrence intervals and slip rates are expected to provide the primary basis for recurrence characterization of the fault sources. For volumetric source zones, the historical and instrumental seismicity records form the primary data for characterization of recurrence. USGS96 provides another point on the recurrence estimates in the area source zones, based on a smoothing algorithm. Additional calculations and experience are used to provide uncertainty on these estimates. Alternative interpretations consistent with the data were evaluated to describe the uncertainty in recurrence relations.

A maximum magnitude is assessed for each seismic source. For fault sources, regression relations between moment magnitude and surface rupture length, rupture area, and rupture displacement are employed. Variability is assessed on the basis of consistency shown by the different regression calculations, the relative quality of the different data types, and alternative interpretations of the data. For volumetric source zones, upper-bound magnitude estimates are based on USGS96, an evaluation of the largest earthquakes that do not rupture the surface, and analogies to other seismic sources. 


\subsubsection{Ground Motion Attenuation}

A ground motion attenuation function is a probability density function whose parameters are functions of the earthquakes and site characteristics. The standard version is a function of the magnitude of the earthquake and its distance from the site of interest (i.e., Pantex Plant). The probability of exceeding a certain value of the ground motion caused by an earthquake of magnitude $M$ and located at a distance $R$ from the site is calculated by means of the ground motion attenuation function.

\subsubsection{Mathematical Model to Calculate Seismic Hazard}

As developed by Cornell (1968), the probabilistic hazard methodology aims to calculate the annual probabilities that various levels of ground motion (e.g., peak horizontal ground acceleration) will be exceeded at a site. Procedures to accomplish this assessment are described by Cornell and form the basis for recent state-of-the-practice methodologies applied to nuclear power plants and to DOE facilities.

The probabilistic hazard curve represents the integration, overall earthquake sources and magnitudes, of the probability of future earthquake occurrence and, given an earthquake occurrence, its effect at a site of interest. In general, the temporal occurrence of earthquakes can be represented as a Poisson process and its distribution in magnitude can be represented by an exponential distribution. Thus, the probability that, at a given site, a ground motion parameter, $Z$, will exceed a specified value, $z$, during a specified time period, $T$, is given by the expression:

$$
\mathrm{P}(\mathrm{Z}>\mathrm{z})=1.0-\mathrm{e}^{-\mathrm{v}(\mathrm{z}) \cdot \mathrm{T}} \leq \mathrm{V}(\mathrm{z}) \cdot \mathrm{T}
$$

Where $v(z)$ is the average frequency during time period $T$ when the level of ground motion parameter $Z$ exceeds $z$ at the site resulting from earthquakes from all sources in the region. The inequality at the right of Equation 1 is valid regardless of the appropriate probabilistic relationship for earthquake occurrence, and $v(z) \cdot T$ provides an accurate estimate of the hazard for probabilities of 0.1 or less provided $v(z)$ is the appropriate value for the time period of interest.

The frequency of exceedance, $v(z)$, incorporates the variability (randomness and uncertainty) in the time, size, and location of future earthquakes and variability in the level of ground motions they produce at the site. It is computed by the expression:

$$
v(z)=\sum_{n=1}^{N} a_{n}\left(m^{\circ}\right) \int_{m=m^{\circ}}^{m^{u}} \int_{r=0}^{\infty} f_{n}(m) f_{n}(r \mid m) P(Z>z \mid m, r) d r d m
$$

where

$a_{n}\left(m^{\circ}\right)$ is the frequency of earthquakes on seismic source $n$ above a minimum magnitude of engineering significance, $m^{\circ}$;

$f_{n}(m)$ is the probability density function of event size on source $n$ between $\mathrm{m}^{\circ}$ and a maximum earthquake size for the source, $m^{\prime \prime}$;

$f_{n}(r \mid m)$ is the probability density function for distance to earthquake rupture on source $n$, which may be conditional on the earthquake size; and

$P(Z>z \mid m, r)$ is the probability that, given a magnitude $m$ earthquake at a distance $r$ from the site, the ground motion exceeds a value $z$.

In practice, the double integral in Equation 2 is replaced by a double summation with the density function $f_{n}(m)$ and $f_{n}(r \mid m)$ replaced by discrete representations of their corresponding cumulative functions. 
As shown in Figure 2.2-1 (Step 4), the result is a hazard curve expressing the annual probability that various levels of the ground motion parameter will be exceeded.

\subsubsection{Presentation of the Hazard Results}

The basic calculation described above results in a seismic hazard estimate for a single characterization of seismic sources, associated recurrence and maximum magnitude evaluations, and a single ground motion/attenuation relation. Thus, the result of this calculation is a single hazard curve (Figure 2.2.1 Step 4) that represents the randomness inherent in the natural phenomena of earthquake generation and seismic wave propagation. There is also uncertainty in the characterizations of seismic sources and ground motion/attenuation. This uncertainty arises from incomplete knowledge of earthquake processes, limited data, and permissible alternative interpretations of the available data. The methodology explicitly incorporates these uncertainties into the analyses to quantify the uncertainty in the final hazard results.

The Monte Carlo approach to uncertainty propagation, used in this study, makes use of multiple subjective probability distributions for the various parameters of the hazard input evaluations. The computation samples from these distributions, using Monte Carlo simulation techniques, are used to derive mean and percentile hazard curves (Figure 2.2-1 Step 5). When using this approach, uncertainty in seismic source zonation is represented by weighted alternative maps; uncertainty in recurrence is characterized by subjective probability distributions on the recurrence parameters; and uncertainty in ground motion evaluations is characterized by a set of alternative ground motion relationships and their associated weights. 


\subsection{ASSESSMENT OF THE SEISMIC HAZARD AT PANTEX PLANT}

\subsection{Introduction}

Several seismic hazard analyses were performed over the years to characterize Pantex Plant. The Blume study (Blume 1976) used the type of deterministic approach that was routinely used for nuclear power plant site licensing at that time. In 1980, TERA Corporation (TERA 1980) updated these results using one of the first probabilistic approaches available. Both studies were specifically designed to characterize Pantex Plant.

The LLNL Study released in 1989 (Bernreuter et al. 1989) used an updated methodology applied to the entire eastern U.S. and modeled the specificity of the sites by assigning eight different classes of site conditions. The overall hazard model, through the modeling of its seismic sources, was still regional in nature. Similarly, the EPRI study (EPRI 1988) was a regional study applied to the entire eastern U.S. Both the LLNL and EPRI studies were specifically designed for licensing nuclear power plants and in that respect, emphasized the characterization of very rare events to be able to reliably estimate the probability of exceedances in the range of 100,000- to 1-million year return periods. To satisfy that need and build the models, these two studies relied not only on the observed seismicity (which with its 500 year recording, at best, does not provide the necessary time duration of data recording for long return periods), but extensively relied on all other geophysical, geological, and geomechanical information.

By contrast, the most recently available results from USGS96 rely essentially on observed seismicity and in some areas on paleoseismic information on earthquake faults, thus limiting its applicability to a more limited range of return periods. Gradually, the USGS is similarly upgrading their models so that in the future this limitation will disappear. In addition, USGS96 does not fully account for the uncertainties in the process and in the data.

This study uses the latest methodology available and the median USGS estimates of seismicity rates for the background earthquakes within approximately $40 \mathrm{~km}$ of the Pantex site. The seismic source models, with their alternative sources, are designed to encompass the range of realistic interpretations expressed in the available studies briefly described below.

\subsection{Available Information}

\subsubsection{Blume and Associates Study, 1976}

This study chartered by MHC, entitled "Seismic Hazard and Building Structure Behaviors at the Pantex Facility" was reported by Blume and Associates in 1976.

It was found that the maximum credible event had a body-wave magnitude $m_{b} 6.5$ (based on felt area) located in the Nemaha fault area. The median peak horizontal acceleration of such a nearby event located $5.6 \mathrm{~km}$ from the site was estimated at $0.33 \mathrm{~g}$ with a standard deviation of $0.17 \mathrm{~g}$ and (using the Trifunac and Brady [1973] equation) an estimated return period of 1,000 years. The information contained in the Blume report was used to select a site condition category for this study (see Blume 1976, Section 4.4.1-2).

\subsubsection{TERA Corporation Study, 1980}

The TER $\Lambda$ Corporation study, "Seismic Hazard Analysis, Pantex Ordnance Plant, Amarillo, Texas," chartered by LLNL (mostly based on the geologic information from the Blume 1976 study), developed the first truly probabilistic hazard estimates at the Pantex Plant. It does not account for all the uncertainties in the process. It found a median estimate peak ground acceleration of $0.21 \mathrm{~g}$ for the 10,000 year return period and, given the (underestimated) uncertainty displayed in its results, we can estimate the mean at approximately $0.25 \mathrm{~g}$ at the 10,000 -year return period. 


\subsubsection{LLNL 1988 and 1993 Update}

The LLNL study, "Seismic Hazard Characterization of 69 Nuclear Plant Sites East of the Rocky Mountains" (Bernreuter et al. 1988) was first published in 1988 and updated in 1993 as "Revised Livermore Seismic Hazard Estimates for 69 Sites East of the Rocky Mountains" (NUREG-1488-from here called LLNL93). The update essentially concerned the characterization of the uncertainty, for which the experts who had first contributed to the 1988 study were elicited anew. A full evaluation of the seismicity rates ensued as well as a few minor changes to the seismic source modeling. A new ground motion attenuation model was developed to reflect the latest thinking. The basis for the seismic source maps was developed in the 1982-1985 time scale. The many alternative seismic source configurations formulated by 11 independent experts were interpreted as a limited random sample of the entire scientific community. The process of elicitation of the experts' interpretations was based on a combination of written questionnaires, one-on-one meetings, interaction workshops and feedback workshops. The analyst remained entirely neutral. In that study, the region affecting the Pantex site was not given any particular emphasis by the experts, probably because of the low seismic activity and lack of nuclear power plants in the area. The documentation contained in LLNL93, interpretations of the data, and some of the source zonations were evaluated for this study.

\subsubsection{USGS96}

USGS96 provides the mean hazard estimates and the documentation on the data used to obtain those estimates. These data were extensively used to anchor our median estimates of the seismicity rates for the Pantex Plant. We also used all the fault and seismic source descriptions and properties available in that report to formulate our set of alternative maps. The seismic source modeling is regional in USGS96, thus leading to a low spatial resolution of the estimates without uncertainty in the calculations. From the information available in USGS96, the mean 2,500-year return period PGA is approximately 0.08g. No estimate of uncertainty is available.

The geologic, geophysical, and seismological information collected in the USGS study was the dominant contributor in our formulation of the seismic source maps. That information was discussed at an informal, one-day, interactive working meeting with the USGS and LLNL teams in Boulder, Colorado in January 1998.

\subsubsection{Pantex Environmental Information Document, September 1996}

Relevant excerpts from The Environmental Information Document (Pantex 1996), provided to the LLNL team by the MHC staff, provided a considerable amount of valuable information on the soils, geology, seismology and engineering geology at the Pantex site.

\subsubsection{Other Information}

- "Seismic Hazards Evaluation of the Los Alamos National Laboratory," by Woodward-Clyde Federal Services, February 1995. Provided the information for the distant faults located in New Mexico, including the system of faults in the Rio Grande rift.

- "Seismotectonic Evaluation, Wichita Uplift Region," by Geomatrix Consultants, 1990. This report gave a good description of the dominant contributors to the hazard.

- "Investigation of the Quaternary Structural and Tectonic Character of the Meers Fault," by Geomatrix Consultants, 1993. Draft Report to NRC.

The LLNL team led extensive discussions with researchers and experts recently involved in studies relevant to the Pantex study. Kathryn Hanson, geologist (Geomatrix Consultants); Keith Kelson, geologist 
(W. Lettis Associates); Roland LaForge (Bureau of Reclamation [BUREC]); and Bert Swan (Geomatrix Consultants) provided important information.

\subsection{Description of the Hazards Model}

\subsubsection{Earthquake Source Characterization}

Seismic sources for the Pantex PSHA comprise 5 major areal source zones of diffuse seismicity and 14 faults.

Characterization of these sources is based on review of past analyses carried out for the Pantex site, in particular the seismic hazard analyses by Blume and Associates (1976), the TERA Corporation (1980), and Pantex (Pantex 1996), recently published literature and unpublished reports, and interviews with key researchers working on pertinent topics. In particular, we have attempted to ensure that the source characterization is consistent with that used by the USGS to produce the maps for the central and eastern U.S. (CEUS) (USGS96), wherever the USGS regional characterization is consistent with the site-specific requirements of the present analysis.

Our zonation model accommodated the variation of seismicity rates in the area of the site in the craton source zone by using smaller cells of approximately $10 \mathrm{~km} \times 10 \mathrm{~km}$ dimension. The variation in zonation was accommodated by considering a set of alternatives for the source zones and faults.

\subsubsection{Tectonic setting}

The seismotectonic setting of the Pantex site is discussed in the Pantex EID (Pantex 1996) and the seismic hazard report by Blume Associates (1976). These reports should be referred to for detailed descriptions; relevant features are summarized in Figure 3.2.1 of the Pantex EID. Recent additional information pertinent to seismic source characterization in the vicinity of the site is contained in a report by Geomatrix Consultants (1990). The site is located within the southern Great Plains tectonic province. This province is included in the North American craton zone of the USGS background source zonation (USGS96). However, the single large-scale tectonic feature that has the greatest influence on seismic source characterization for the site is the Amarillo -Wichita Uplift (AWU) (described in Section 3.3.1.2 below), which is identified as part of the extended Iapetan margin in the USGS zonation. The Pantex site is located about $10 \mathrm{~km}$ from the fault-defined southern boundary of the uplift. Epicenters of earthquakes contained in the USGS CEUS catalog ( $\mathrm{m}_{\mathrm{bLg}} 3.0$ and above) and western U.S. (WUS) catalog $\left(\mathrm{M}_{\mathrm{w}} 4\right.$ and above) (Mueller et al. 1997; USGS96) are plotted in Figure 3.3-1. Both the craton and the AWU zone are characterized by relatively low rates of earthquake occurrence.

\subsubsection{Seismic source zones}

The 53 modeled seismic source zones are shown in Figures 3.3-1 to 3.3-3. The seismicity rate within each zone is treated as uniform and is derived from the USGS CEUS catalog except for the Rio Grande zone, in which the rate estimate is based on the WUS catalog. Magnitude recurrence parameters for the zones are summarized in Tables 3.3-1 and 3.3-2.

\subsubsection{I Zones in the immediate vicinity of the Pantex Plant}

Seismic source characterization in the vicinity of the Pantex Plant is based directly upon the USGS smoothed seismicity rate map for the CEUS (Frankel 1995; USGS96). This characterization is appropriate for the site vicinity, given both the scarcity of historical events (Figure 3.3-3) and the relatively large uncertainties in epicentral locations in this area (Blume 1976; Geomatrix Consultants 1990). We treated each of the 47 cells immediately surrounding the Pantex site (Figure 3.3-3) as a separate source zone. This inner grid of cells extends roughly $40 \mathrm{~km}$ from the plant in each direction except to the north, where the grid is truncated by the southwestern boundary of the AWU zone (described in the next paragraph). 
To produce the USGS map, Frankel (1995) counted the number of $\mathrm{m}_{\mathrm{bLg}} 3$ and greater earthquakes within each cell of a $0.1^{\circ} \times 0.1^{\circ}$ grid and computed incremental $10^{\mathrm{a}}$ values for the cells using a b-value of 0.95 . He then spatially smoothed these rates using a Gaussian kernel having a 50-km smoothing length to produce the final $10^{\mathrm{a}}$ values for the cells. Seismicity rates for the inner grid cells were computed by adjusting the mapped (USGS) $10^{a}$ values using a best estimate b-value of 1.1, appropriate for the Pantex region, based on earthquake recurrence estimates for both the craton background zone used in the present study (Figure 3.3-1; Table 3.3-2) and for the AWU zone (Figure 3.3-2; Table 3.3-2). Lower- and upperbound rates for the inner grid cells were similarly computed using upper- and lower-bound b-value estimates of 0.95 and 1.2, respectively. The maximum magnitude for the inner grid is $M 6.5$, the same as the craton background zone, and is based on the value estimated for stable cratonic regions worldwide (Johnston et al. 1994); lower- and upper-bound estimates are M 6.0 and M 6.75, respectively.

\subsection{Amarillo-Wichita Uplift zone}

The AWU is a complex, fault-bounded zone of uplifts, basins and faults that extends west-northwest from southeast Oklahoma into the Texas Panhandle (see Pantex 1996, Figure 3.2.1-1). The uplift is identified as an aulacogen, or failed Late Proterozoic-Cambrian rift, that extends into the craton from the North American margin (Geomatrix Consultants 1990). The AWU is treated as a separate source zone in the present study because it is defined as a distinct tectonic feature that may have the potential for producing elevated seismicity rates compared with the surrounding region. Earthquakes that have occurred in this and other aulacogens along the North American margin have been attributed to compressional reactivation of Late Proterozoic-Cambrian extensional faults. Within the AWU, the left-oblique Meers fault (Figure 3.3-2) appears to be such a reactivated fault. The Meers fault itself is defined as a separate source in this study (Section 3.3.1.3.1), and the AWU source zone accounts for seismicity below the $\mathrm{M}_{\mathrm{w}} 7.0 \pm 0.25$ characteristic magnitude assigned to the fault. In a comparison of six of the aulacogens in eastern North America, Wheeler (1998) ranks the AWU (southern Oklahoma aulacogen) as having "intermediate relative hazard" below the Reelfoot rift (source of the 1811-12 New Madrid earthquakes) and Ottawa graben. Historical seismicity within the zone (Figure 3.3-2) shows no obvious correlation with mapped faults, including the Meers fault.

The boundary of the AWU source zone shown in Figure 3.3-2 follows the faults that bound the uplift (Pantex 1996, Figure 3.2.1-1; Geomatrix Consultants 1990), and conforms closely with the aulacogen boundary defined in USGS96. Seismicity rates were estimated from the 24 M 3-4.8 earthquakes listed in the USGS catalog as having occurred in the zone. Estimates of catalog completeness for this region at M 4 and below (Geomatrix Consultants 1990; LaForge 1997) vary significantly, particularly for northern Texas. This, in addition to the small data set, produces relatively large uncertainties in the rate estimates given in Table 3.3-2 for $\mathrm{m}_{\mathrm{hl}} \mathrm{g}$ scale. Our best estimate completeness model yields a b-value of 1.1, similar to that estimated by LaForge (1997). The b-value estimated by Geomatrix Consultants (1990) for a northwest-trending zone that includes our AWU zone but extends further to the north, agrees with our upper-bound estimate of 1.2. The maximum magnitude estimated for the AWU zone is $\mathrm{m}_{\mathrm{bLg}} 6.75+0.25 /-0.75$.

\subsection{Background zones}

The Rocky Mountain, extended margin, and craton zones shown in Figure 3.3-1 are sub-areas of the corresponding USGS (model 4) background zones (USGS96). Rate estimates for the Rocky Mountain and extended margin zones are area-normalized USGS rates $\left(10^{\mathrm{a}}=269 / \mathrm{yr}\right.$. and $417 / \mathrm{yr}$. for the USGS Rocky Mountain and extended margin zones, respectively). There are sufficient events in the catalog to compute recurrence parameters for the craton zone defined in Figure 3.3-1, as given in Table 3.3-2. Rates

for the Rio Grande zone were estimated from the USGS WUS catalog; magnitude completeness estimates 
were from Woodward-Clyde Federal Services (1995). The b-value of 0.72 for this zone is in good agreement with the value of 0.75 estimated by Woodward-Clyde for the northern portion of the zone.

\subsubsection{Fault sources}

The nearest known or suspected Quaternary active fault to Pantex is the Meers fault, approximately $150 \mathrm{~km}$ from the site in southern Oklahoma. No evidence has been found for Quaternary active faulting either at the Pantex site or in its vicinity (Blume 1976; Geomatrix Consultants 1990). (Pantex [1996] ascribes a report of a possible Holocene fault scarp $20 \mathrm{~km}$ northwest of the site to Blume [1976], but the latter report states that faulting in that vicinity does not displace Pliocene strata.) The Meers fault, the Cheraw and Sangre de Cristo faults in Colorado, and faults in the Rio Grande Rift were included in the source characterization to examine their contribution to the hazard at low probability levels and at long ground motion periods. Recurrence parameters for the fault sources are given in Tables 3.3-3 and 3.3-4.

\subsection{Meers fault}

The Meers fault is part of the frontal Wichita fault system, the northeastern border of the southern Oklahoma aulacogen in southwestern Oklahoma. The fault exhibits evidence for Quaternary reactivation along a 26-37-km-long trace. Detailed paleoseismic investigations have identified two Holocene surface faulting events, the most recent dated 1300-1400 yr. BP (Before Present) by Swan et al. (1993) and $1200-1300$ yr. BP by Crone and Luza (1990). Swan et al. dated the penultimate event at 2100-2900 yr. BP. However, the displacement history indicates that the Holocene events were preceded by a period of quiescence that lasted a few hundred thousand to several hundred thousand years, suggesting that earthquakes on the fault are clustered in time. This results in the very broad bounds on the characteristic earthquake recurrence estimates given in Table 3.3-3. The lower bound and best estimate recurrence periods on the order of 1,000 years conservatively assume that the two Holocene events are members of a continuing cluster, and are based on the interval between the events and the elapsed time since the most recent event. The upper bound estimate of 500,000 years is the estimated long-term Quaternary rate, and assumes that the most recent event was the last of that cluster. The range of characteristic earthquake magnitudes, $M_{w} 7.0 \pm 0.25$, is derived from estimates of seismic moment and from the empirical relationships of fault length and area versus $M_{w}$ of Wells and Coppersmith (1994), based on a fault length and width of $26-37 \mathrm{~km}$ and $16 \mathrm{~km}$, respectively, and average displacement per event of $3.0 \mathrm{~m}$ (Swan et al. 1993).

Like the Meers fault, many of the faults within the AWU are favorably oriented for activation within the current regional stress field. Therefore, given the close proximity of the northwestern end of the AMU to the Pantex site, we considered the potential for other active faults along the uplift zone and the possibility of fault rupture to the northwest of the Meers fault. However, the Geomatrix Consultants (1990) study, which investigated all potentially seismogenic structures along the entire length of the AMU, found evidence for Quaternary activity only on the Meers fault and on the 12-km-long Criner fault at the southeastern end of the Meers-Duncan-Criner fault system. The age of the last event on the Criner fault is poorly constrained, but it did not slip during the Holocene events on the Meers fault (Swan et al. 1993). In the opinion of Keith Kelson, lead geologist on the 1990 Geomatrix Consultants study (personal communication 1998), there is only a very low likelihood that evidence for faults having Quaternary slip rates as low as $0.1 \mathrm{~mm}$ per year would remain undetected in post-Miocene strata, particularly in the northwestern part of the AMU. Anthony Crone, USGS (personal communication 1998) feels that, based upon existing evidence, the probability of fault rupture extending to the northwest of the Meers fault would be on the order of one-tenth of one percent. Therefore, we include rupture on the hypothetical extension of the Meers fault shown in Figure 3.3-2 as the alternative characterization to rupture of the Meers fault alone, but with a probability of existence of $0.1 \%$. The characteristic magnitude assigned to this characterization is $M_{w} 7.5$, which is the maximum magnitude assigned to the extended margin as 
discussed in USGS96. For an earthquake of this size, we allowed the rupture to occur on any $100-\mathrm{km}$ long segment of the hypothetical fault. The long-term Quaternary recurrence rate based on the Meers fault data is assigned to this event.

\subsection{Cheraw fault}

The Cheraw fault is located about $360 \mathrm{~km}$ north-northwest of the Pantex site (Figure 3.3-1). Paleoseismic investigations (Crone et al. 1997) revealed evidence for three events during the last 30,000 years, the most recent dated 8,000-8,400 yr. BP. The Holocene recurrence estimates shown in Table 3.3-3 are based on the intervals between the three events and on the elapsed time since the last event. Like the Meers fault, the Cheraw fault data suggest that events are clustered in time, with inter-cluster intervals of several hundreds of thousand of years.

\subsection{Rio Grande Rift faults}

Characterization of faults associated with the Rio Grande Rift is based on comprehensive investigations recently carried out by Woodward-Clyde Federal Services (1995) as part of the seismic hazard study for the Los Alamos National Laboratory. Faults located in the central and eastern parts of the Rift that show firm evidence for Quaternary activity are included as sources for the PSHA (Table 3.3-4). The closest fault is approximately $380 \mathrm{~km}$ to the west of the Pantex site. Maximum magnitude estimates are taken directly from the Woodward-Clyde report. The best estimate recurrence intervals given in Table 3.3-4 are the mean estimates from Figure 9-2 of the Woodward-Clyde report. Lower- and upper-bound recurrence intervals were estimated using minimum and maximum slip rate and maximum magnitude values from the Woodward-Clyde report and a b-value of 0.75 to fit a truncated exponential recurrence model (Youngs and Coppersmith 1985). Source parameters for the Colorado segment of the Sangre de Cristo fault were taken from the compilation of active faults used by USGS96.

\subsubsection{Ground Motion Model}

In this section, we document the selection of the appropriate ground motion model to be used in the Pantex site study. We compared several recent models and selected the LLNL93 model developed for the NRC-sponsored eastern U.S. study. This model was developed using similar principles as those given by the SSHAC (NUREG/CR-6372). It is based on the interpretations of six experts: D. Boore, USGS; Ken Campbell, EQE; Prof. Aki, USC; Prof. Bollinger, VPI; Prof. Chapman, VPI; and Prof. Trifunac, USC. All the ground motion models available as of 1993 were considered in the interpretations of the experts. The experts' inputs were integrated and formulated as a composite model. The two types of uncertainties, epistemic and aleatory are included in the model.

In recent years, ground motion relations describing peak ground motion and response spectra for eastern North America (ENA) and central North America (CNA) have been dominated by the use of physical modeling and stochastic models (e.g., Atkinson and Boore 1993; Boore and Atkinson 1987; EPRI 1988; Toro and McGuire 1987; and Toro et a1. 1997). For the USGS96 project, two equally weighted sets of attenuations were used. Both sets of relations were derived by stochastic simulation and random vibration theory. The first (Toro et al. 1993) was a rock site model based on $\mathrm{m}_{\mathrm{bLg}}$, and the second set was a firm rock site model derived by USGS based on a Brune source model with a stress drop of 150 bars.

The A/B95 model did provide an estimate of the epistemic uncertainty by adding a constant variance from previous studies to the aleatory variance. In the Toro, Abrahamson and Schneider 1997 model, titled "Model of Strong Ground Motions from Earthquakes in Central and Eastern America: Best Estimates and Uncertainties" (from here called TAS97), the associated uncertainties are derived by considering the uncertainties in parametric values in the numerical simulations, as well as the uncertainties associated with the ground motion itself. Ad hoc probability distribution functions were assumed for the distribution of the uncertain parameters. In USGS96, the epistemic uncertainty was considered with the use of a rangc 
of models selected in an ad hoc fashion and assigned equal weights. The Lawrence Livermore National Laboratory developed a model for the purpose of updating the seismic hazard estimates for all the nuclear power plant sites in the eastern U.S. (Savy et al. 1993).

In the development of LLNL93, the emphasis was put on the characterization of the epistemic uncertainty. The method used was later adopted by the SSHAC (NUREG/CR-6372), who refined it and performed a small test application which was later completed by the Nuclear Regulatory Commission in a recent update (Savy et al. 1998).

Briefly, the method used to develop the LLNL model employed a combination of data workshops, interviews, one-on-one elicitations, interactive technical discussions and feedback workshops with a set of specially selected experts.

Using the various information and data, the ground motion experts each developed a series of estimates of ground motions for a defined suite of earthquake magnitudes and distances. The estimates included the median ground motion and its aleatory variability, and the epistemic uncertainty on both. These point estimates were fitted to yield attenuation equations for all four quantities: (1) the median estimate of the ground motion $\mathrm{a}_{50} ;(2)$ its uncertainty, $\sigma\left(\mathrm{a}_{50}\right) ;(3)$ the median, $\sigma$, estimate of the standard deviation of the aleatory uncertainty; and (4) its uncertainty $\sigma(\sigma)$. The independent variables used in the regression were selected by the expert and the analyses were performed by the Technical Facilitator Integrator (TFI) team (see NUREG/CR-6372).

Each expert formed interpretations using the information and data presented in workshops. Additionally, the elicitation process included a formal interview, in which each expert presented and defended his preliminary point estimates. The TFI challenged each expert to defend and, as necessary, clarify his or her thought process to ensure that all relevant data and information were evaluated. As a computational aid, the TFI provided the experts with estimates of the ground motions from the proponent models that the experts selected for the study.

One advantage to the LLNL approach is that in formulating their estimates of the ground motion for a given pair of magnitude and distance, the experts were provided an exhaustive array of estimates with all the available ground motion attenuation models, and concurrently a display of all relevant available ground motion data. In order to incorporate the epistemic uncertainty, each expert estimate was given in the form of a central value and a distribution function for each of the median values and for the aleatory uncertainty (sigma). The experts were required to sample and evaluate all the available items of information (i.e., data and all available models).

The LLNL93 model is therefore a composite model which fully integrates epistemic and aleatory uncertainty. We selected the above-mentioned models

- LLNL93

- $\mathrm{A} / \mathrm{B} 95$

- TAS97

- USGS96

as representative of the most recent models of ground motion prediction for the Pantex site. In the final selection, our purpose was to select a model which, for use in the hazard calculation, would incorporate the opinion of the committee of ground motion modelers, including the epistemic uncertainty associated with it, without being biased with over-conservatism or under-estimation of the ground motion. 
We compared the four peak ground acceleration prediction models for three magnitudes: $M_{w}=5,6$ and 7 , corresponding to $\mathrm{m}_{\mathrm{bLg}} 5.5,6.3$ and 7 as obtained by the relation:

$$
\mathrm{M}_{\mathrm{w}}=2.715-0.277 \mathrm{M}_{\mathrm{N}}+0.127 \mathrm{M}_{\mathrm{N}}^{2}
$$

(Boore and Atkinson 1987)

where

$\mathrm{M}_{\mathrm{N}}$ is the magnitude scale developed by Nuttli, and is equal to $\mathrm{m}_{\mathrm{bLg}}$.

A/B95, TAS97 and USGS96 use the $\mathrm{M}_{\mathrm{w}}$ scale. The USGS model was taken from USGS96 which gives the results for the USGS B/C boundary. We converted those results into a rock condition by dividing them by 1.52 , the USGS correction factor for PGA.

Similarly, for LLNL93, which uses the $m_{b L g}$ scale (described by a set of different equations for each percentile of the median), we used the 50th percentile for the comparison. Each of the models treats random uncertainty differently with some having magnitude and/or distance dependence (TAS97) and some constant (i.e., the random uncertainty is constant) (A/B95, USGS96). In the LLNL93 model, the aleatory uncertainty model is also derived from the elicitation of experts' interpretation and is dependent on the percentile of the median curve, i.e., they are negatively correlated.

Its value is also magnitude-dependent. For each $M, R$ and ground motion percentile of the median, the aleatory uncertainty used in the hazard calculation is described by a distribution function, the mean of which is approximately 0.6 on the natural $\log$ scale, and can vary from 0.3 to 0.9 .

Figures 3.3-4, 3.3-5 and 3.3-6 show the PGA in $\mathrm{cm} / \mathrm{s} / \mathrm{s}$ as a function of the distance for $\mathrm{M}_{\mathrm{w}}=5,6,7$ and $\mathrm{m}_{\mathrm{bLg}}=5.5,6.3$ and 7 , respectively. The figures show a remarkable degree of agreement between the four models. For the distances of interest, the LLNL93 model sits well in the middle of the set. Given that it has incorporated the possible altcrnative of models such as the other three, we believe this model is appropriate for the Pantex site study.

Similarly we compared the above four 5\%-damped acceleration response spectra models for the same three magnitude levels and three distances $\mathrm{D}=10,20$ and $100 \mathrm{~km}$. The comparison is made for Rock site condition, where the USGS model for the USGS B/C boundary is corrected with the amplification factors given in Section 3.4.1.1 and Figure 3.4-24. Similar to the PGA case, the LLNL93 median prediction 5\%-damped response spectra falls squarely between A/B95 and TAS97, as shown in Figures 3.2-3 to 3.3-15. Therefore, we believe that the LLNL93 response spectra model is appropriate for the Pantex site study.

In conclusion, a brief comparison of the four most recently available ground motion attenuation models applicable to the south-central U.S. shows that the LLNL93 model realistically incorporates all four probabilistically, and is believed to be appropriate for the Pantex site study.

The coefficients of the median attenuation functions are given in Table 3.3-5 for the LLNL93 model and in Table 3.3-6 for the A/B95 model. The USGS values are read from USGS96.

Table 3.3-7 provides the comparisons for the four PGA models, as shown in Figures 3.3-5 and 3.3-6 for $\mathrm{M}_{\mathrm{w}} 6$ and $\mathrm{M}_{\mathrm{w}} 7\left(\mathrm{~m}_{\mathrm{bLg}}=5.5,7\right)$.

Table 3.3-8 provides the comparisons for the four 5\%-damped spectral acceleration models for $M_{w} 6.0$ $m_{b L g} 6.3$ and distance of $20 \mathrm{~km}$ as shown in Figures 3.3-11, and for $M_{w}=m_{b L g}=7.0$ distance of $100 \mathrm{~km}$ as shown in Figure 3.3-15. 


\subsection{Hazard Estimates}

\subsubsection{Site Description}

\subsubsection{Site geology}

The coordinates of Pantex Plant, as used in our analysis, are:

$$
\begin{array}{lll}
\text { longitude } & 101.567^{\circ} & \text { west } \\
\text { latitude } & 35.317^{\circ} & \text { north }
\end{array}
$$

The Pantex plant is situated on the uneroded plain surface south of Lake Meredith and the broad canyon cut by the Canadian River. The surface soils at the site and immediately around it are mainly silty clay and fine sand of the Pleistocene age. The top layer of soils is 8- to 10-meters thick and rests upon the Ogallala formation of the Tertiary age. The Ogallala formation consists mainly of sand, silt, clay, gravel and caliche and has a maximum thickness of about 165 meters. Underlying the Ogallala are the Triassic rocks of Dockum group which are up to 75-meters thick (Blume 1976).

Faults in the area were active in the Paleozoic times. However, there is no evidence to suggest any movement in the uppermost Mesozoic and Cenozoic formations indicating the absence of any active faults in the region. There is also no surface expression of faults in the region (Blume 1976). The main fault associated with the Amarillo Mountains is buried about 1,000 meters below the ground surface.

Given the relatively clevated diffuse seismicity in the gencral area around the site, mostly low magnitude with a maximum $\mathrm{m}_{\mathrm{bLg}} 4.5$, it is expected that the dominant contributors to the hazard are the random earthquakes of low to moderate magnitude occurring in the vicinity of the site.

\subsubsection{Pantex site soil amplification factors}

An adequate characterization of the site response of any critical facility includes (1) best estimate and variance of parameters such as depth to bedrock, shear-wave velocity and density for the soil column and shallow bedrock, (2) soil material strain-dependent shear modulus, and (3) hysteretic damping. Twelve documents, provided by Mason \& Hanger Corporation, were reviewed for relevant information to characterize the Pantex facility site response:

1. Blume (1976)

2.Pantex (1996)

3. Department of Interior (1997)

4. Amarillo Testing and Engineering (1979)

5. Amarillo Testing and Engineering (1981)

6. Amarillo Testing and Engineering (1985)

7. Amarillo Testing and Engineering (1986)

8. Baker-Shiflett, Inc. (1982)

9. Ralph Parsons Co. (1993)

10. Dyers Testing Laboratory, Inc. (1988)

11. TERA Corporation (1980)

12. Geomatrix Consultants (1993) 
The Blume (1976) hazard evaluation for the Pantex facility used logs from eight boreholes drilled into the Dockum Triassic rocks to develop a cross-section running NE-SW across the Pantex facility. This crosssection indicates that the depth to the Triassic rock ranges in thickness from about 120 to $245 \mathrm{~m}$, increasing in thickness to the northeast.

The Pantex Environmental Information Document (1996) contains a cross-section running north-south (Figure 3.4-2) that was also inferred from eight boreholes and is essentially consistent with the inferences made in the Blume report (these boreholes are not labeled in the Pantex (1996) report and may be the same boreholes used in the Blume (1976) study).

Shear-wave velocities for the Pantex facility soils were reported by Blume (1976). Based on a series of seismic refraction surveys with lines of maximum offset of $45 \mathrm{~m}$, shear-wave velocities were inferred to a maximum depth of $15 \mathrm{~m}$ in the soils. Shear-wave velocities of the three layer model reported by Blume (1976) were 174,290 , and $533 \mathrm{~m} / \mathrm{sec}$ for soil layers of thicknesses $3,6.1$, and $6.1 \mathrm{~m}$, respectively.

Standard geotechnical soils information for the upper $6 \mathrm{~m}$ of the soil column are contained in the Amarillo Testing and Engineering (1979, 1981, 1985, 1986), Baker-Shiflett, Inc. (1982), Ralph Parsons Co. (1993), and Dyers Testing Laboratory, Inc. (1988) reports. Standard blow-count soil strength tests are reported in several of the reports and values range from about 7-10 near the surface to about $30-40$ at a 6-m depth. There were no laboratory testing data available for strain-dependent material properties.

Because of the limited degree to which the Pantex soils and bedrock have been characterized, no sitespecific soil amplification function can be developed. Consequently, site response must be inferred from parametric investigations for sites having, or that may have, similar characteristics available in the literature.

Frequency-dependent, soil/rock spectral amplification factors from several published studies and a DOE facility were reviewed for application at Pantex. Two site-response studies for the 180-460-m deep soil Savannah River Site are illustrated in Figure 3.4-24: (1) the LLNL (1992) median values which were developed for the New Production Reactor site (wave propagation techniques on a suite of randomized soil columns having uncertain properties characterized by probability distributions based on the data available), and (2) the WSRC (1997) median values for the envelope of the site-wide response. Both the SRS studies took into account strain-dependent soil properties. The LLNL (1992) investigation used NPR site-specific data available through 1991. Subsequent to the LLNL (1992) study, additional site characterization was conducted at the SRS which included deep borings to basement and detailed shearwave interpretations. In addition, an extensive soil dynamic testing program was completed. Results of these new investigations were integrated in the site response model for the SRS (WSRC 1997). Because of the availability of additional data, the WSRC (1997) SRS site-amplification model supersedes the LLNL (1992) SRS model. Median amplifications in excess of 3.0 are estimated for frequencies less than $2 \mathrm{~Hz}$ for this deep soil site.

The A/B95 soil amplification factors shown in Figure 3.4-4 are based on stochastic ground motion prediction ratios of deep soil and rock but do not account for soil degradation. The EPRI soil amplification factors (reported in EPRI 1993-from here called EPRI93) used stochastic ground motion analyses on suites of randomized soil columns having average shear-wave velocities similar to measured eastern U.S. velocities (Figure 3.4-4). These amplification factors are control-motion dependent. The EPRI93 soil/rock spectral amplification factors shown in Figure 3.4-4 correspond to the depth range of 122-305 $\mathrm{m}$ and have an average shear-wave speed of about $640 \mathrm{~m} / \mathrm{sec}$. This soil class most closely approximates the properties known for the Pantex facility soil column. The selected EPRI93 amplification factors correspond to the lowest soil-strains (lowest soil input motion), and therefore do not take credit for possible significant soil degradation in the near surface sands that could reduce the amplification factors. Dynamic testing of Pantex soil samples would be required to properly take into account nonlinear soil 
response. The recent National Earthquake Hazard Reduction Program (NEHRP 1997) deep-soil (class 'D') recommendations are also shown in Figure 3.4-4.

Based on the limited Pantex site data, the EPRI93 site amplification factors are judged most appropriate. This judgment assumes that the Dockum Triassic rocks can be categorized seismically as "hard rock." This characterization suggests basement shear-wave velocities in excess of $2 \mathrm{~km} / \mathrm{sec}$. The EPRI93 model is illustrated by the median plus 1-sigma soil/rock spectral amplification factors (Figure 3.4-4) and envelopes all other models considered except the 1-Hz SRS amplification. Given the large uncertainties pertaining to these amplification factors, using the most conservative approach could lead to an unrealistic set of factors. Because this uncertainty should be reflected in the calculations, the median EPRI set of correction factors was selected with a standard deviation of 0.5 . This relatively conservative site amplification model should be applied to the Pantex hazard model until adequate site-specific data, bearing on site response, can be collected to reduce site amplification.

\subsubsection{Total Hazard at the Pantex Plants Nominal Case}

The analysis was performed using the ground motion models from LLNL93. The minimum magnitude of integration was $\mathrm{m}_{\mathrm{bLg}} 5$, which corresponds to $\mathrm{M}_{\mathrm{w}} 4.5$ (A/B95). We used the median soil amplification factors (EPRI93), as discussed in Section 3.4.1.2 and listed in Table 3.4-1.

Figure 3.4-1 and Table 3.4-2 show the PGA total hazard curve for the Pantex site (soil) for the mean hazard, the 15 th, $50^{\text {th }}$, and 85 th percentile hazards. Figures 3.4-2 to 3.4-7 show the 5\%-damped uniform hazard spectra (UHS) in terms of spectral acceleration $S_{a},(\mathrm{~cm} / \mathrm{s} / \mathrm{s})$ versus frequency, in Hertz, and for the mean hazard 15 th, $50^{\text {th }}$, and 85 th percentile hazards for $100,500,1000,2000,10,000$ and 100,000 yr. return periods, respectively. We note that in some cases, i.e., the 100-year return period, the 15th UHS is not well defined at high frequency.

\subsubsection{De-aggregation of the Hazard}

Following DOE-STD-1023-95, the total mean rock site hazard results were de-aggregated for the mean hazard corresponding to the avcrage of $5-10 \mathrm{~Hz}$, and for the average of 1-2.5 Hz. The de-aggregation is performed for 5 bins of magnitudes and 7 bins of distance and the weighted average magnitude and distance were calculated as indicated in DOE-STD-1023-95, Appendix A. This is also explained in more detail in Section 4.1. The controlling earthquake corresponding to $500 \mathrm{yr}$., $2000 \mathrm{yr}$., and 10,000 yr. return periods and for the two sets of combined frequencies are given in Table 3.4.3.

Figure 3.4-19 to 3.4-22 show the median soil sitc response for the six controlling earthquakes, corresponding to the six return periods, and for LLNL93 and A/B95 with soil amplification (Figures 3.4-19 and 3.4-20), and for LLNL93 and A/B95 and rock ground motion models (Figures 3.4-21 and 3.4-22).

\subsubsection{Sensitivity Analysis}

\subsubsection{Hazard results for rock condition}

We calculated the total hazard assuming the Pantex site was eastern U.S. rock, using the LLNL93 ground motion model. Figure 3.4-8 shows the total PGA hazard for minimum magnitude of integration of $\mathrm{M}_{\mathrm{o}}=\mathrm{m}_{\mathrm{bLg}}=5$. The mean curve shows an average reduction approximately equal to the mean amplification factor of 1.82 to go from rock to soil (see Section 3.4.1.2). Similarly, Figures 3.4-9 to 3.4-14 show the 5\%-damped UHS for $\mathrm{M}_{0}=\mathrm{m}_{\mathrm{bLg}}=5$. The mean UHS show an average reduction approximately equal to the spectral amplification factors used in the Pantex soil site analyses (Table 3.4-1). 
3.4.4.2 Probabilistic seismic hazard analysis with Atkinson-Boore (1995) ground motion model with the
USGS B/C boundary amplification

We calculated the probabilities of exceedance using the A/B95 set of ground motion models with the USGS B/C boundary amplification factors. The parameter values from A/B95 are given in Table 3.3-6 in which their amplification factors are given, here only for comparison, as they are plotted in Figure 3.4-23. However, this calculation uses the same values as those used in USGS96 and listed in Table 3.4.4.

The results are shown in Figures 3.4-15 for the PGA hazard curves and Figure 3.4-16 for the mean UHS for the six return periods of interest $(100,500,1000,2000,10,000$ and $100,000 \mathrm{yr}$.). The amplification factors are shown in Table 3.4-4. They were estimated from USGS96. The report gives the values of the amplification factors for $1 \mathrm{~Hz}, 33 \mathrm{~Hz}$ and $5 \mathrm{~Hz}$; the remaining values were estimated by setting up a ratio with the values given in USGS96 Tables A7 and A5, and interpolating the results. These calculations, shown in Figures 3.4-15 and 3.4-16, lead to lower estimates than the full LLNL93/EPRI93 amplification whose results are shown in Figures 3-4-1 to 3.4-7. It is due, in part, to the difference in amplification factors, and also due to the difference in ground motion models. The results compare very favorably with those obtained with the LLNL93 model, as expected by the good agreement shown.

\subsubsection{Effect of the lower magnitude bound of integration}

Integrating from $m_{b L y}=5\left(M_{w} \sim 4.5\right)$ rather than 3.75 reduces the hazard estimates in the $10^{-2}$ to $10^{-3}$ hazard range. It does not reduce it in the range of interest between $10^{-3}$ and $10^{-6}$. The ground motion is reduced between $3-5 \%$ at the $10^{-4}$ hazard level. It is reduced $2-3 \%$ at $10^{-6}$.

\subsubsection{Effect of considering only the area source zone located within approximately $40 \mathrm{~km}$ to $60 \mathrm{~km}$ from the site}

Table 3.4-5 shows the contributions of the source zones as a percentage of the total hazard. The AmarilloWichita (labeled A-W in the table) source zone dominates the contribution to the total hazard at high hazards (low acceleration). The Meers fault also shows some contribution at the low acceleration levels, and the local region close to the site does not contribute any substantial amount. As the hazard probability decreases and the acceleration increases, the contribution of A-W and the Meers fault diminishes. The contribution of the alternative model, the extended Meers fault which comes much closer to the site, becomes greater than that of the Meers fault.

At very low probabilities, the hazard is dominated by local events within $20 \mathrm{~km}$ of the site and in the A-W source zones.

The PGA hazard curves were calculated for the case where only the events within $40 \mathrm{~km}$ contributed. The results of this calculation were still very close to the case of all sources contributing, thus confirming the dominant contributing position of the areas within $40 \mathrm{~km}$ of the site.

\subsubsection{Sensitivity to the weight given to the extended Meers fault}

In the nominal calculations, the extended Meers fault is given some weight (discussed at the USGS/LLNL working meeting January 1998). Although low ( $\mathrm{W}=1 \%$ or lower), the weight on this alternative model did not exclude a possible substantial contribution for low to very-low hazard levels (i.e., $10^{-4}$ or lower annual probability of exceedance). We tested this hypothesis by virtually eliminating the Meers fault extension as a viable model, by dividing its weight by $10(\mathrm{w} / 10)$. The results from this comparison are shown on Figure 3.4-17. As expected, the two cases do not show any substantial difference in the estimated hazard. 


\subsubsection{Sensitivity to the location of the Amarillo-Wichita uplift boundary}

Figure 3.4-18 compares the nominal case and two cases where (1) the rate of occurrence has becn multiplied by 5 (upper curve) for the inner grid cells which are contiguous to the AWU zone, and (2) where the occurrence rate within the overall AWU zone has been divided by 5 . The little difference between the three mean hazard curves shows that the exact location of the actual AWU boundary is not very sensitive for the final hazard estimate.

\subsubsection{Influence of the epistemic uncertainty in ground motion prediction on the uniform hazard spectra spectral shapes}

It can be noted from inspection of Figures 3.4-24 through 3.4-27 that the mean UHS tends to have a flattening portion for high frequencies. Inherent in the PSHA methodology, where different parameters contribute different portions of the hazard including different frequency bands, one would not necessarily expect the final mean UHS to be strictly of the same shape as the median model of the spectral ground motion attenuation (shown in Figures 3.3-7 through 3.3-15 for rock site conditions).

However, the use of fairly constant values of epistemic uncertainty throughout all frequencies can generally assure that the final mean UHS shape will be close to the overall median shape of the spectral ground motion attenuation model.

In the development of the LLNL93 model, the epistemic uncertainty was found to vary with frequency. The epistemic uncertainty for the low frequencies $(1-2.5 \mathrm{~Hz})$ was found to be in the range of 2 to 2.4 larger (measured by the logarithm of the standard deviation of the median model value), than for the high frequencies $(10-25 \mathrm{~Hz})$ (see Savy et al. 1993).

This result was corroborated in a recent study (Savy, Foxall and Abrahamson 1998) where a similar approach than the Savy 1993 study was used. Although smaller overall in the 1998 study, the lowfrequency $(1 \mathrm{~Hz})$ epistemic uncertainty is approximately one-half that of the high frequency $(25 \mathrm{~Hz})$ epistemic uncertainty.

In the 1993 study, the ratio between 15 th and 85 th percentile uncertainty on the median is approximately 6.6, for $1 \mathrm{~Hz}$ at $10 \mathrm{~km}$, for $\mathrm{M}_{\mathrm{w}} 6$. For $25 \mathrm{~Hz}$, that ratio is approximately 2.4 (Savy et al. 1993).

In the 1998 study (Savy, Foxall, and Abrahamson 1998) for $M_{w} 5$, these ratios are approximately 2.0 and 2.5, respectively. Figures 3.4-28, 3.4-29 and 3.4-30 show some comparisons between the median model and several 10,000 year return period UHS. The curves labeled "Full UNC" refer to calculations with full account of the epistemic uncertainty in the ground motion. The curves labeled "No UNC" refer to calculations with no epistemic uncertainty in the median model of the attenuation and in the model of aleatory uncertainty. These figures show that the UHS shapes labeled "No UNC" are very close to the median attenuation model shape. The median curves labeled "Full UNC" depart moderately, and the mean "Full UNC" show noticeable difference in shape.

This comparison shows that the amount of epistemic uncertainty in the ground motion models raises the estimate of spectral velocity more in the low-frequency range than in the high-frequency range, thus flattening the UHS. The correlation between spectral ordinates at various frequencies is preserved by calculating the contribution of each elementary zone (bins of distance and magnitude) for a specific (simulated) ground motion spectral model. 


\subsection{DESIGN PARAMETERS}

\subsection{Application of DOE-STD-1023-95}

Using the guidelines set out in DOE-STD-1023-95, the design criteria devclopment followed these steps:

Step 1: We performed a PSHA for the site, producing PGA and spectral value mean hazard curves. The results of this step are shown in Figures 3.4-1 to 3.4-7.

Step 2: From the hazard analysis, we used the mean hazard curve to determine the level of ground motion (e.g., PGA) corresponding to the desired hazard (e.g., 10 $10^{-4}$ for PC4).

Step 3: We deaggregated the mean PGA hazard curve to determine the contribution of each selected bin of magnitude and distance (we used 7 bins of distances and 5 bins of magnitude).

Step 4: We computed the controlling earthquakes as the weighted (the bin contributions) average of magnitude and distance values, using bin-central values in calculations.

Step 5: We performed Step 4 for two return periods as requested in the scope of work for this project, and for two frequencies: (1) the average of the hazard at 5 and $10 \mathrm{~Hz}$, and (2) the average of the hazard at 1 and $2.5 \mathrm{~Hz}$. The results of this step are shown in Table 3.4-3.

Step 6: We developed the median 5\%-damped response spectrum for each of the six controlling earthquakes of Table 3.4-3. These response spectra are shown in Figures 3.4-19, 3.4-20, 3.4-21 and 3.4-22.

Figure 3.4-19 shows the 5\%-damped response spectra for the six controlling earthquakes using the LLNL93 ground motion spectra models (described in Section 3.3.2 whose parameters are given in Table 3.3-5 for the rock condition).

For soil site at Pantex, we used the EPRI93 amplification factors shown on Figure 3.4-24 and in Table 3.4-11.

Figure 3.4-20 shows the same parameters, using the A/B95 rock ground motion model and EPRI93 amplification factors.

Figures 3.4-21 and 3.4-22 show the rock site 5\%-damped response spectra for the six controlling earthquakes, for the LLNL93 and A/B95 rock models.

As expected, the A/B95 spectra are higher than the LLNL93 curves, since the median A/B95 model is higher than the LLNL93 model (see discussion in Section 3.3.2). The A/B model also shows higher spectral values in the frequencies above $10 \mathrm{~Hz}$ and lower values below approximately $7 \mathrm{~Hz}$.

Step 7: The deterministic 5\%-damped response spectra shapes of the LLNL93 models were scaled as follows:

The spectra shapes corresponding to the controlling earthquakes obtained in the deaggregation of the $(5-10 \mathrm{~Hz})$ rock hazard corrected with soil amplification factors of Table 3.4-1 were scaled to the $(5-10 \mathrm{~Hz})$ value of the UHS. Similarly, the deterministic shape obtained in the $(1-2.5 \mathrm{~Hz})$ deaggregation was scaled to the $(1-2.5 \mathrm{~Hz})$ value of the UHS, with the application of the soil amplification factors of Table 3.4-1. Figures 3.4-24, 3.4-25, 3.4-26 and 3.4-27 show the results of this scaling for the four PC hazard levels: $2 \times 10^{-3}, 10^{-3}, 5 \times 10^{-4}$ and $10^{-4}$, respectively. In these figures, the continuous line represents the 5\%-damped mean UHS, the lower dotted line represents the $5 \%$-damped deterministic shape for the $(5-10 \mathrm{~Hz})$ deaggregation controlling 
earthquakes, and the upper dotted line corresponds to the $(1-2.5 \mathrm{~Hz})$ deaggregation controlling earthquakes.

Step 8: The results of Step 7 showed that for PC1, PC2, PC3 and PC4, the scaled deterministic spectrum corresponding to the (1-2.5 Hz) de-aggregation controlling earthquakes envelopes the other two curves.

This implies that the high frequencies are also controlled by the spectral shape scaled to $1-2.5 \mathrm{~Hz}$ and suggests the consideration of a "low-frequency" scenario earthquake different from the scenario obtained above.

Following the guidance given in DOE-STD 1023-95, we examined the surface of hazard contribution. Figure 4.1-1 shows the contributions of each bin of magnitude and distance to the average $(1.0-2.5 \mathrm{~Hz})$ mean 10,000-year spectral velocity hazard. Figure 4.1-2 shows the same for ( $5-10 \mathrm{~Hz})$. The surface of contribution appears to be bi-modal for the (1-2.5 Hz) (the "low-frequency") case and unimodal for the $(5-10 \mathrm{~Hz})$ ("high-frequency") case. The second mode in the "low-frequency" case corresponds to the contribution of events occurring on the Meers fault or its extension. Therefore, a better representation of the seismic environment is obtained by dividing the scenario earthquakes into two sets: one for the "highfrequency" scaling and one for the "low-frequency" scaling. The high frequency scenarios remain unchanged from those given Table 3.4-3 in the column "Average $(5-10 \mathrm{~Hz})$."

We characterize the "low frequency" scenario by calculating the M-bar, D-bar corresponding to the second mode of the contribution surface of Figure 4.1-1.

$$
\begin{gathered}
\text { "Low frequency" } \\
\text { scenario }
\end{gathered} \quad\left\{\begin{array}{l}
\mathrm{M}-\mathrm{bar}=\mathrm{m}_{\mathrm{bLg}} 6.8=\mathrm{M}_{\mathrm{w}} 6.7 \\
\mathrm{D}-\mathrm{bar}=151 \mathrm{~km}
\end{array}\right.
$$

This scenario corresponds to an event located on the Meers fault or on its extension.

Figure 4.1-3 shows a comparison of the UHS for each PC category and the corresponding "low-frequency" earthquake scenario, scaled to the UHS value at the average of $1-2.5 \mathrm{~Hz}$. This "low-frequency" spectral shape is more consistent with the UHS since it specifically relates to the events occurring on the Meers fault or its extension. The final design basis earthquake response spectra are obtained by enveloping the UHS, the "low frequency" and the "high frequency," and taking the value of the corresponding PGA for $100 \mathrm{~Hz}$ as read from the hazard curve (Figures 4.2-1 and 4.2-2).

\subsection{Recommendations}

\subsubsection{Recommendations on the Design Basis Peak Ground Acceleration and Spectra for Pantex Site}

\subsubsection{Mean hazard curve and design basis peak ground acceleration for Pantex soil}

The final estimate of the total mean hazard is shown in Figures 4.1-1 and 4.2-2. The two figures display the same data, Figure 4.2-2 for a logarithmic PGA axis scale.

The results are shown in Table 3.4-2 for PGA values ranging from $10 \mathrm{~cm} / \mathrm{s} / \mathrm{s}$ to $2000 \mathrm{~cm} / \mathrm{s} / \mathrm{s}$. The corresponding PGA values corresponding to PC1, PC2, PC3 and PC4 are shown in Table 4.2-1.

We note from Figure 4.2-1 and 4.2-2 that the $10^{-5}$ mean hazard level PGA is estimated to be equal to approximately $650 \mathrm{~cm} / \mathrm{s} / \mathrm{s}(.66 \mathrm{~g})$ and the $10^{-6}$ mean hazard PGA value is $1550 \mathrm{~cm} / \mathrm{s} / \mathrm{s}(1.58 \mathrm{~g})$. 


\subsubsection{Design basis response spectra for Pantex soil}

Table 4.2-2 and Figure 4.2-3 give the final DBE values of the 5\%-damped response spectral velocities for 5 frequencies and the PGA (which is treated as a 100-Hz value) for PC1, PC2, PC3 and PC4, as described in Step 8 of Section 4.1. Table 4.2-3 gives the ratio of the final DBE to the UHS for each PC category. Figures 4.2-4 to 4.2-7 give the final DBE for 0.5, 2.0, 5.0, 7.0, and 10\% damping and for PC1, PC2, PC3 and PC4, respectively. The conversion ratios are given in NRC NUREG/CR-0098 (NRC 1978).

\subsubsection{Comments and Recommendations}

In our opinion, the most critical aspect of this study has been the characterization of the Pantex site soil column, and consequently the determination of the appropriate amplification factors to convert the rock site estimates into Pantex site soil estimates. Given the limitations on availability of geotechnical data to allow us to do a refined analysis, we selected the EPRI93 amplification model, as explained in Section 3.4.1. We selected that model, believing that it best represents the limited geological, depth to bedrock data, and a level of conservatism consistent with the relative lack of knowledge of the site conditions at Pantex. In other words, we think that the use of EPRI93 gives a high level of confidence that the actual amplification factors would not be substantially higher if we were to perform a refined analysis. On the other hand, we do not believe that the level of conservatism introduced by the EPRI93 model is arbitrarily high, since the model was developed from realistic representative soil properties and geometries similar to what is known of the Pantex site.

Based on the discussion in Section 3.4.4-7, it is recognized that the UHS does not reflect the original LLNL93 median shape. In particular, its spectral ordinates are raised by the effect of the epistemic uncertainty being higher at low frequencies than at high frequencies, thus creating an artificial flattening of the UHS spectrum.

Since the purpose of calculating the UHS is to develop a design with equal level of risk for all frequencies, it is our opinion that this aspect should be preserved. We are then presented with the problem of applying the guidance of DOE-STD-1023 which leads to a large increase in the final design spectrum for high frequencies by comparison to the median LLNL93 spectral shape. Given the somewhat ad-hoc nature of the rules, as stated in Step 7 of Section 4.1, and no specific guidance in the standard to resolve this issue, we cannot develop any strong argument for changing the recommendation at this point. We can only note that the recent results on composite ground motion modeling (Savy et al. 1998) which cannot be used here because of their preliminary nature, could possibly lead to lower spectral values in low frequencies relative to the high frequencies and thus possibly lead to a less-flat UHS in high frequencies due to their lower epistemic uncertainties.

Performing additional geotechnical tests at Pantex site would allow reduction of the level of uncertainty in the amplification factors and possibly reduce the DBE PGA and/or spectral estimates. 


\section{REFERENCES}

A/B95. See Atkinson and Boore 1995.

Amarillo Testing \& Engineering, Inc. "Sub-Soil Investigation - Proposed Addition to Zonc 12 North of Building 12-84, Pantex Plant, Amarillo, Texas," 17 pages.

Amarillo Testing \& Engineering, Inc. "Sub-Soil Investigation-Proposed Remote Hole Drilling Facility and Weapons Aging Facility, Pantex Plant, Amarillo, Texas," report submitted to Bernard Johnson Incorporated, Houston, Texas, 15 pages, August 1981.

Amarillo Testing \& Engineering, Inc. "Sub-Soil Investigation-Liquid/Solid Waste Incinerator, Pantex Plant, Amarillo, Texas (Booker Project No. E-2825)," report submitted to Booker Associates, Inc., St. Louis, Missouri, 16 pages.

Amarillo Testing \& Engineering, Inc. "Sub-Soil Investigation Production and Assembly Facilities DOE Contract DE-AC04-79AL1050, Pantex Plant, Amarillo, Texas," report submitted to Gibbs \& Hill, Inc., New York, 36 pages, November 1979.

Atkinson, G. M. and D. M. Boore. "Ground Motion Relations for Eastern North America," Bull. Seis. Soc. Am., Vol. 85, no. 1, pp. 17-30, February 1995 (called A/B95 in this report).

Baker-Shiflett, Inc. Consulting Geotechnical Engineers, Fort Worth, Texas. "Geotechnical Investigations - Pantex Plant, Amarillo, Texas," report submitted to Teague Nall \& Perkins, Inc., Fort Worth, Texas, 62 pages, November 1982.

Bernreuter, D. L., A. Boissonnade, and S. Short. "Investigation of Techniques for the Development of Seismic Design Basis Using the Probabilistic Seismic Hazard Analysis," NUREG/CR-6066 (UCRL-ID-128920), October 1997.

Bernreuter, D. L., J. B. Savy, R. W. Mensing and J. C. Chen. "Seismic Hazard Characterization of 69 Nuclear Plant Sites East of the Rocky Mountains," NUREG/CR-5250, Vols. 1-8, 1988.

Blume and Associates. "Seismic Hazard and Building Structure Behavior at the Pantex Facility," report prepared for the U.S. Energy Research and Development Administration, Amarillo Area Office, 1976.

Boore, D. M. and G. M. Atkinson. "Stochastic Prediction of Ground Motion and Spectral Response Parameters at Hard-Rock Sites in Eastern North America," Bull. Seis. Soc. Am., Vol. 77, pp. 440$467,1997$.

Coats, D. W. and R. C. Murray. "Natural Phenomena Hazards Modeling Project: Seismic Hazard Models for Department of Energy Sites," Lawrence Livermore National Laboratory, UCRL-53582, Rev. 1, pp. 34-35, November 1984.

Crone, A. J., and K. L. Luza. "Style and Timing of Holocene Surface Faulting on the Meers Fault, Southwestern Oklahoma," Geol. Soc. Am. Bull., 102, pp. 1-17, 1990.

Crone, A. J., M. N. Machette, L. A. Bradley, and S. A. Mahan. Late Quaternary Surface Faulting on the Cheraw Fault, Southeastern Colorado, USGS Geological Investigations Map I-2591, 1997.

Department of Energy. DOE Standard, "Natural Phenomena Hazards Performance Categorization Guidelines for Structures, Systems, and Components," DOE-STD-1021-96, January 1996. 
Dyers Testing Laboratory, Inc. "Report of a Foundation Soils Investigation for a General Stores

Warehouse at the Pantex Plant, Amarillo, Texas," report to Merrick \& Company, Masouf Zorraby, P. E., Los Alamos, New Mexico, Attachment A, pp. 1-5; Appendix C.

EPRI. "Engineering Model of Earthquake Ground Motion for Eastern North America," EPRI NP-6074, Electric Power Research Institute, Palo Alto, California, 1988.

EPRI. "Seismic Hazard Methodology for Central and Eastern United States," EPRI NR-4726, Electric Power Research Institute, Palo Alto, California, Vols. 1-10, 1988.

EPRI. "Guidelines of Determining Design Basis Ground Motions," EPRI-TR-1022931193, Electric Power Research Institute, Palo Alto, California, Vol. 1, 1993.

Frankel, A. et al. "National Seismic-Hazard Maps: Documentation," USGS Open File Report 96-532, Denver, Colorado, June 1996 (called USGS96 in this report).

Frankel, A. "Mapping Seismic Hazard in the Central and Eastern United States," Seismol. Res. Let., 66, pp. 8-21, 1995.

Geomatrix Consultants, Inc. "Investigation of the Quaternary Structural and Tectonic Character of the Meers Fault (Southwestern Oklahoma)," draft report submitted to U.S. Nuclear Regulatory Commission, NRC-04-87-007, pp. 72-86, 21 pages, 1993.

Geomatrix Consultants, Inc. "Seismotectonic Evaluation: Wichita Uplift Region, Southern Oklahoma and Northern Texas," final report to U.S. Department of the Interior, Bureau of Reclamation, 113 p., 1990.

Johnston, A. C., K. J. Coppersmith, L. R. Kanter, and C. A. Cornell. The Earthquakes of Stable Continental Regions, Vol. I: Assessment of Large Earthquake Potential. Prepared for the Electric Power Research Institute, Palo Alto, California, 1994.

LaForge, R. C. "Seismic Hazard and Ground Motion Analysis for Altus, Arbuckle, Fort Cobb, Foss, McGee Creek, Mountain Park, and Norman Dams, Oklahoma," Department of the Interior, U.S. Bureau of Reclamation, Seismotectonic Report 97-1, Denver, Colorado, 19 pages, 1997.

Lawrence Livermore National Laboratory. "Seismic Hazard Characterization of the DOE New Production Reactor Sites. Vol. 3: Application to the SR Site, South Carolina," report for the Department of Energy by J. Savy, D. Bernreuter, J. C. Chen, B. C. Davis, J. Ueng, and C. Short, NPR92-147JBS, Rev. A Draft, March 31, 1992.

LLNL93. See U.S. Nuclear Regulatory Commission NUREG-1488.

Mueller, C., M. Hopper, and A. Frankel. "Preparation of Earthquake Catalogs for the National SeismicHazard Maps: Contiguous 48 States.," U.S. Geological Survey Open File Report 97-464, Denver, Colorado, 36 p., 1997.

NEHRP. Recommended Provisions for Seismic Regulations for New Buildings and Other Structures, Part 1: Provisions (FEMA 302), National Earthquake Hazards Reduction Program, prepared by the Building Seismic Safety Council, 1997.

Pantex. "Environmental Information Document," Pantex Plant Report, September 1996.

Ralph M. Parsons Company. "Soil Investigation - Proposed High Explosives Formulation Facility Amarillo, Texas," report submitted to Mason \& Hanger-Silas Mason Co., Inc., 50p., March 1993. 
Savy, J. B., A. C. Boissonnade, R. W. Mensing, and C. M. Short, 1993. "Eastern United States Seismic Hazard Characterization Update," Lawrence Livermore National Laboratory, UCRL-ID-115111, June 1993.

Savy, J. B., W. Foxall, and N. Abrahamson, and D. Bernreuter. "Guidance for Performing Probabilistic Seismic Hazard Analysis for a Nuclear Plant Site: Example Application to the Southern United States," NUREG/CR-6607, 1998.

SSHAC. "Recommendations for Probabilistic Seismic Hazard Analysis: Guidance on Uncertainty and Use of Experts," Senior Seismic Hazard Analysis Committee: R. J. Budnitz, G. Apostolakis, D. Boore, L. Cluff, K. Coppersmith, A. Cornell and P. Morris, NUREG/CR-6372 (UCRL-ID-122160), Vol. 1, 2, 1997.

Swan, F. H., J. R. Wesling et al. "Investigation of the Quaternary Structural and Tectonic Character of the Meers Fault (Southwestern Oklahoma)," draft report prepared for the U.S. Nuclear Regulatory Commission, 1993.

TAS97. See Toro et al. 1997.

Tera Corporation. "Seismic Hazard Analysis Pantex Ordnance Plant, Amarillo, Texas," draft report submitted to Lawrence Livermore National Laboratory, Livermore, California, 46 pages, May 1980.

Toro, G. R., N. Abrahamson, and J. F. Schneider. "Model of Strong Ground Motions from Earthquakes in the Central and Eastern United States," in Guidelines for Determining Design Basis Ground Motion. EPRI TR-102293, J. F. Schneider, ed. Electric Power Research Institute, 1993.

Toro, G. R., N. Abrahamson, and J. F. Schneider. Model of Strong Ground Motions from Earthquakes in Central and Eastern America: Best Estimates and Uncertainties, Seismological Research Letters, Vol. 68, No. 1, January/February 1997 (called TAS97 in this report).

Toro, G. R. and R. McGuire. "An Investigation into Earthquake Ground Motion Characteristics in Eastern North America,” Bull. Seis. Soc. Am., 77, pp. 468-489, 1987.

Trifunac, M. D. and A. G. Brady. "On the Correlation of Seismic Intensity Scales with Peak Recorded Strong Motion,” Bull. Seis. Soc. Am., Vol. 65, no. 1, pp. 139-162, 1975.

USGS96. See Frankel, A. et al.

U.S. Nuclear Regulatory Commission. "Development of Criteria for Design Review of Selected Nuclear Power Plants," NUREG/CR-0098, N.M. Newmark, W. J. Hall, 1978.

U.S. Nuclear Regulatory Commission. "Revised Livermore Seismic Hazard Estimates for 69 Sites East of the Rocky Mountains," NUREG-1488, 1993 (called LLNL93 in this report).

Wheeler, R. L. Geologic Controls of Earthquakes in Iapetan Rifts and Grabens, Southeastern North America, Manuscript preprint, 1998.

Wells, D. L. and K. J. Coppersmith. "New Empirical Relationships among Magnitude, Rupture Length, Rupture Width, Rupture Area, and Surface Displacement," Bull. Seis. Soc. Am., 84, pp. 974-1002, 1994.

Woodward-Clyde Federal Services. "Seismic Hazards Evaluation of the Los Alamos National Laboratory," Final Report, Vol. I, prepared for the Los Alamos National Laboratory and the U.S. Department of Energy, 1995. 
Westinghouse Savannah River Company. "SRS Seismic Response Analysis and Design Basis

Guidelines," by R. C. Lee, M. E. Maryak, and M. D. McHood, WSRC-TR-97-0085, Rev. 0, 1997.

Youngs, R. R., and K. J. Coppersmith. "Implications of Fault Slip Rates and Earthquake Recurrence Models to Probabilistic Seismic Hazard Estimates," Bull. Seis. Soc. Am., 75, pp. 939-964, 1985. 


\section{TABLES}

Table caption numbers correspond to the sections in this report where they are discussed.

The table captions include abbreviations for the following references:

A/B95 Atkinson, G. M. and D. M. Boore. "Ground Motion Relations for Eastern North America," Bull. Seis. Soc. Am., Vol. 85, no. 1, pp. 17-30, February 1995.

LLNL93 U.S. Nuclear Regulatory Commission. "Revised Livermore Seismic Hazard Estimates for 69 Sites East of the Rocky Mountains," NUREG-1488, 1993.

TAS97 Toro, G. R., N. Abrahamson, and J. F. Schneider. Model of Strong Ground Motions from Earthquakes in Central and Eastern America: Best Estimates and Uncertainties, Seismological Research Letters, Vol. 68, No. 1, January/February 1997.

USGS96 Frankel, A. et al. "National Seismic-Hazard Maps: Documentation," USGS Open File Report 96-532, Denver, Colorado, June 1996. 
Table 3.3-1 Inner grid zones recurrence parameters

\begin{tabular}{|c|c|c|c|c|c|c|c|c|c|}
\hline \multirow[t]{2}{*}{ Zone } & \multirow[t]{2}{*}{$\mathbf{f}(\mathbf{3})^{(\mathbf{1})}$} & \multirow[t]{2}{*}{ Zone } & \multirow[t]{2}{*}{$\mathbf{f}(\mathbf{3})^{(\mathbf{1})}$} & \multicolumn{3}{|c|}{$\mathbf{b}$} & \multicolumn{3}{|c|}{$\mathbf{M}_{\max }$} \\
\hline & & & & $b e^{(1)}$ & $\mathrm{Ib}^{(1)}$ & $u b^{(1)}$ & be & $1 b$ & $u b$ \\
\hline $\mathrm{c} 10$ & $4.46 \mathrm{E}-04$ & $c 40$ & 4.42E-04 & & & & & & \\
\hline c11 & $3.03 \mathrm{E}-04$ & $\mathrm{c} 41$ & 4.63E-04 & 1.10 & 0.95 & 1.20 & 6.50 & 6.00 & 6.75 \\
\hline $\mathrm{c} 12$ & $1.64 \mathrm{E}-04$ & $\mathrm{c} 42$ & $5.02 \mathrm{E}-04$ & & & & & & \\
\hline $\mathrm{c} 13$ & $4.92 \mathrm{E}-05$ & $c 43$ & $5.52 \mathrm{E}-04$ & & & & & & \\
\hline c19 & $5.39 \mathrm{E}-04$ & c44 & $6.01 \mathrm{E}-04$ & & & & & & \\
\hline $\mathrm{c} 20$ & 5.01E-04 & $\mathrm{c} 45$ & $6.43 \mathrm{E}-04$ & & & & & & \\
\hline c21 & 4.87E-04 & $c 46$ & $4.66 \mathrm{E}-04$ & & & & & & \\
\hline $\mathrm{c} 22$ & $5.02 \mathrm{E}-04$ & $c 47$ & $4.20 \mathrm{E}-04$ & & & & & & \\
\hline$c 23$ & $4.84 \mathrm{E}-04$ & $\mathrm{c} 48$ & $3.90 \mathrm{E}-04$ & & & & & & \\
\hline$c 24$ & $3.86 \mathrm{E}-04$ & c49 & $3.83 \mathrm{E}-04$ & & & & & & \\
\hline c25 & $2.35 \mathrm{E}-04$ & $c 50$ & $3.97 \mathrm{E}-04$ & & & & & & \\
\hline$c 26$ & $7.35 \mathrm{E}-05$ & $c 51$ & $4.26 \mathrm{E}-04$ & & & & & & \\
\hline $\mathrm{c} 28$ & $5.48 \mathrm{E}-04$ & $\mathrm{c} 52$ & $4.65 \mathrm{E}-04$ & & & & & & \\
\hline $\mathrm{c} 29$ & 5.02E-04 & $c 53$ & $5.04 \mathrm{E}-04$ & & & & & & \\
\hline $\mathrm{c} 30$ & $4.79 \mathrm{E}-04$ & $c 54$ & 5.38E-04 & & & & & & \\
\hline c31 & $4.85 \mathrm{E}-04$ & $c 55$ & $3.88 \mathrm{E}-04$ & & & & & & \\
\hline $\mathrm{c} 32$ & $5.16 \mathrm{E}-04$ & c56 & $3.50 \mathrm{E}-04$ & & & & & & \\
\hline c33 & $5.66 \mathrm{E}-04$ & $c 57$ & $3.28 \mathrm{E}-04$ & & & & & & \\
\hline c34 & $6.26 \mathrm{E}-04$ & $c 58$ & $3.22 \mathrm{E}-04$ & & & & & & \\
\hline c35 & $6.84 \mathrm{E}-04$ & c59 & $3.29 \mathrm{E}-04$ & & & & & & \\
\hline c36 & $6.37 \mathrm{E}-04$ & c60 & $3.49 \mathrm{E}-04$ & & & & & & \\
\hline c37 & 5.22E-04 & c61 & $3.79 \mathrm{E}-04$ & & & & & & \\
\hline c38 & 4.73E-04 & c62 & $4.09 \mathrm{E}-04$ & & & & & & \\
\hline c39 & $4.45 \mathrm{E}-04$ & c63 & $4.37 \mathrm{E},-04$ & & & & & & \\
\hline
\end{tabular}

Notes: (1) Frequency of earthquakes $\mathrm{M} \geq 3.0$

(2) be, best estimate; lb, lower bound; ub, upper bound 
Table 3.3-2 Source zone recurrence parameters

\begin{tabular}{|c|c|c|c|c|c|c|c|c|c|c|c|c|c|}
\hline Zone & & b & & & $\mathbf{f}(\mathbf{3 . 7 5})^{(2)}$ & & $\mathbf{M}_{1}$ & & $\mathbf{f}\left(\mathbf{M}_{1}\right)^{(2)}$ & & & $\mathbf{M}_{\max }$ & \\
\hline & $\mathbf{b e}^{(1)}$ & $\mathbf{l b}^{(1)}$ & $\mathbf{u} \mathbf{b}^{(1)}$ & be & lb & ub & & be & Ib & ub & be & $\mathbf{l b}$ & $\mathbf{u b}$ \\
\hline Craton & 1.09 & 0.95 & 1.20 & $5.45 \mathrm{E}-01$ & $5.03 \mathrm{E}-01$ & $5.81 \mathrm{E}-01$ & 6.00 & $1.90 \mathrm{E}-03$ & $1.20 \mathrm{E}-03$ & $3.70 \mathrm{E}-03$ & 6.50 & 6.00 & 6.75 \\
\hline Extended Margin & 0.95 & 0.85 & 1.10 & $1.14 \mathrm{E}-01$ & $3.10 \mathrm{E}-02$ & $2.71 \mathrm{E}-01$ & 6.00 & $8.30 \mathrm{E}-04$ & $1.00 \mathrm{E}-04$ & $3.30 \mathrm{E}-03$ & 7.50 & 6.75 & 7.80 \\
\hline Rio Grande-W. Texas & 0.72 & 0.65 & 0.85 & $6.46 \mathrm{E}-01$ & $2.10 \mathrm{E}-01$ & $1.18 \mathrm{E}+00$ & 6.00 & $1.55 \mathrm{E}-02$ & $2.57 \mathrm{E}-03$ & $4.07 \mathrm{E}-02$ & 6.50 & 6.30 & 7.00 \\
\hline Rocky Mt. & 0.80 & 0.70 & 0.90 & $2.69 \mathrm{E}-01$ & $1.14 \mathrm{E}-01$ & $6.38 \mathrm{E}-01$ & 6.00 & 4.27E-03 & $1.70 \mathrm{E}-03$ & $1.70 \mathrm{E}-02$ & 6.50 & 6.00 & 6.75 \\
\hline Wichita-Amarillo & 1.10 & 1.00 & 1.20 & $1.49 \mathrm{E}-01$ & $1.32 \mathrm{E}-01$ & 3.84E-01 & 5.50 & $1.75 \mathrm{E}-03$ & $1.05 \mathrm{E}-03$ & $6.83 \mathrm{E}-03$ & 6.75 & 6.00 & 7.00 \\
\hline
\end{tabular}

Notes: (1) be, best estimate; lb, lower bound; ub, upper bound

39. $f(M)=$ frequency of earthquakes $\geq M$

Table 3.3-3 Recurrence parameters for the Meers and Cheraw faults

\begin{tabular}{|l|c|c|c|c|c|c|c|}
\hline \multicolumn{1}{|c|}{ Fault } & Length & \multicolumn{3}{c|}{$\mathbf{M}_{\mathbf{c}}$} & \multicolumn{3}{c|}{$\mathbf{f}\left(\mathbf{M}_{\mathbf{c}}\right)^{(2)}$} \\
\hline & $\mathbf{k m}$ & $\mathbf{b e}^{(1)}$ & $\mathbf{l b}^{(1)}$ & $\mathbf{u b}^{(\mathbf{1})}$ & $\mathbf{b e}$ & $\mathbf{l b}$ & $\mathbf{u b}$ \\
\hline Meers & 37 & 7.00 & 6.75 & 7.25 & $8.70 \mathrm{E}-04$ & $2.00 \mathrm{E}-06$ & $1.43 \mathrm{E}-03$ \\
\hline Meers extension & 630 & 7.50 & 7.25 & 7.75 & $2.00 \mathrm{E}-06$ & $1.00 \mathrm{E}-06$ & $5.00 \mathrm{E}-06$ \\
\hline Cheraw & 48 & 7.00 & 6.75 & 7.25 & $1.54 \mathrm{E}-04$ & $2.00 \mathrm{E}-06$ & $2.78 \mathrm{E}-04$ \\
\hline
\end{tabular}

Notes: (1) be, best estimate; lb, lower bound; ub, upper bound

(2) Frequency of characteristic earthquake, $M_{c}$ 
Table 3.3-4 Recurrence parameters for Rio Grande faults

\begin{tabular}{|c|c|c|c|c|c|c|c|c|c|c|}
\hline \multirow[t]{2}{*}{ Fault } & \multirow{2}{*}{\begin{tabular}{|c|} 
Length \\
$\mathbf{k m}$
\end{tabular}} & \multicolumn{3}{|c|}{$\mathbf{M}_{c}^{(\mathbf{1})}$} & \multicolumn{3}{|c|}{$\mathbf{f}(\mathbf{5})^{(2)}$} & \multicolumn{3}{|c|}{$\mathbf{f}\left(\mathbf{M}_{1}\right)^{(2)}$} \\
\hline & & be & $\mathbf{l b}$ & $\mathbf{u b}$ & $b^{(3)}$ & $\mathbf{l b}^{(3)}$ & $\mathbf{u b}^{(3)}$ & be & lb & $\mathbf{u b}$ \\
\hline Pajarito & 34 & 6.8 & 6.4 & 7.2 & $1.20 \mathrm{~F}-03$ & $1.40 \mathrm{~F}-04$ & $1.30 \mathrm{~F}-02$ & $2.30 \mathrm{~F}-04$ & $2.10 \mathrm{~F}-05$ & 2.00E-03 \\
\hline La Bajada & 40 & 6.9 & 6.6 & 7.2 & $1.20 \mathrm{E}-03$ & $1.40 \mathrm{E}-04$ & $7.90 \mathrm{E}-03$ & $2.30 \mathrm{E}-04$ & $2.10 \mathrm{E}-05$ & $1.20 \mathrm{E}-03$ \\
\hline San Francisco & 43 & 6.9 & 6.6 & 7.2 & $1.60 \mathrm{E}-03$ & $1.50 \mathrm{E}-04$ & $8.50 \mathrm{E}-03$ & $2.40 \mathrm{E}-04$ & $2.30 \mathrm{E}-05$ & $1.30 \mathrm{E}-03$ \\
\hline Embudo SW segment & 31 & 7.0 & 6.7 & 7.3 & $2.60 \mathrm{E}-03$ & $2.50 \mathrm{E}-04$ & $9.10 \mathrm{E}-03$ & 5.00E-04 & $3.80 \mathrm{E}-05$ & $1.30 \mathrm{E}-03$ \\
\hline NE segment & 30 & 7.0 & 6.7 & 7.3 & $2.60 \mathrm{E}-03$ & $2.60 \mathrm{E}-04$ & 9.40E-03 & $5.00 \mathrm{E}-04$ & 3.90E-05 & $1.40 \mathrm{E}-03$ \\
\hline Tijeras-Canoncito ${ }^{(4,5)}$ & 31 & 6.7 & 6.4 & 7.0 & $2.70 \mathrm{E}-03$ & $2.60 \mathrm{E}-04$ & 9.40E-03 & $5.20 \mathrm{E}-04$ & 3.90E-05 & $1.40 \mathrm{E}-03$ \\
\hline Picuris-Pecos & 96 & 7.3 & 7.0 & 7.6 & 4.20E-04 & $1.50 \mathrm{E}-04$ & $6.60 \mathrm{E}-03$ & 8.30E-05 & $2.50 \mathrm{E}-05$ & $1.10 \mathrm{E}-03$ \\
\hline Rio Grande-Sandia & 45 & 6.9 & 6.6 & 7.2 & $4.20 \mathrm{E}-03$ & 4.60E-04 & $2.90 \mathrm{E}-02$ & $8.00 \mathrm{E}-04$ & $7.30 \mathrm{E}-05$ & $4.60 \mathrm{E}-03$ \\
\hline Sangre de Cristo, segs. $3+4^{(5)}$ & 32 & 6.8 & 6.5 & 7.1 & $9.00 \mathrm{E}-04$ & $7.80 \mathrm{E}-04$ & $3.80 \mathrm{E}-03$ & $1.80 \mathrm{E}-04$ & $1.20 \mathrm{E}-04$ & $5.80 \mathrm{E}-04$ \\
\hline $\operatorname{segs} 2+3+4^{(5)}$ & 62 & 7.1 & 6.8 & 7.4 & $9.00 \mathrm{E}-04$ & $9.00 \mathrm{E}-04$ & $4.40 \mathrm{E}-03$ & $1.80 \mathrm{E}-04$ & $1.50 \mathrm{E}-04$ & $7.20 \mathrm{E}-04$ \\
\hline Sangre de Cristo, Colorado & 195 & 7.5 & 7.2 & 7.8 & $4.30 \mathrm{E}-03$ & $2.20 \mathrm{E}-03$ & $8.70 \mathrm{E}-03$ & $1.00 \mathrm{E}-04$ & $5.00 \mathrm{E}-05$ & $2.00 \mathrm{E}-04$ \\
\hline
\end{tabular}

Notes:

1. Characteristic magnitude

2. $f(M)=$ frequency of earthquakes $\geq M: M_{1}=7.0$ for the Sangre de Cristo fault in Colorado, and 6.0 for all other faults.

3. be, best estimate; $1 \mathrm{~b}$, lower bound; ub, upper bound

4. Tijeras-Four Hills segment.

5. See Woodward-Clyde Federal Services (1995) 
Table 3.3-5 Coefficient of the median LLNL93 composite model used for the study at Pantex Plant for rock $\log _{\mathrm{c}} \mathrm{y}=\mathrm{C}_{1}+\mathrm{C}_{2} \mathrm{~m}_{\mathrm{bLg}}+\mathrm{C}_{3} \log _{\mathrm{c}} \mathrm{R}+\mathrm{C}_{4} \mathrm{R}+\mathrm{C}_{5} \mathbf{m}_{\mathrm{bLg}} \log _{\mathrm{c}} \mathrm{R}$

\begin{tabular}{|c|c|c|c|c|c|c|}
\hline & & \multicolumn{5}{|c|}{ Coefficients for PSV (cm/s) } \\
\cline { 2 - 7 } & $\begin{array}{l}\text { Coefficients } \\
\text { for PGA } \\
(\mathbf{c m} / \mathbf{s} / \mathbf{s})\end{array}$ & $\mathbf{1 ~ H z}$ & $\mathbf{2 . 5 ~ H z}$ & $\mathbf{5 ~ H z}$ & $\mathbf{1 0 ~ H z}$ & $\mathbf{2 5 ~} \mathbf{~ z z}$ \\
\hline $\mathrm{C}_{1}$ & 5.02013 & -7.2634 & -3.6646 & -1.8810 & -.6674 & .0038 \\
\hline $\mathrm{C}_{2}$ & 0.4430 & 1.8102 & 1.2917 & 1.0197 & .8166 & .6482 \\
\hline $\mathrm{C}_{3}$ & -1.9193 & -.8661 & -1.1459 & -1.3724 & -1.6159 & -1.7459 \\
\hline $\mathrm{C}_{4}$ & -.0066 & -.0024 & -.0037 & -.0043 & -.0057 & -.0079 \\
\hline $\mathrm{C}_{5}$ & 0.1793 & 0.0224 & .0662 & .0960 & .1266 & .1395 \\
\hline
\end{tabular}

Note: - logs are natural logs

- PGA in $\mathrm{cm} / \mathrm{s} / \mathrm{s}$

- PSV in $\mathrm{cm} / \mathrm{s}$

- $\mathrm{R}$ in $\mathrm{km}$ 
Table 3.3-6 Coefficients of A/B95 model used in the sensitivity analysis for rock site conditions

$$
\log _{10}\left[\begin{array}{l}
\operatorname{Acc}(\mathrm{cm} / \mathrm{s} / \mathrm{s}) \\
\operatorname{Vel}(\mathrm{cm} / \mathrm{s})
\end{array}\right]=C_{1}+C_{2}(M-6)+C_{3}(M-6)^{2}-\log _{10} R-C_{4} R
$$

\begin{tabular}{|c|c|c|c|c|c|}
\hline $\begin{array}{c}\text { Frequency } \\
\mathbf{H z}\end{array}$ & $\mathbf{C}_{1}$ & $\mathbf{C}_{2}$ & $\mathbf{C}_{3}$ & $\mathbf{C}_{4}$ & $\begin{array}{c}\text { Correction } \\
\text { Factor } \\
\text { Soil/Rock }\end{array}$ \\
\hline 0.5 & 2.27 & 0.634 & -.0170 & .0 & 1.9 \\
\hline 1.0 & 2.77 & 0.620 & -.0409 & .0 & 1.9 \\
\hline 2.0 & 3.26 & 0.550 & -.0640 & .0 & 2.0 \\
\hline 3.2 & 3.54 & 0.475 & -.0717 & .000106 & $1.87 *$ \\
\hline 5.0 & 3.75 & 0.418 & -.0644 & .000457 & 1.7 \\
\hline 10.0 & 3.99 & 0.360 & -.0527 & .00121 & 1.4 \\
\hline 13.0 & 4.06 & 0.346 & -.0492 & .00153 & 1.26 \\
\hline 20.0 & 4.19 & 0.328 & -.0477 & .00226 & 0.93 \\
\hline PGA (50Hz) & 3.79 & 0.298 & -.0536 & .00135 & 1.0 \\
\hline
\end{tabular}

* Interpolated from Table 3, A/B95 
Table 3.3-7 Tabulation of PGA comparison between composite LLNL93 model, A/B95, USGS96 and TAS97 for $\mathrm{m}_{\mathrm{bLg}}=M_{\mathrm{w}} 6$ and 7 rock site condition

\begin{tabular}{|c|c|c|c|c|}
\hline \multirow{2}{*}{$\begin{array}{c}\mathrm{m}=6 \\
\text { Distance }(\mathrm{km})\end{array}$} & \multicolumn{4}{|c|}{ Peak Ground Acceleration in $(\mathrm{cm} / \mathrm{s} / \mathrm{s})$} \\
\hline & LLNL93 & A/B95 & USGS96 & TAS97 \\
\hline 3 & 1017 & 2036 & - & 487 \\
\hline 10 & 375 & 598 & 549 & 313 \\
\hline 25 & - & - & 178 & - \\
\hline 31 & 134 & 181 & 一 & 100.0 \\
\hline 63 & 62 & 80.5 & 45.7 & 39.7 \\
\hline 100 & 33.6 & 45.2 & 29.5 & 20.6 \\
\hline 255 & 5.77 & 10.9 & 7.94 & 5.04 \\
\hline \multicolumn{5}{|l|}{$m=7$} \\
\hline 3 & 1592 & 3575 & - & 1094 \\
\hline 10 & 684 & 1049 & 1148 & 705 \\
\hline 25 & - & - & 389 & - \\
\hline 31 & 281 & 317 & 一 & 225 \\
\hline 63 & 142 & 142 & 112 & 89.2 \\
\hline 100 & 81.8 & 79.3 & 75.8 & 46.3 \\
\hline 255 & 15.9 & 19.2 & 22.9 & 11.3 \\
\hline
\end{tabular}


Table 3.3-8 Response spectral acceleration value comparisons for four ground motion models for two pairs of magnitudes and distances for rock site conditions $(\mathrm{cm} / \mathrm{s} / \mathrm{s})$

\begin{tabular}{|c|c|c|c|c|c|}
\hline M-R & $\begin{array}{l}\text { Frequency } \\
(\mathbf{H z})\end{array}$ & $\operatorname{LLNL93}\left(\mathbf{m}_{\mathrm{bLg}}\right)$ & A/B95 & $\begin{array}{c}\text { USGS96 } \\
\text { B-C Boundary }\end{array}$ & $\begin{array}{c}\text { Corrected } \\
\text { From } \\
\text { TAS97 }\end{array}$ \\
\hline$M=m_{b L g}=6$ & 0.5 & & 9.33 & & \\
\hline \multirow[t]{9}{*}{$R=20 \mathrm{~km}$} & 1 & 42.9 & 29.4 & 70.5 & 65.7 \\
\hline & 2.0 & & 91.0 & & \\
\hline & 2.5 & 144 & & & 155 \\
\hline & 3.2 & & 173 & 204 & \\
\hline & 5 & 271 & 275 & 260 & 252 \\
\hline & 10 & 425 & 462 & & 327 \\
\hline & 20 & & 697 & & \\
\hline & 25 & 595 & & & 399 \\
\hline & 0.5 & & 7.7 & & \\
\hline $\mathbf{M}=\mathbf{m}_{\mathrm{bLg}}=7$ & 1 & 42 & 22.3 & 53.5 & 45.7 \\
\hline \multirow[t]{7}{*}{$\mathrm{R}=100 \mathrm{~km}$} & 2.0 & & 55.7 & & \\
\hline & 2.5 & 101 & & & 73.2 \\
\hline & 3.2 & & 85.6 & 100.0 & \\
\hline & 5.0 & 156 & 114.3 & 113.6 & 92.1 \\
\hline & 10 & 192 & 150 & & 99.3 \\
\hline & 20 & & 175.5 & & \\
\hline & 25 & 193 & & & 90.4 \\
\hline
\end{tabular}

(*Soil correction deep soil category from LLNL93) 
Table 3.4-1 Amplification factors used for the seismic hazard characterization of the Pantex site (EPRI 1993)

\begin{tabular}{|c|c|c|}
\hline $\begin{array}{c}\text { Frequency } \\
\text { Hz }\end{array}$ & \multicolumn{2}{|c|}{ A: Amplification Factors (Soil/Rock) } \\
\hline & A (Mean) & A (Mean + 1 sigma) \\
\hline 1 & 2.10 & 3.00 \\
\hline 1.5 & 1.82 & 2.71 \\
\hline 2.5 & 1.98 & 2.67 \\
\hline 3.45 & 2.00 & 2.76 \\
\hline 5. & 1.91 & 2.58 \\
\hline 7.5 & 1.86 & 2.45 \\
\hline 10.0 & 1.85 & 2.40 \\
\hline 20.0 & 1.66 & 2.17 \\
\hline 25.0 & 1.39 & 1.81 \\
\hline 34.0 & 1.29 & 1.63 \\
\hline PGA & 1.82 & 2.22 \\
\hline
\end{tabular}

Note: The soil ground motion is obtained by multiplying the rock estimate by $\mathrm{A}$. 
Table 3.4-2 Pantex soil mean PGA hazard

\begin{tabular}{|c|c|c|c|c|}
\hline \multirow{2}{*}{ 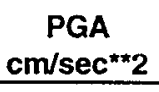 } & \multicolumn{4}{|c|}{ Annual Probability of Exceedance } \\
\hline & Arithemetic Mean & 15th & 50th & 85th \\
\hline 10 & $5.78 \mathrm{E}-03$ & 2.41E-03 & 4.95E-03 & $9.38 E-03$ \\
\hline 18 & $2.73 \mathrm{E}-03$ & $1.27 E-03$ & $2.40 E-03$ & $4.30 \mathrm{E}-03$ \\
\hline 32 & 1.35E-03 & $6.75 \mathrm{E}-04$ & $1.16 E-03$ & $2.15 E-03$ \\
\hline 50 & 8.11E-04 & $3.96 \mathrm{E}-04$ & $6.73 E-04$ & 1.27E-03 \\
\hline 75 & 4.87E-04 & 2.34E-04 & $4.01 E-04$ & 7.69E-04 \\
\hline 150 & 1.87E-04 & 8.05E-05 & 1.51E-04 & 3.03E-04 \\
\hline 250 & 8.19E-05 & $3.03 E-05$ & $6.36 \mathrm{E}-05$ & 1.35E-04 \\
\hline 300 & 5.90E-05 & 2.03E-05 & $4.51 E-05$ & $9.80 E-05$ \\
\hline 400 & 3.36E-05 & $9.84 \mathrm{E}-06$ & $2.47 E-05$ & $5.68 E-05$ \\
\hline 500 & 2.09E-05 & 5.35E-06 & $1.48 E-05$ & 3.60E-05 \\
\hline 650 & 1.14E-05 & 2.41E-06 & 7.43E-06 & 1.99E-05 \\
\hline 800 & 6.72E-06 & 1.17E-06 & 4.11E-06 & 1.20E-05 \\
\hline 1000 & 3.67E-06 & 4.70E-07 & 2.05E-06 & 6.81E-06 \\
\hline 1110 & $2.52 E-06$ & $2.89 E-07$ & 1.37E-06 & 4.90E-06 \\
\hline 2000 & 3.75E-07 & 1.43E-08 & $1.41 \mathrm{E}-07$ & 7.18E-07 \\
\hline
\end{tabular}

Table 3.4-3 Summary of controlling earthquakes for $500 \mathrm{yr}$, $2000 \mathrm{yr}$., $10,000 \mathrm{yr}$, , return periods and for the average of $(1-2.5 \mathrm{~Hz})$ mean hazard and $(5-10 \mathrm{~Hz})$ mean hazard

\begin{tabular}{|c|c|c|c|c|c|c|}
\hline $\begin{array}{c}\text { Return } \\
\text { Period } \\
(\mathbf{y r} .)\end{array}$ & \multicolumn{3}{|c|}{ Average (1-2.5 Hz) } & \multicolumn{3}{c|}{ Average (5-10 Hz) } \\
\hline & $\mathbf{M}_{\mathbf{w}}$ & $\mathbf{m}_{\mathbf{b L g}}$ & $\mathbf{D}(\mathbf{k m})$ & $\mathbf{M}_{\mathbf{w}}$ & $\mathbf{m}_{\mathbf{b L g}}$ & $\mathbf{D}(\mathbf{k m})$ \\
\hline 10,000 & 5.4 & 5.75 & 52 & 5.3 & 5.7 & 37 \\
\hline 2,000 & 5.4 & 5.8 & 88 & 5.3 & 5.7 & 63 \\
\hline 500 & 5.5 & 5.9 & 142 & 5.3 & 5.7 & 109 \\
\hline
\end{tabular}

Note: The magnitude values are converted from ${ }_{M b L g}$ to $\mathrm{M}_{\mathrm{w}}$ with the (Atkinson and Boore 1993) relation

$$
\mathrm{M}_{\mathrm{W}}=2.715-0.277 \mathbf{m}_{\mathrm{bLg}}+0.127 \mathbf{m}_{\mathrm{bLg}}{ }^{2}
$$


Table 3.4-4 B/C boundary (USGS96) soil amplification factors used in the calculation of the total hazard with the A/B95 ground motion model

\begin{tabular}{|l|c|l|l|l|l|l|l|l|l|l|}
\hline Frequency $(\mathrm{Hz})$ & 0.5 & 1.0 & 1.3 & 2.0 & 3.2 & 5.0 & 10.0 & 13.0 & 20.0 & PGA \\
\hline $\begin{array}{l}\text { Amplification } \\
\text { Soil/Rock }\end{array}$ & 1.15 & 1.34 & 1.42 & 1.65 & 1.72 & 1.76 & 1.94 & 2.00 & 2.03 & 1.52 \\
\hline
\end{tabular}

Table 3.4-5 Percent contributions of seismic sources to the total mean hazard in terms of PGA

\begin{tabular}{|c|c|c|c|c|c|c|}
\hline & & & \multicolumn{2}{|c|}{ Contribution $\%$ at PGA } & & \\
\hline Acceleration & & & \multicolumn{2}{|c|}{ Region Close to Site } & & \\
\hline Level (g) & Craton & $\begin{array}{l}\text { Amarillo- } \\
\text { Wichita }\end{array}$ & $\leq 40 \mathbf{k m}$ & $\leq 15 \mathrm{~km}$ & $\begin{array}{c}\text { Extended } \\
\text { Meers }\end{array}$ & Meers \\
\hline 0.010 & 50 & 25 & & & & 9.5 \\
\hline 0.25 & 42 & 36 & $\geq 6$ & & & \\
\hline 0.075 & 21 & 41 & $\geq 25$ & & & \\
\hline 0.150 & 10 & 38 & $\geq 34$ & 24 & & \\
\hline 0.250 & 6 & 33 & $\geq 45$ & 30 & & \\
\hline 0.400 & 4 & 29 & $\geq 56$ & 42 & & \\
\hline 0.500 & 3 & 27 & $\geq 59$ & 45 & 1 & \\
\hline 0.650 & 2 & 25 & $\geq 62$ & 49 & 1 & \\
\hline 0.800 & 2 & 24 & $\geq 64$ & 50 & 2 & \\
\hline 1.00 & 1.6 & 22 & $\geq 66$ & 53 & 3 & \\
\hline
\end{tabular}

Note: Total percentages do not add up to 100 since only sources contributing $1 \%$ or more are shown. 
Table 4.2-1 5\%-damped design basis response spectra PGA values for Pantex soil

\begin{tabular}{|c|c|c|}
\hline PC & $\begin{array}{c}\text { Hazard Level } \\
(\text { yr. return Period) }\end{array}$ & $\begin{array}{c}\text { DBE - PGA } \\
(\mathbf{g})\end{array}$ \\
\hline 1 & 500 & .02 \\
\hline 2 & 1,000 & .04 \\
\hline 3 & 2,000 & .08 \\
\hline 4 & 10,000 & .22 \\
\hline
\end{tabular}

Table 4.2-2 Final design basis earthquake, $5 \%$-damped spectral velocities $(\mathrm{cm} / \mathrm{s})$ for the Pantex site, for PC1, PC2, PC3 and PC4

\begin{tabular}{|c|c|c|c|c|}
\hline & \multicolumn{4}{|c|}{ Spectral Velocities $(\mathrm{cm} / \mathrm{sec})$} \\
\hline $\begin{array}{l}\text { Frequency } \\
\qquad(\mathbf{H z})\end{array}$ & $\begin{array}{c}\text { PC1 } \\
500 \text { yr }\end{array}$ & $\begin{array}{c}\text { PC2 } \\
1000 \text { yr }\end{array}$ & $\begin{array}{c}\text { PC3 } \\
2000 \text { yr }\end{array}$ & $\begin{array}{c}\text { PC4 } \\
10,000 \text { yr }\end{array}$ \\
\hline 1 & 2.37 & 3.58 & 5.37 & 13.60 \\
\hline 2.5 & 2.13 & 3.23 & 4.90 & 13.40 \\
\hline 5.0 & 1.56 & 2.36 & 3.59 & 9.46 \\
\hline 10.0 & 0.87 & 1.30 & 2.11 & 6.17 \\
\hline 25.0 & 0.27 & 0.48 & 0.82 & 2.61 \\
\hline 100 - PGA & 0.039 & 0.065 & 0.108 & 0.325 \\
\hline
\end{tabular}


Table 4.2-3 Ratio of the final DBE to the UHS spectral velocity spectra

\begin{tabular}{|c|c|c|c|c|}
\hline \multirow{2}{*}{$\begin{array}{c}\text { Frequency } \\
(\text { Hz) }\end{array}$} & \multicolumn{3}{|c|}{ Ratio DBE/UHS } \\
\cline { 2 - 5 } & PC1 & PC2 & PC3 & PC4 \\
& & & & 1.079 \\
\hline 1 & 1 & 1 & 1 & 1 \\
\hline 2.5 & 1.029 & 1.016 & 1.004 & 1.173 \\
\hline 5.0 & 1.139 & 1.098 & 1.065 & 1.526 \\
\hline 10.0 & 1.205 & 1.111 & 1.608 & 1 \\
\hline 25.0 & 1.429 & 1.584 & 1 & 1 \\
\hline $100-$ PGA & 1 & 1 & & \\
\hline
\end{tabular}




\section{FIGURES}

Figure caption numbers correspond to the sections in this report where they are discussed. 

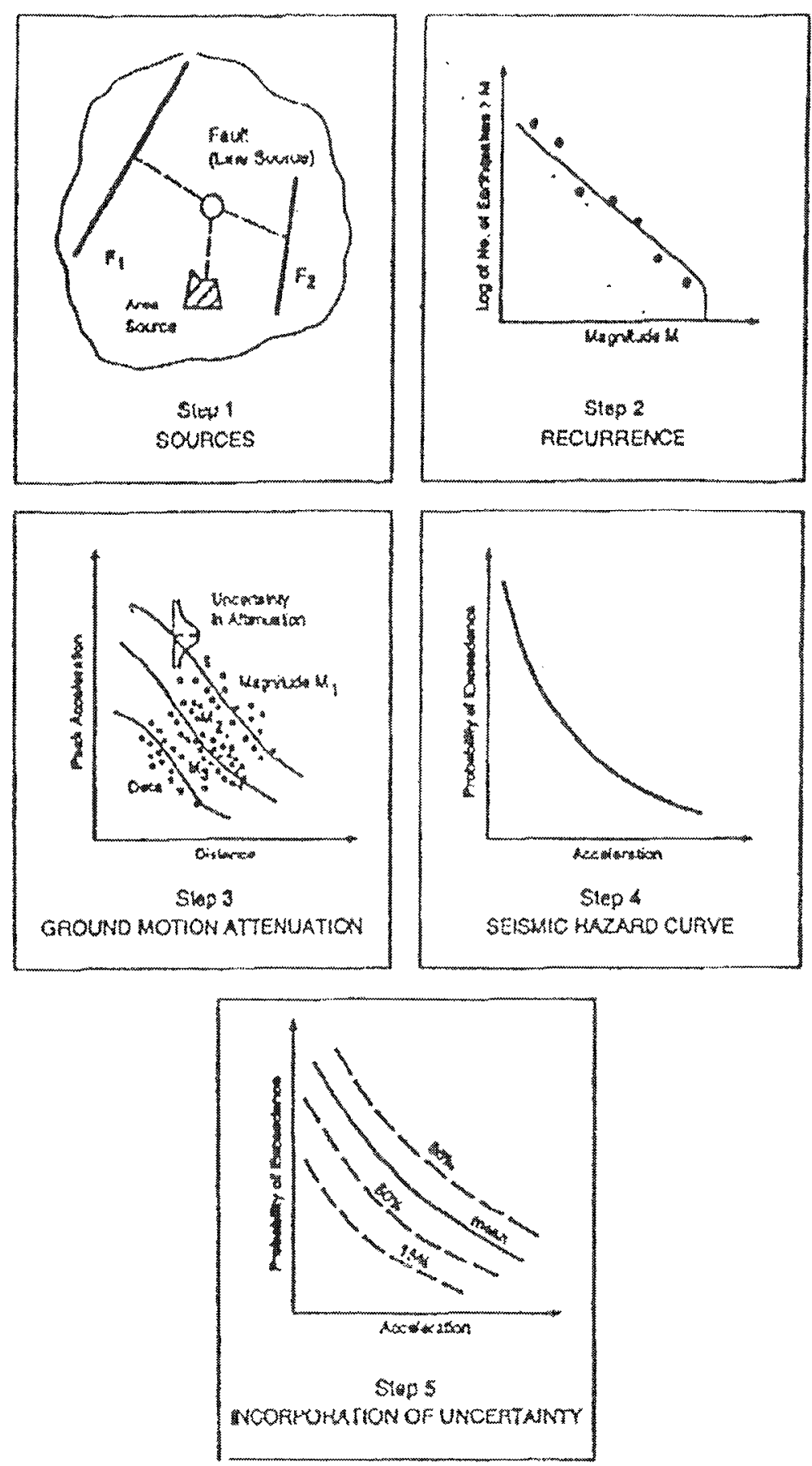

Figure 2.2-1 Basic steps of the methodology of assessing vibratory ground motion hazard 


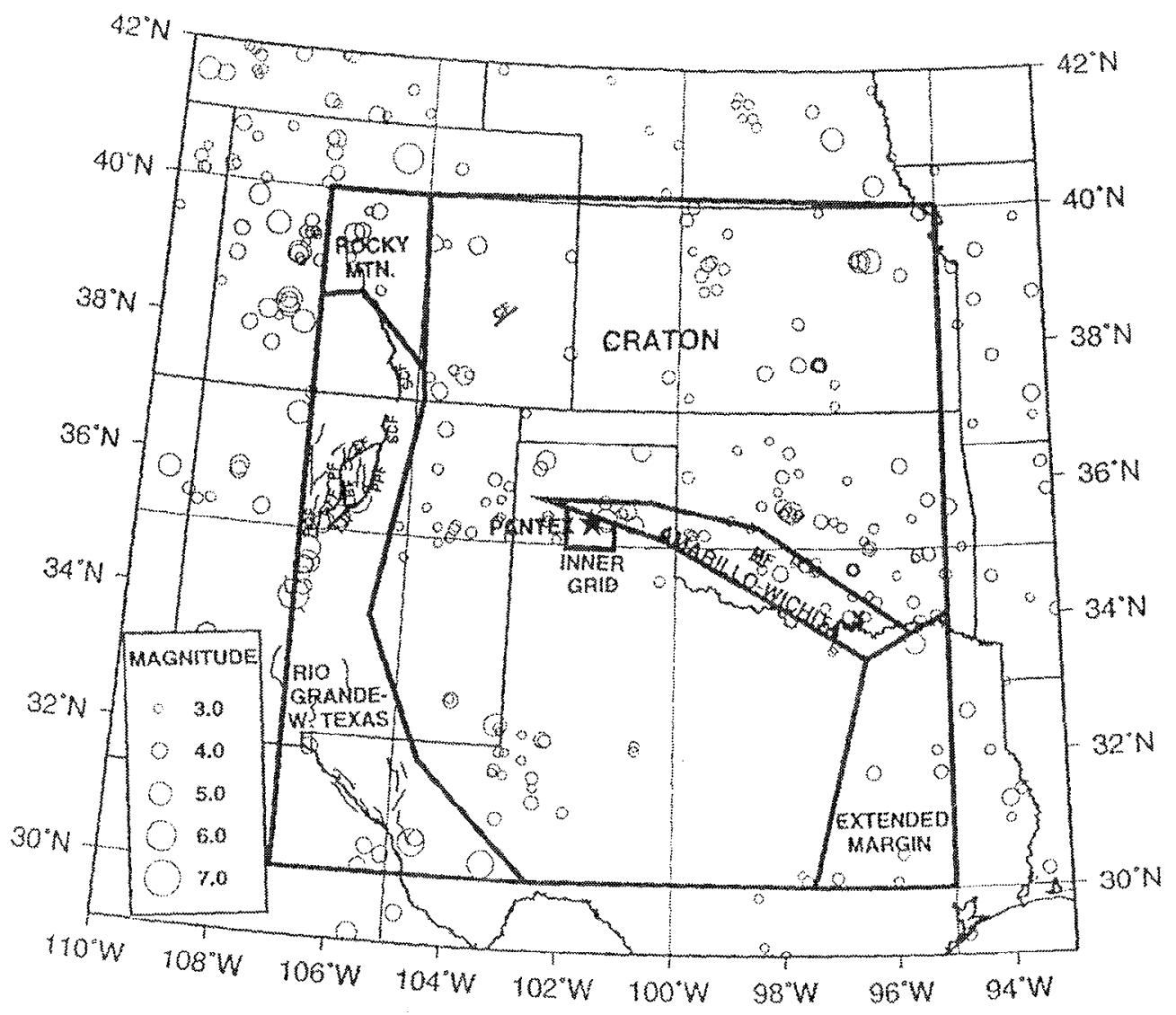

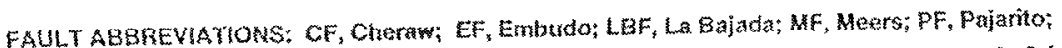
PPF, Pacos Pectris; RGSF, Rio Grande-sandia; SCF, Sangre do Cristo; SFF, San Francisco; TJF, Tieras-Canoncito

Figure 3.3-1 Regional seismotectonics and zonation 


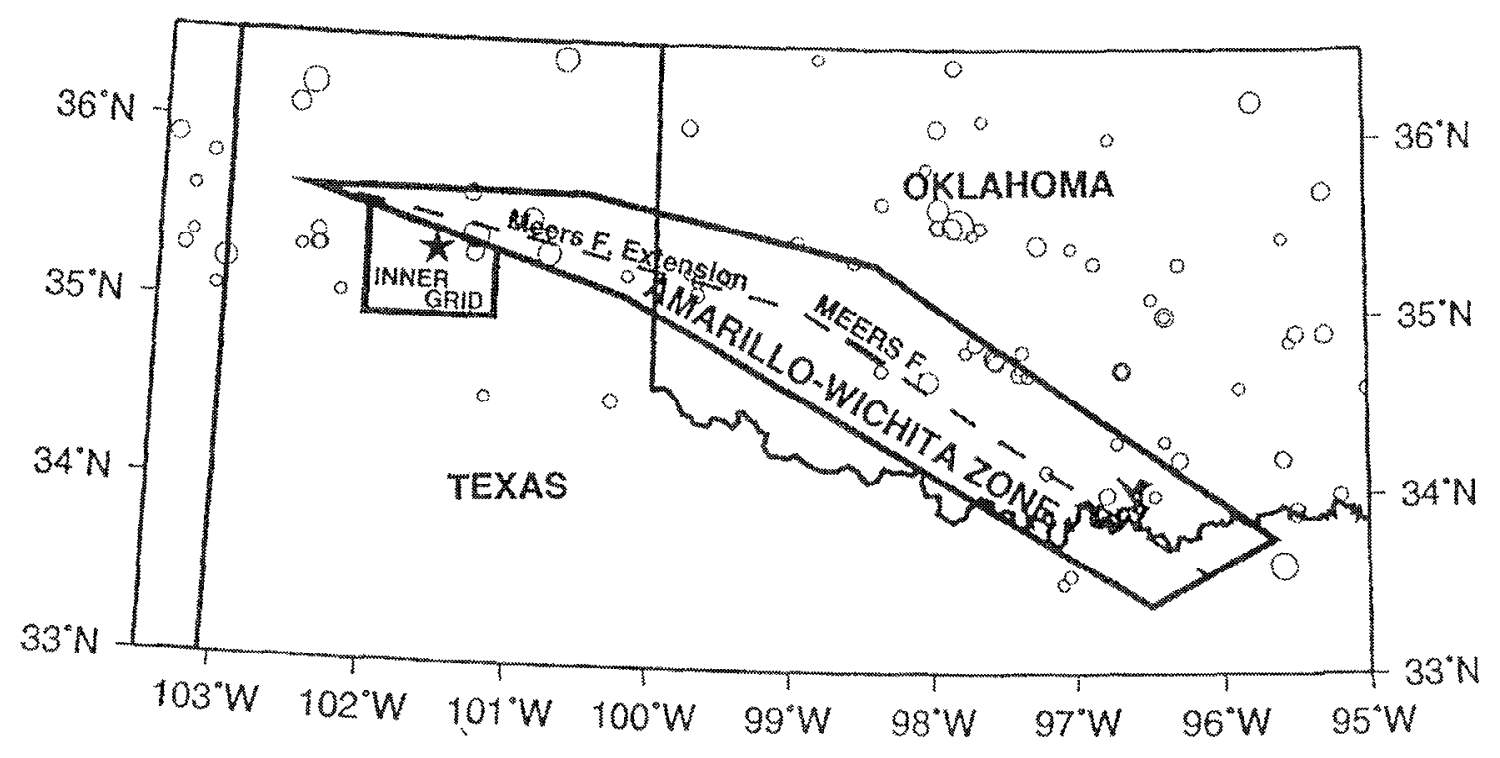

Figure 3.3-2 Amarillo-Wichita Uplift zone

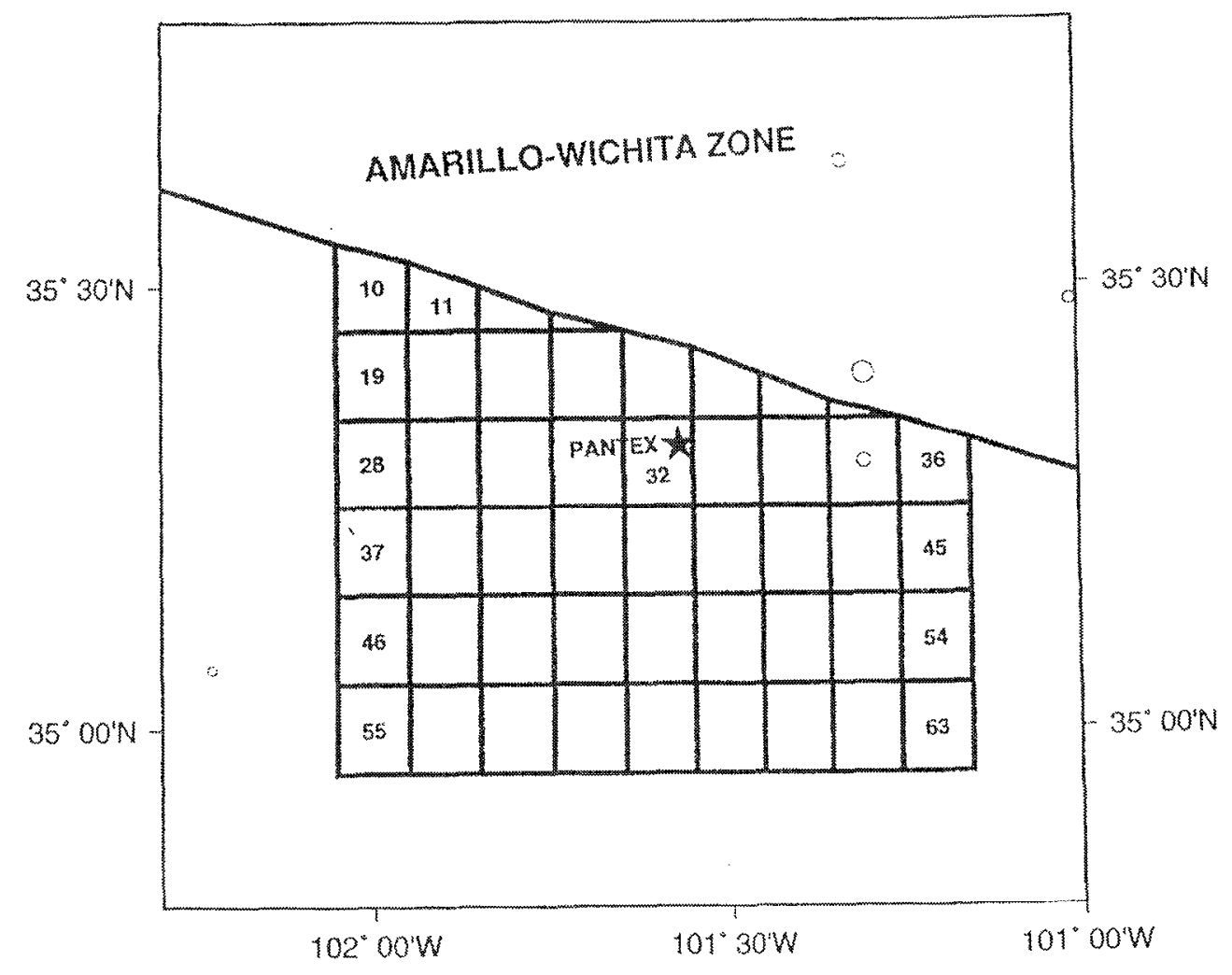

Figure 3.3-3 Pantex site inner grid zones 


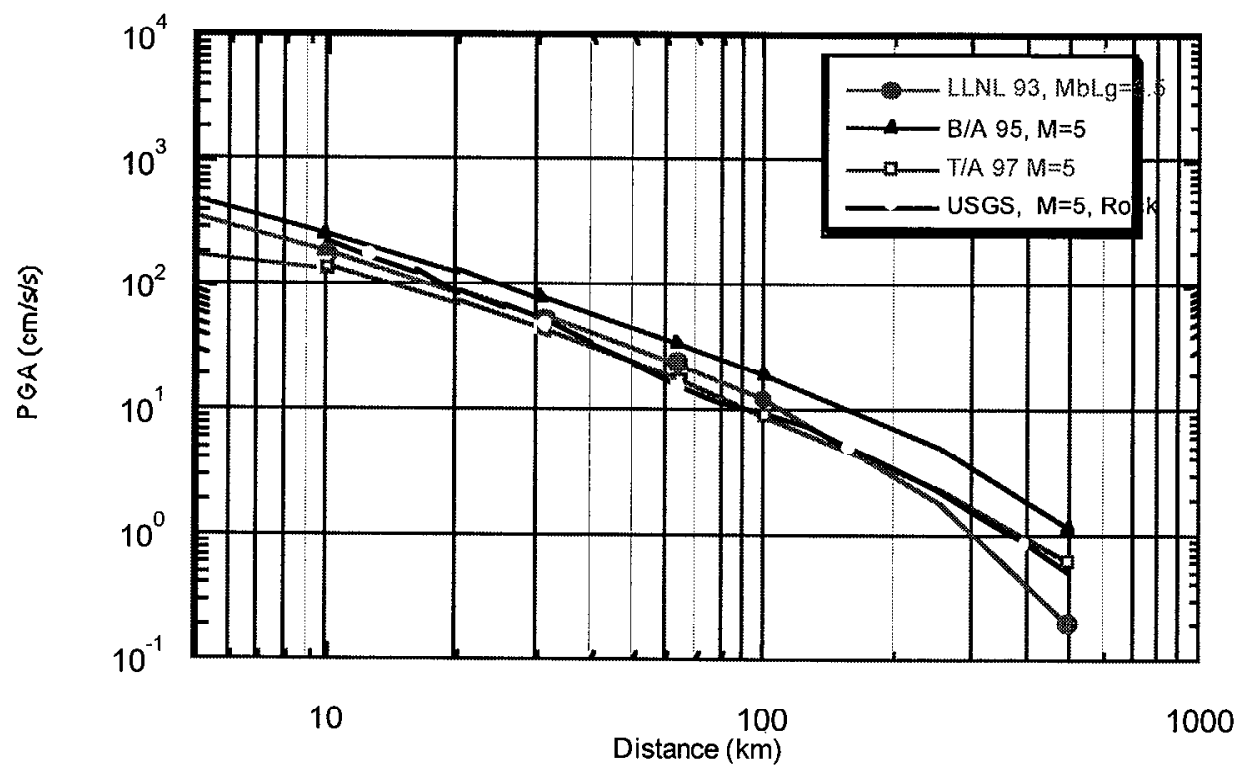

Figure 3.3-4 Comparison of median PGA estimates for $M_{w}=5.0, m_{b L g}=5.5$ on rock

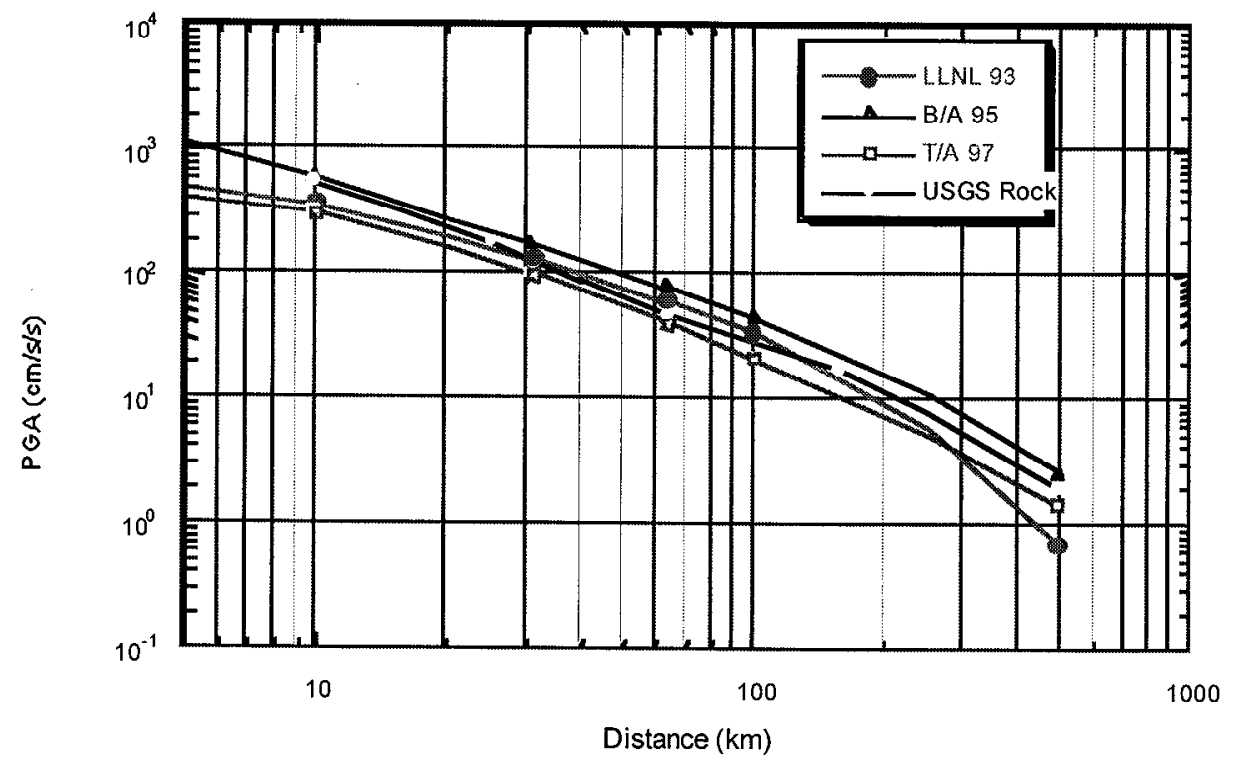

Figure 3.3-5 Comparison of median PGA estimates for $M_{w}=6.0, m_{b L g}=6.3$ on rock 


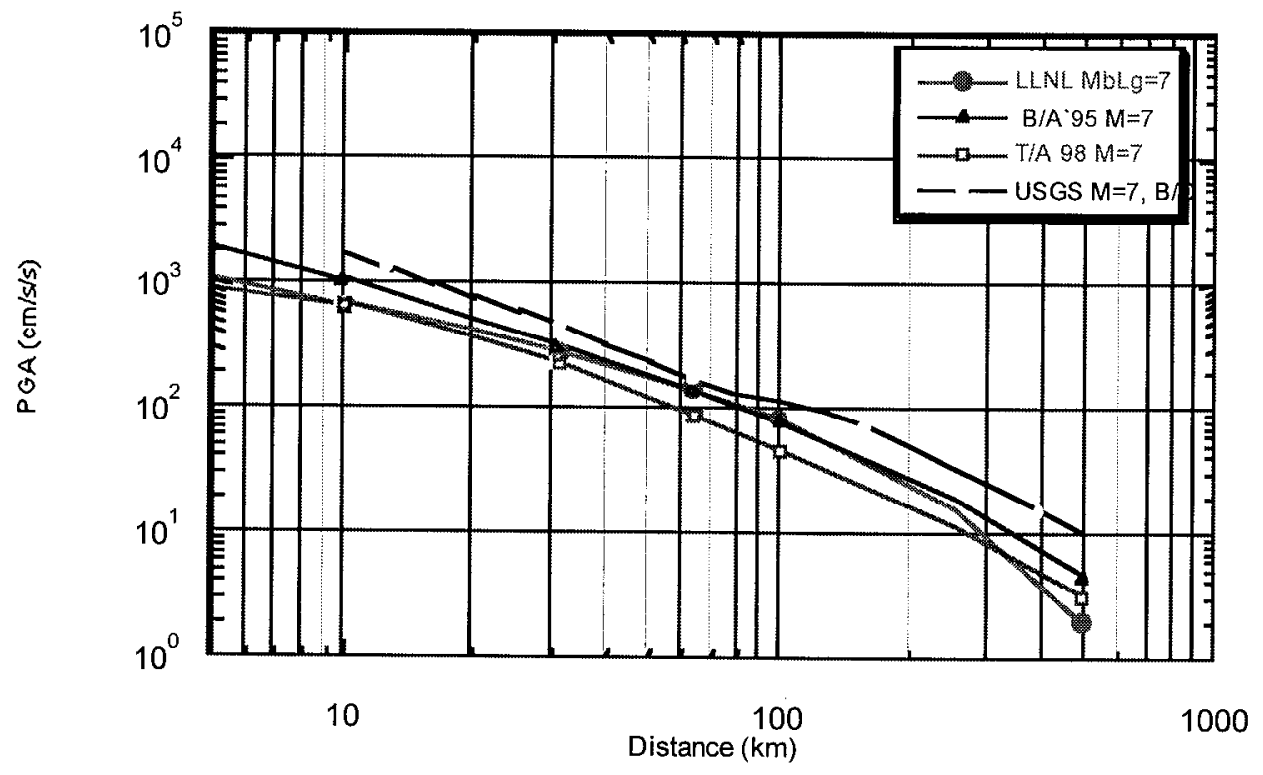

Figure 3.3-6 Comparison of median PGA estimates for $M_{w}=m_{b L g}=7: 0$ on rock

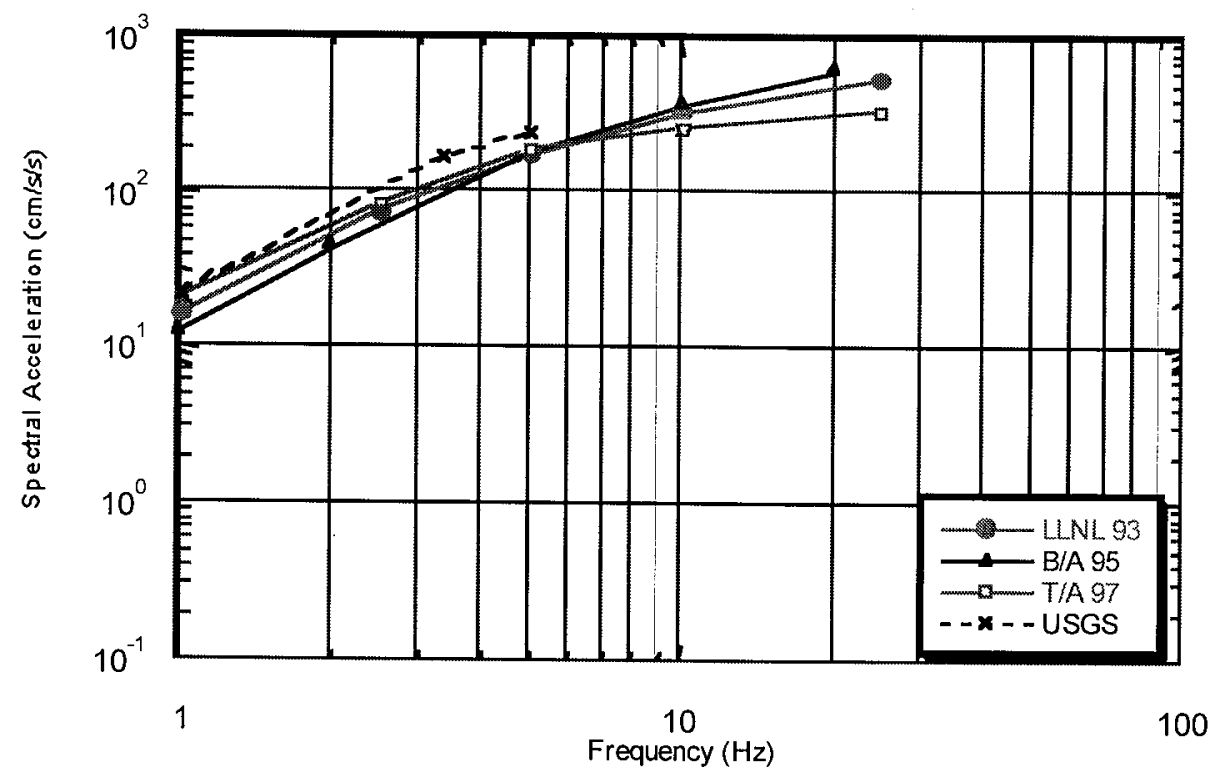

Figure 3.3-7 Comparison of median spectral acceleration estimates for $10 \mathrm{~km}, \mathrm{M}_{w}=5.0$, $\mathrm{m}_{\mathrm{bLg}}=5.5$ on rock 


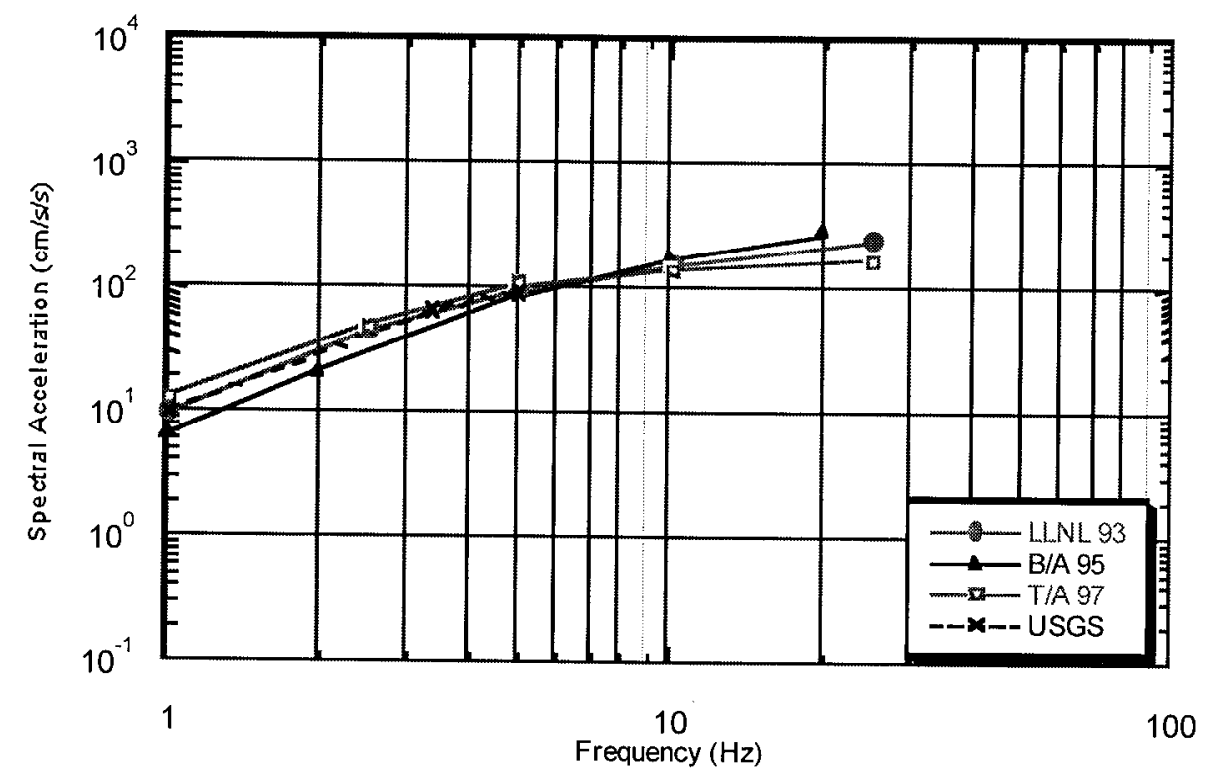

Figure 3.3-8 Comparison of median acceleration spectral estimates for $20 \mathrm{~km}, \mathrm{M}_{\mathrm{w}}=5.0, \mathrm{~m}_{\mathrm{bLg}}=5.5$ on rock

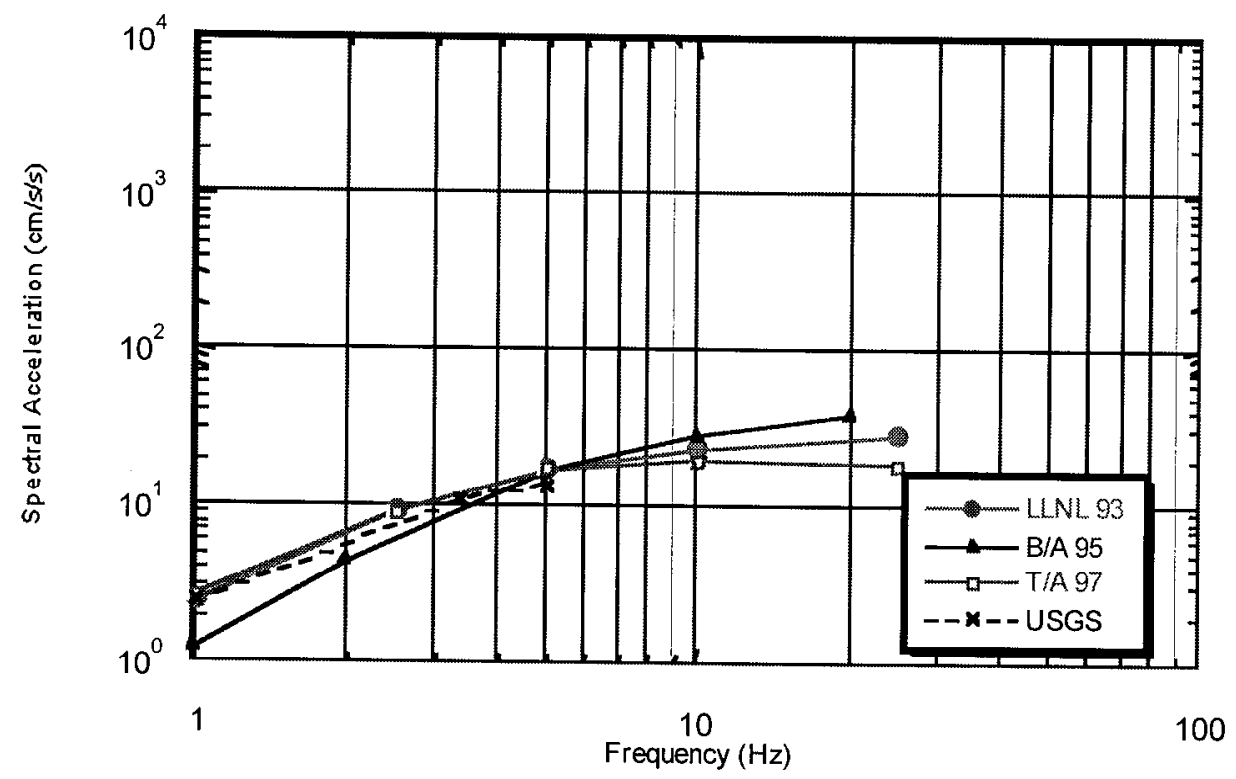

Figure 3.3-9 Comparison of median spectral acceleration estimates for $100 \mathrm{~km}, M_{w}=5.0, m_{b L g}=5.5$ on rock 


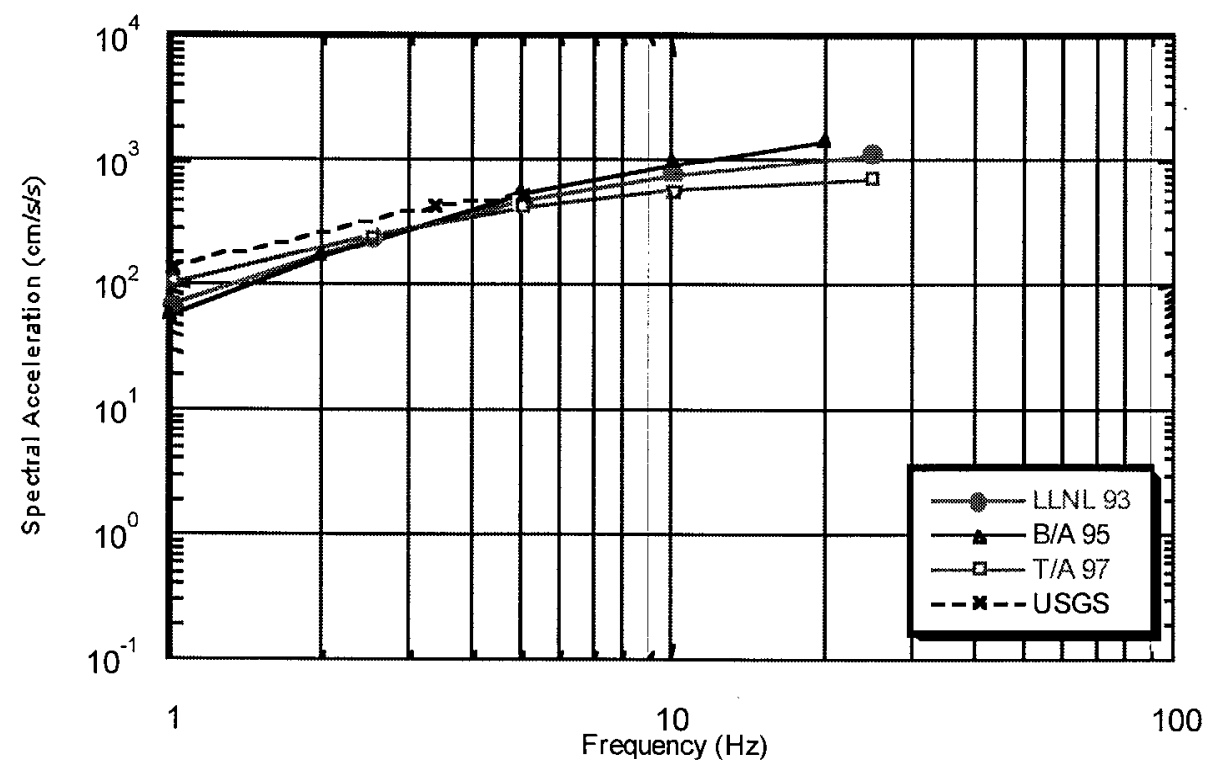

Figure 3.3-10 Comparison of median spectral acceleration estimates for $10 \mathrm{~km}, M_{w}=6.0, m_{b L g}=6.3$ on rock

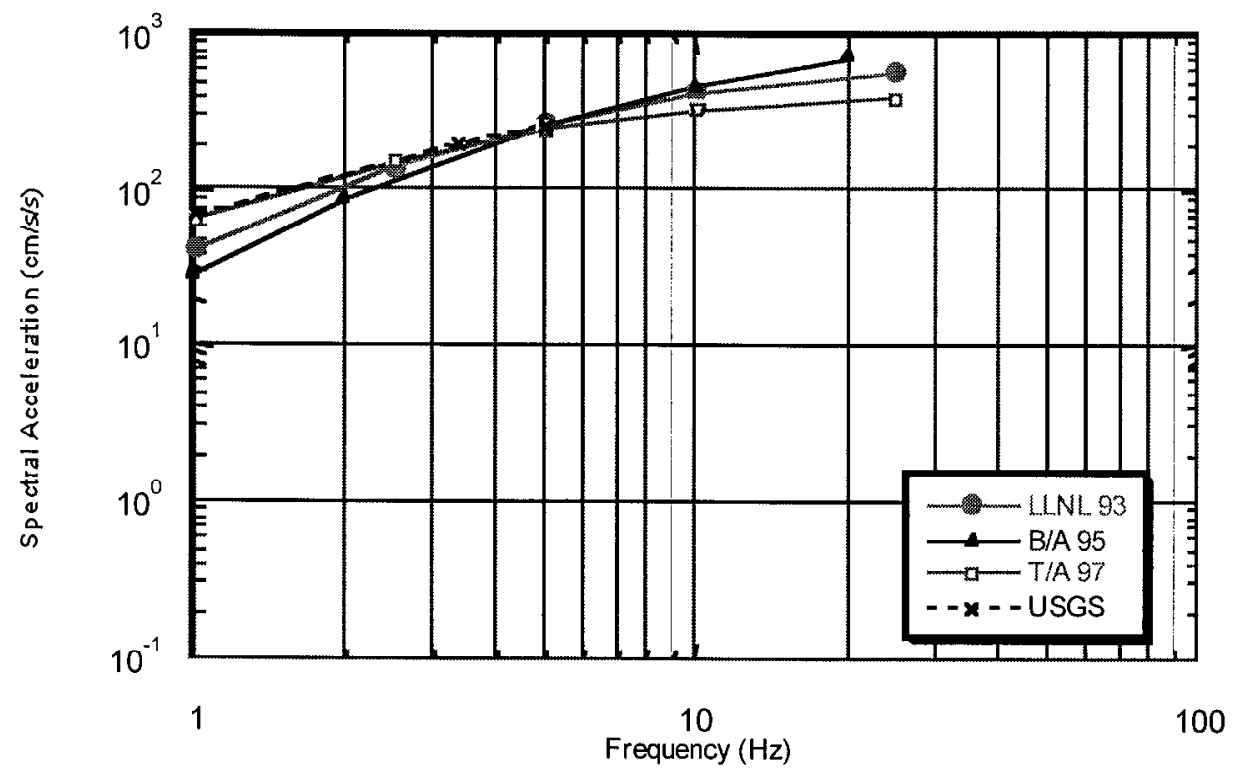

Figure 3.3-11 Comparison of median spectral acceleration estimates for $20 \mathrm{~km}, M_{w}=6.0, m_{b L g}=6.3$ on rock 


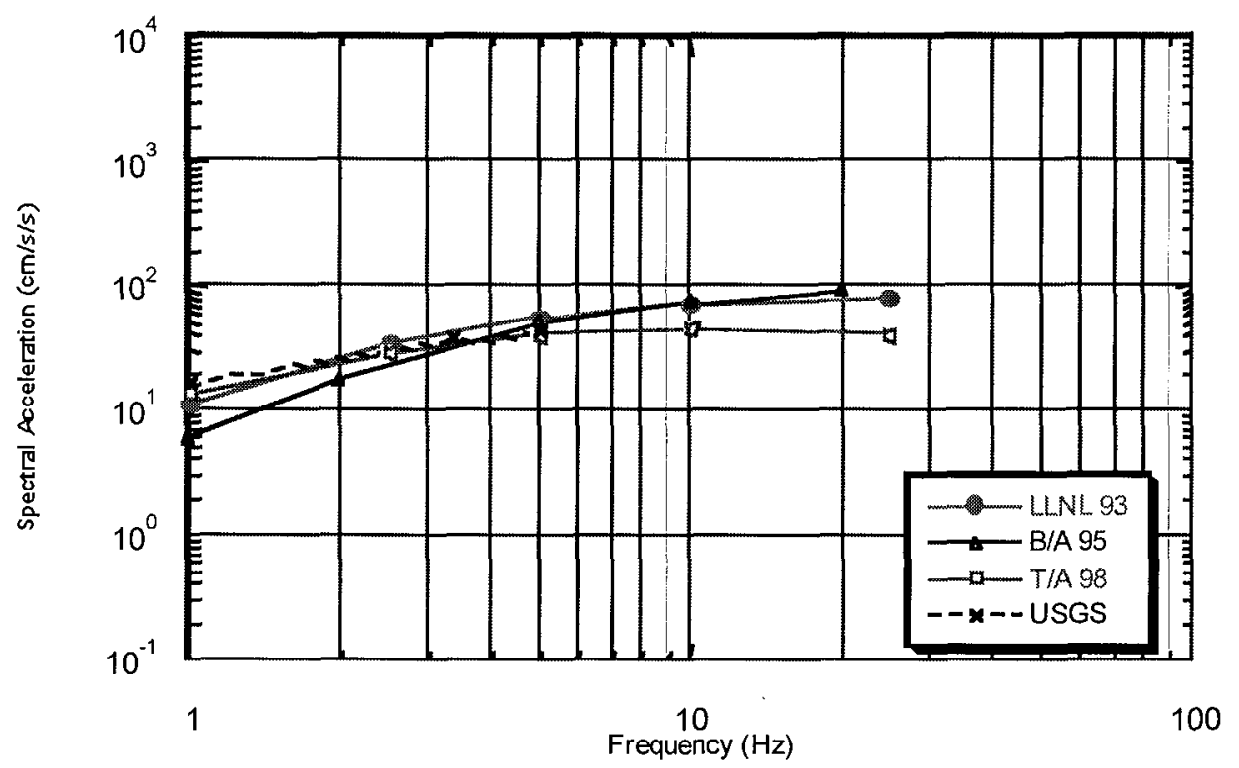

Figure 3.3-12 Comparison of median spectral acceleration estimates for $100 \mathrm{~km}, M_{w}=6.0, m_{b L g}=6.3$ on rock

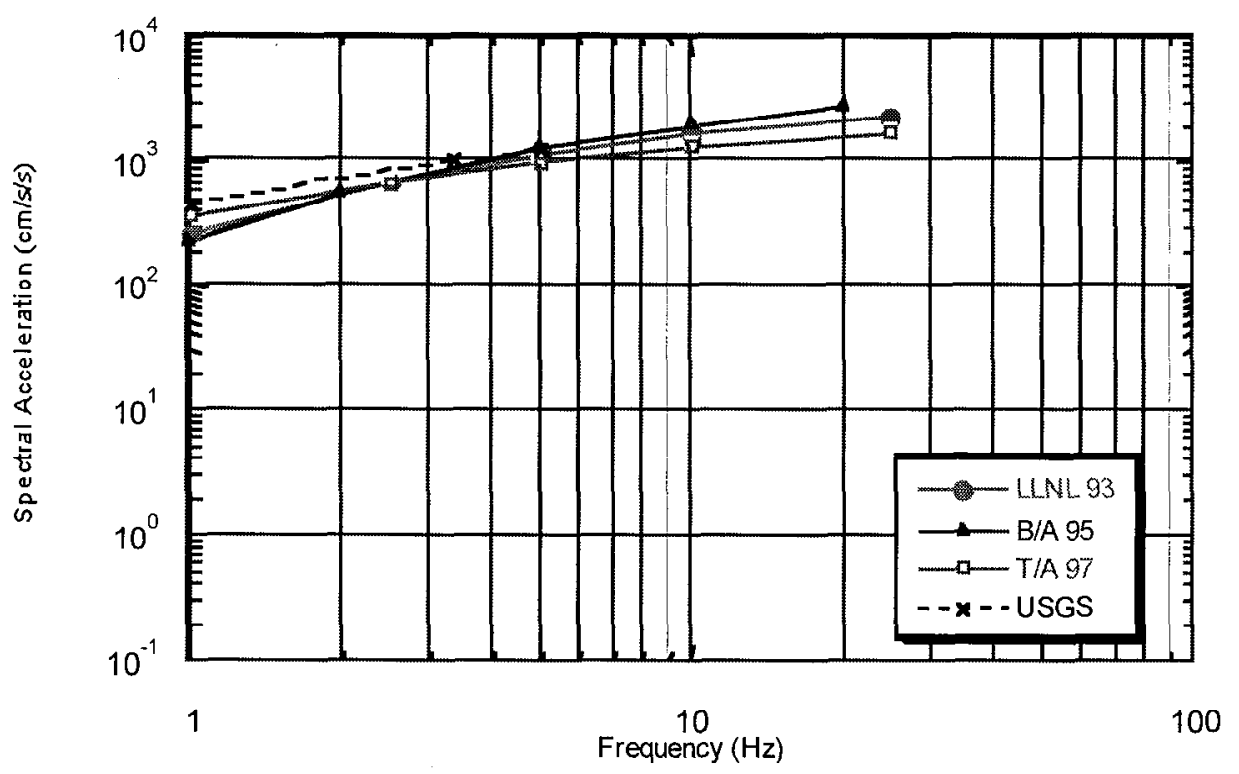

Figure 3.3-13 Comparison of median spectral acceleration estimates for $10 \mathrm{~km}, M_{\mathrm{w}}=\mathbf{m}_{\mathrm{bLg}}=7.0$ on rock 


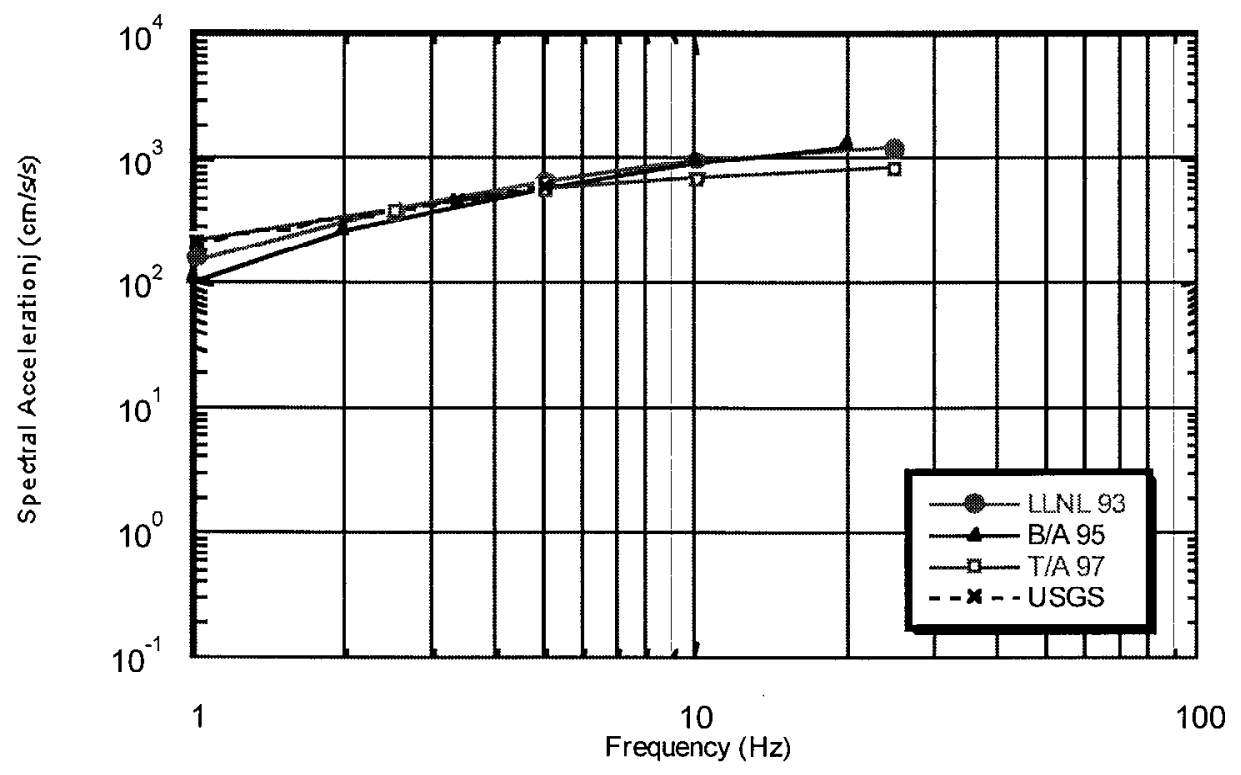

Figure 3.3-14 Comparison of median spectral acceleration estimates for $20 \mathrm{~km}, M_{w}=m_{b L g}=7.0$ on rock

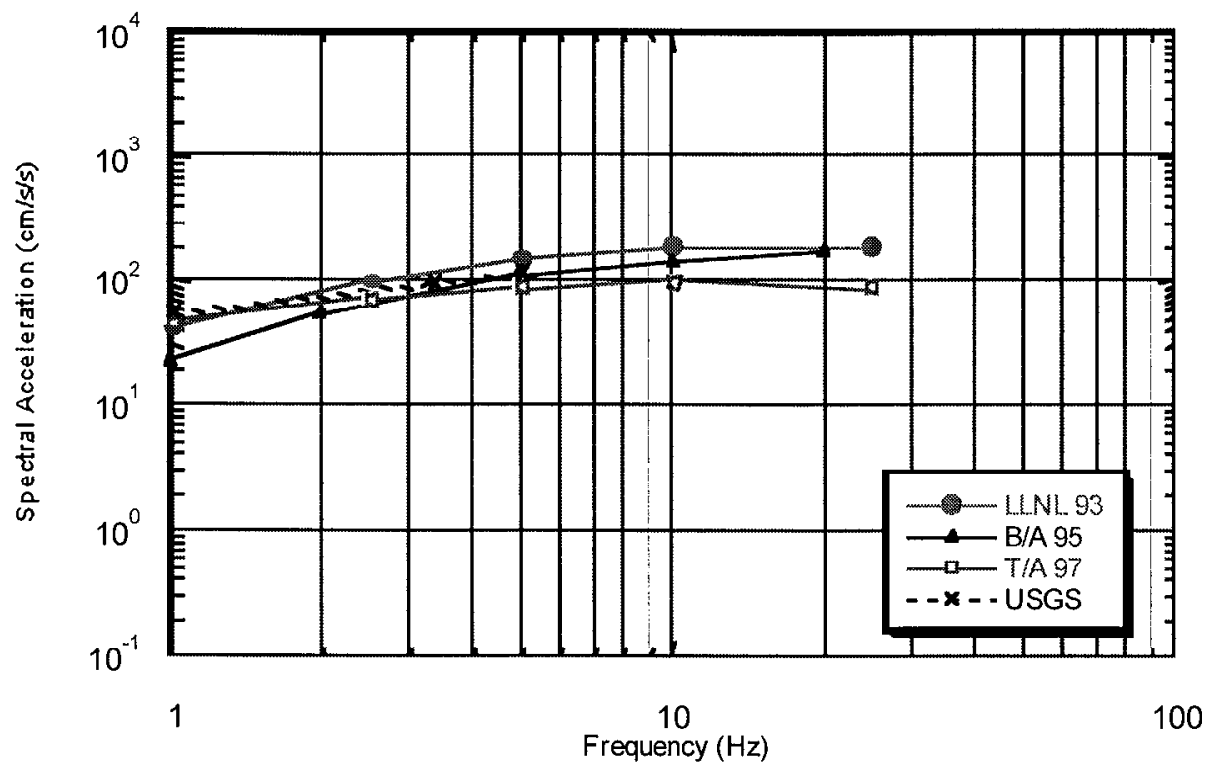

Figure 3.3-15 Comparison of median spectral acceleration estimates for $100 \mathrm{~km}, M_{w}=m_{b L g}=7.0$ on rock 


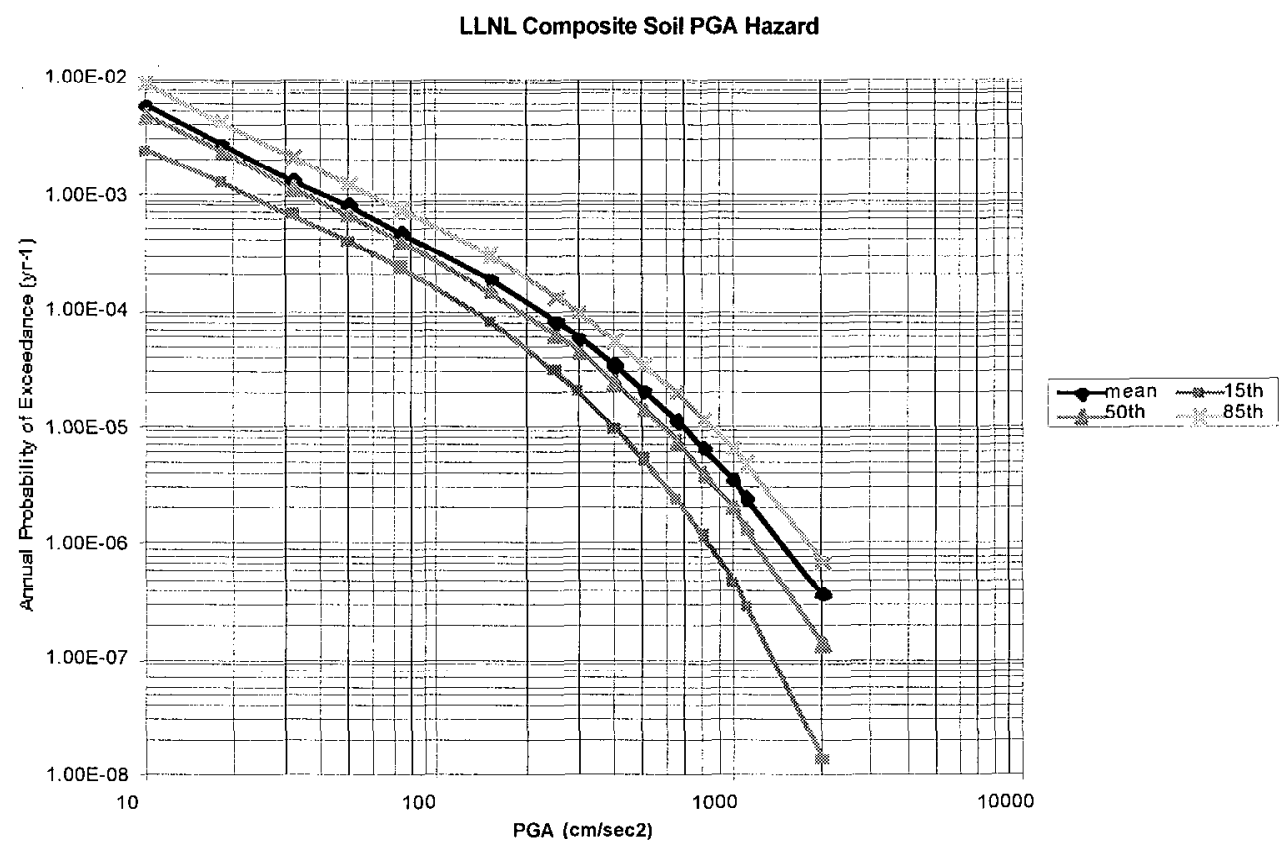

Figure 3.4-1 15th, 50th, 85th percentiles and mean annual probability of exceedance of the PGA for the Pantex soil site, using the LLNL93 rock ground motion model and the EPRI93 amplification factor

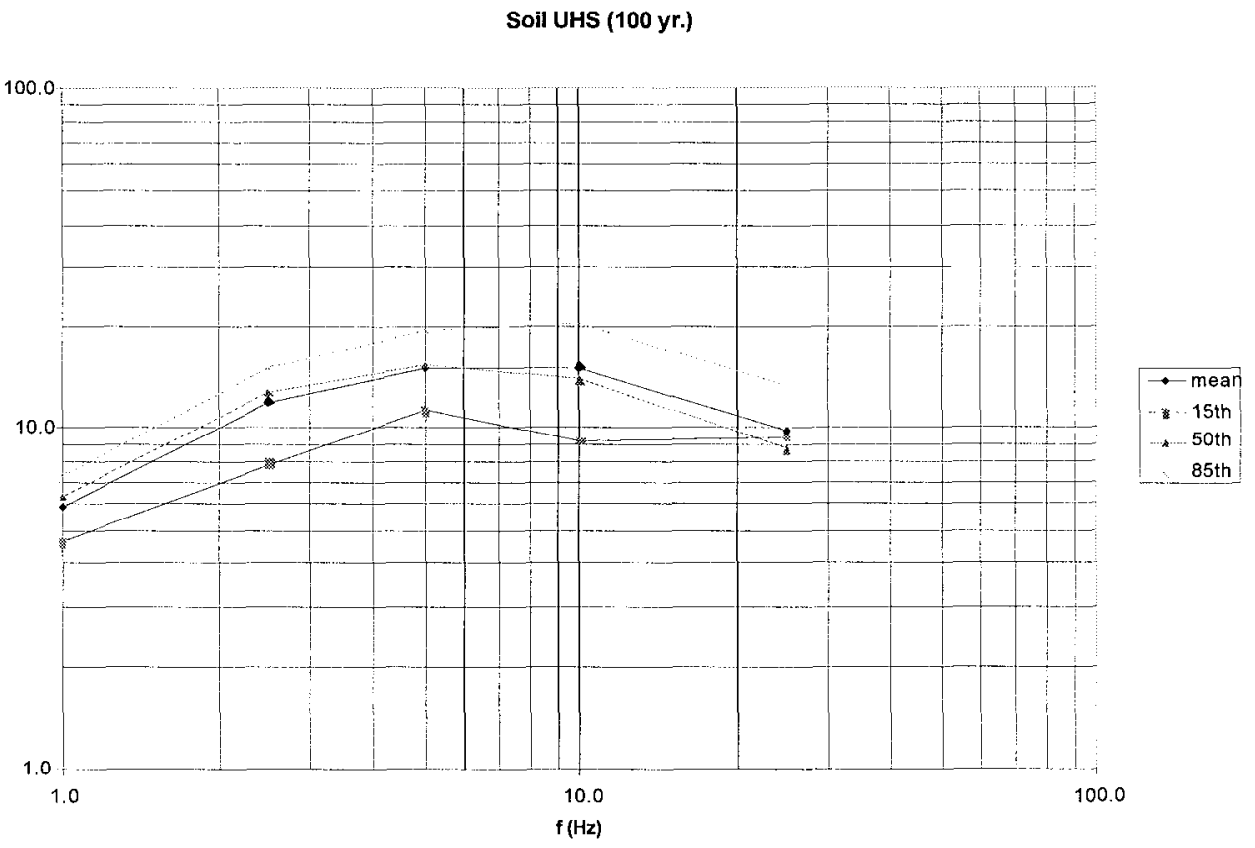

Figure 3.4-2 100-year return period 5\%-damped mean, 15th, 50th and 85th percentile uniform hazard response spectra for the Pantex site soil conditions using the LLNL93 rock ground motion model and EPRI93 amplification factors 
Soil UHS (500 yr.)

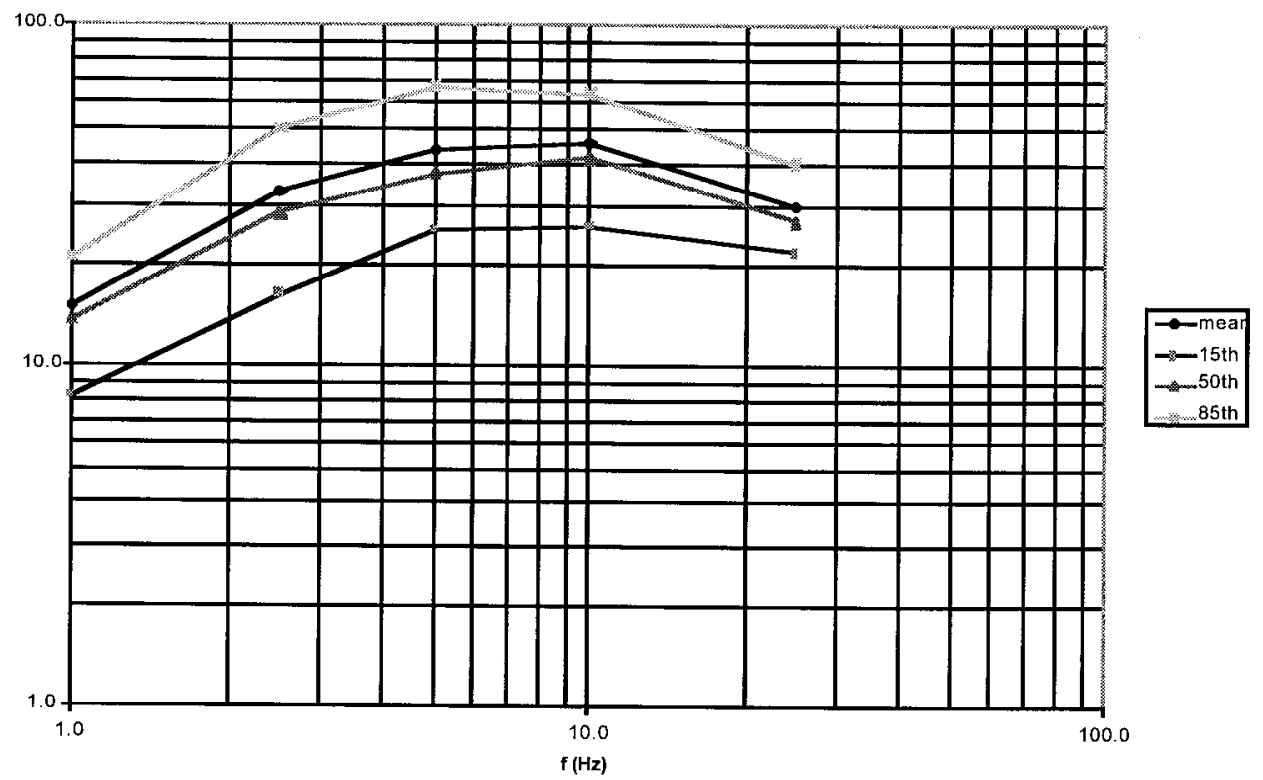

Figure 3.4-3 500-year return period 5\%-damped mean, 15th, 50th and 85th percentile uniform hazard response spectra for the Pantex site soil conditions using the LLNL93 rock ground motion model and EPRI93 amplification factors

Soil UHS (1000 yr.)

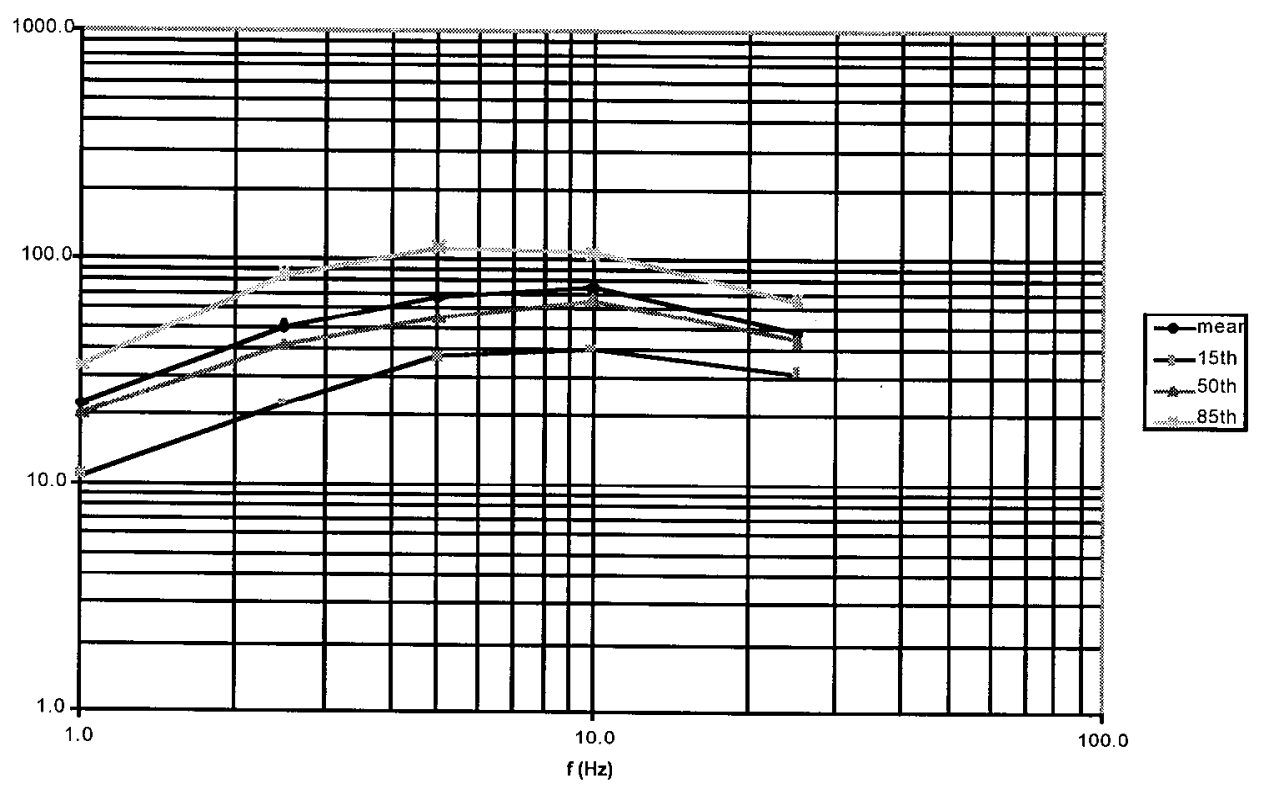

Figure 3.4-4 1,000-year return period 5\% -damped mean, 15th, 50th and 85th percentile uniform hazard response spectra for the Pantex site soil conditions using the LLNL93 rock ground motion modcl and EPRI93 amplification factors. 
Soil UHS (2000 yr.)

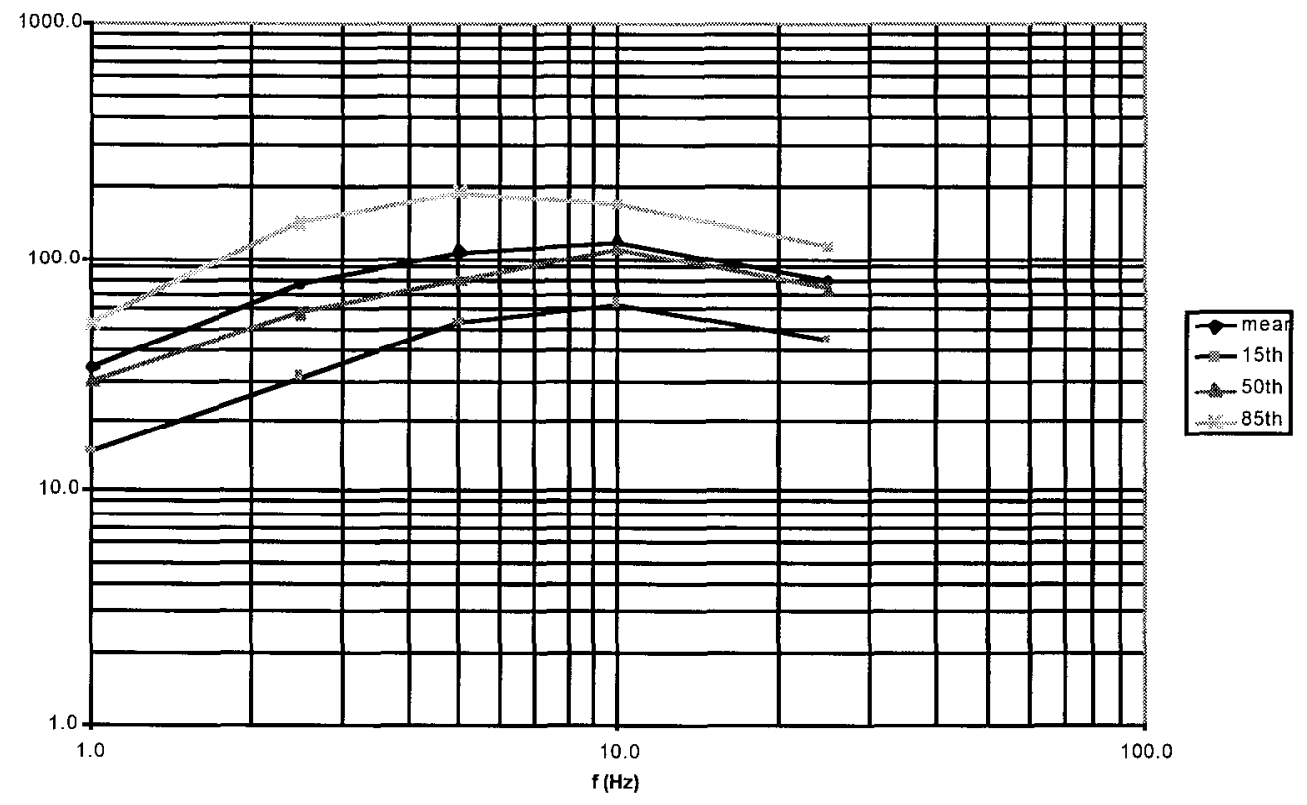

Figure 3.4-5 2,000-year return period 5\%-damped mean, 15th, 50th and 85th percentile uniform hazard response spectra for the Pantex site soil conditions using the LLNL93 rock ground motion model and EPRI93 amplification factors.

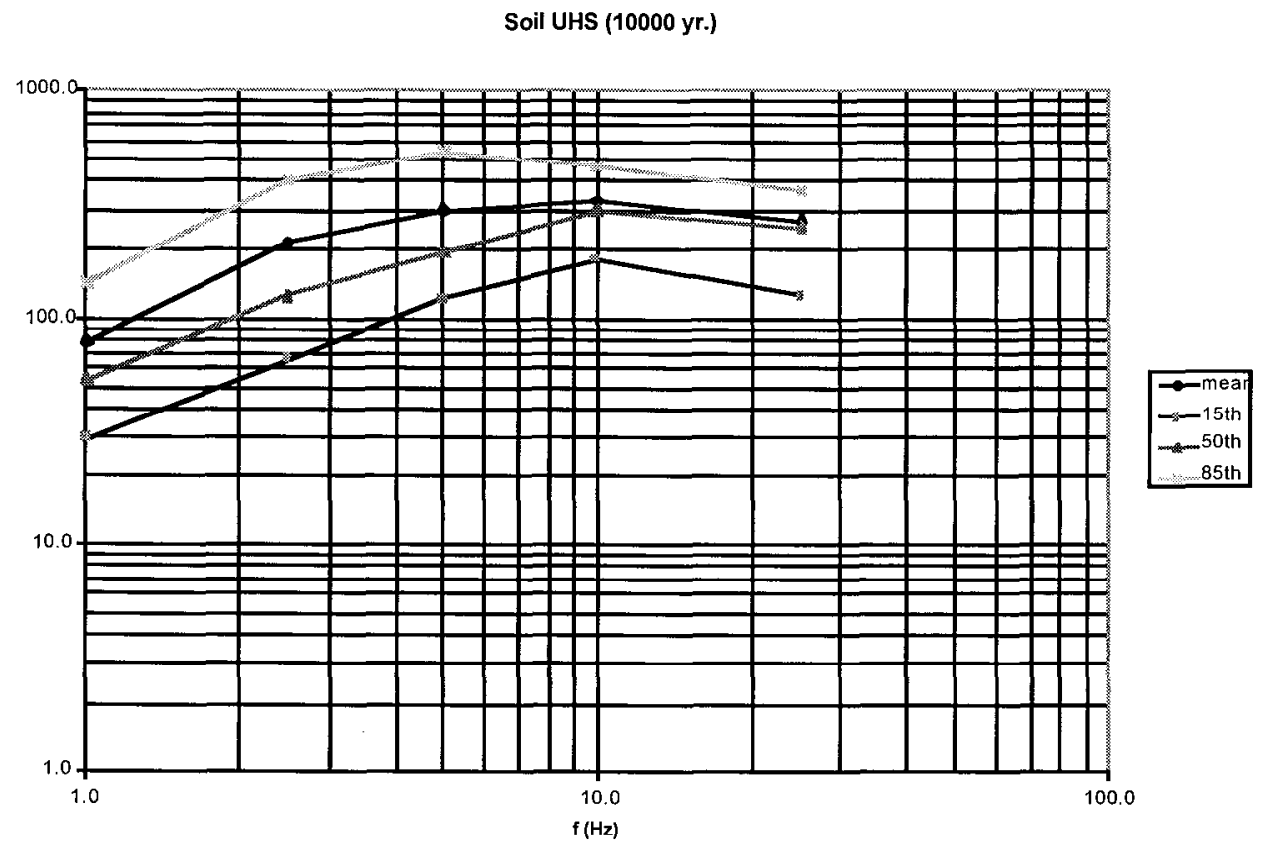

Figure 3.4-6 10,000-year return period 5\%-damped mean, 15th, 50th and 85th percentile uniform hazard response spectra for the Pantex site soil conditions using the LLNL93 rock ground motion model and EPRI93 amplification factors. 
Soil UHS (100000 yr.)

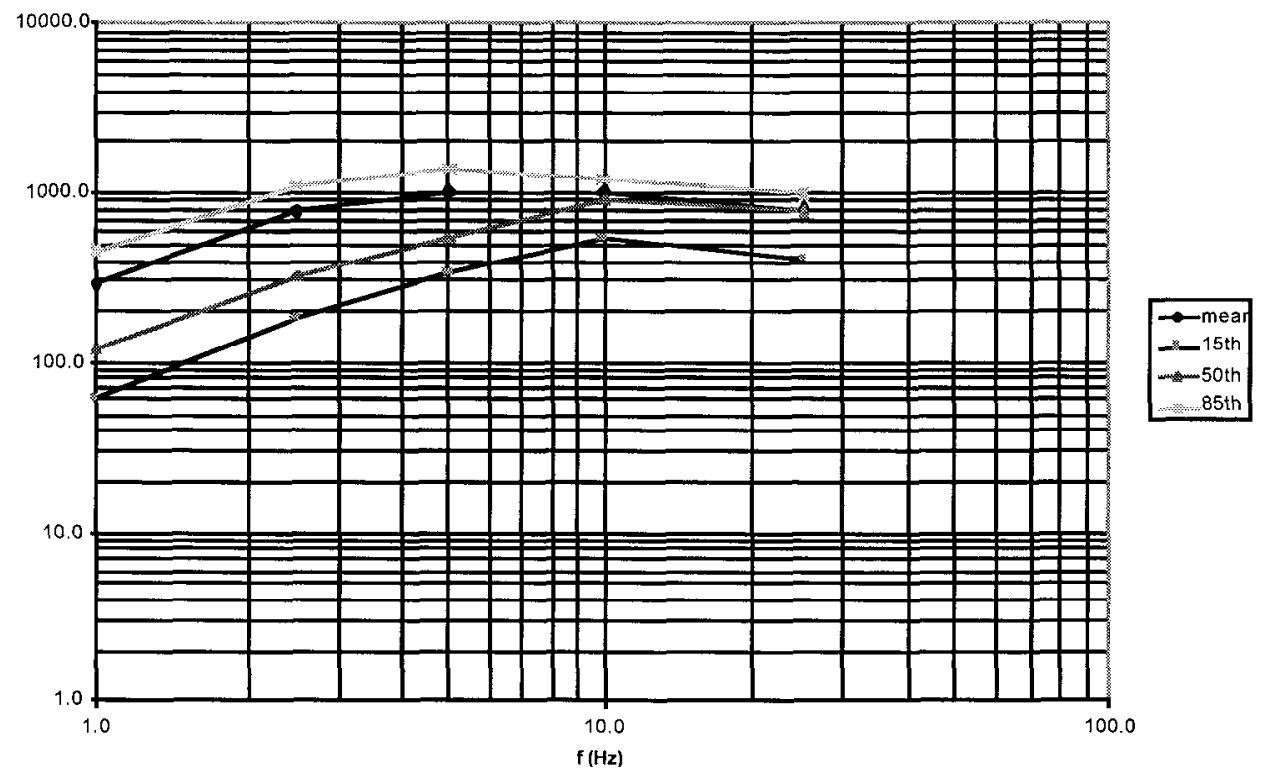

Figure 3.4-7 100,000-year return period 5\%-damped mean, 15th, 50th and 85th percentile uniform hazard response spectra for the Pantex site soil conditions using the LLNL93 rock ground motion model and EPRI93 amplification factors.

LLNL Composite Soil PGA Hazard

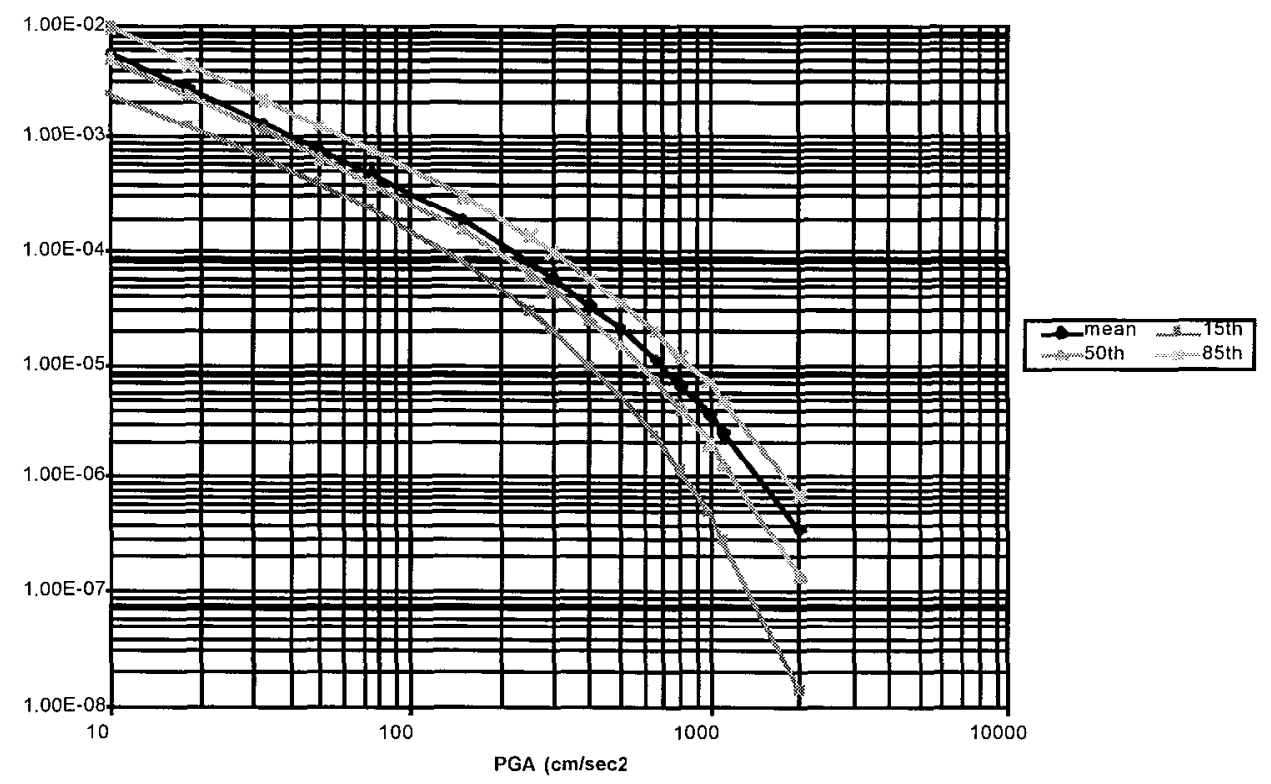

Figure 3.4-8 Mean hazard curve for Pantex rock site with LLNL93 ground motion model. 


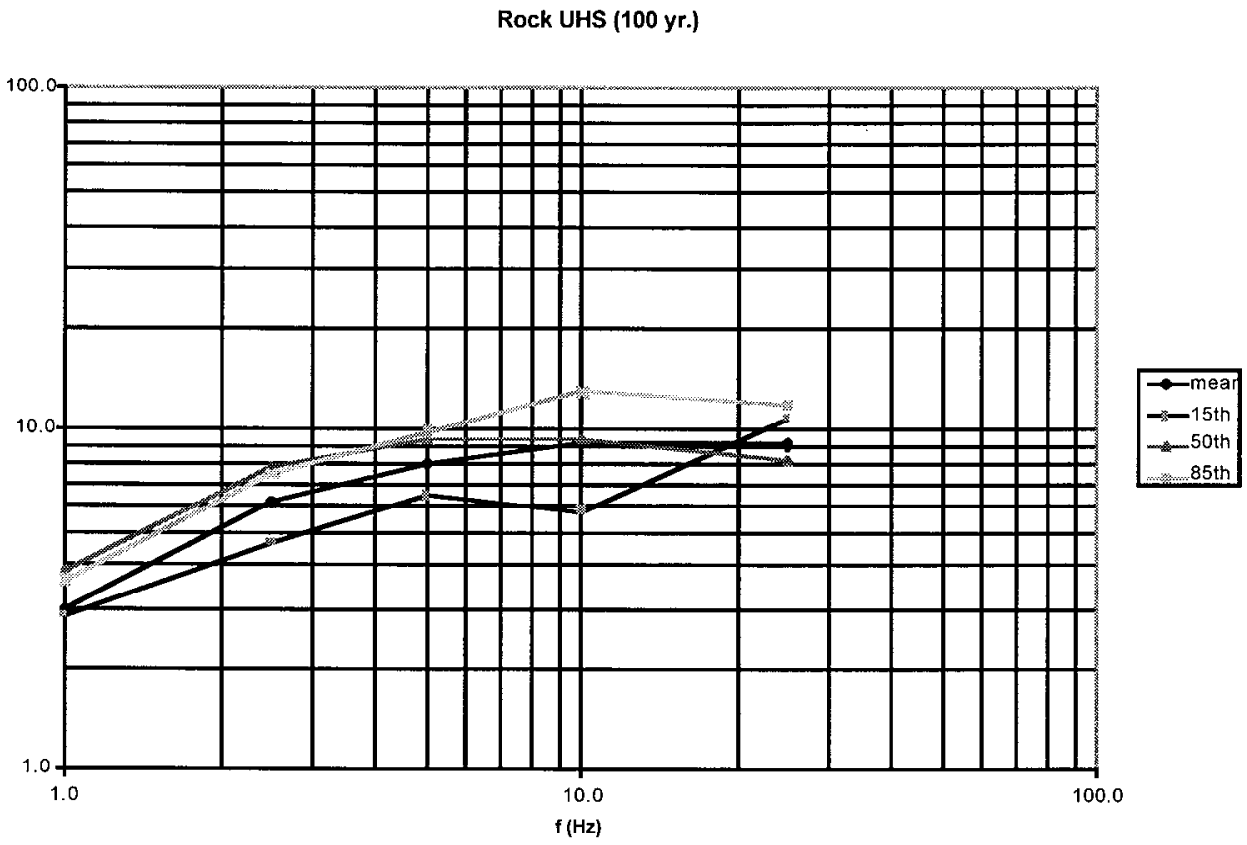

Figure 3.4-9 100-year return period 5\%-damped, mean, 15th, 50th and 85th percentiles UHS for Pantex rock site using the LLNL93 ground motion model.

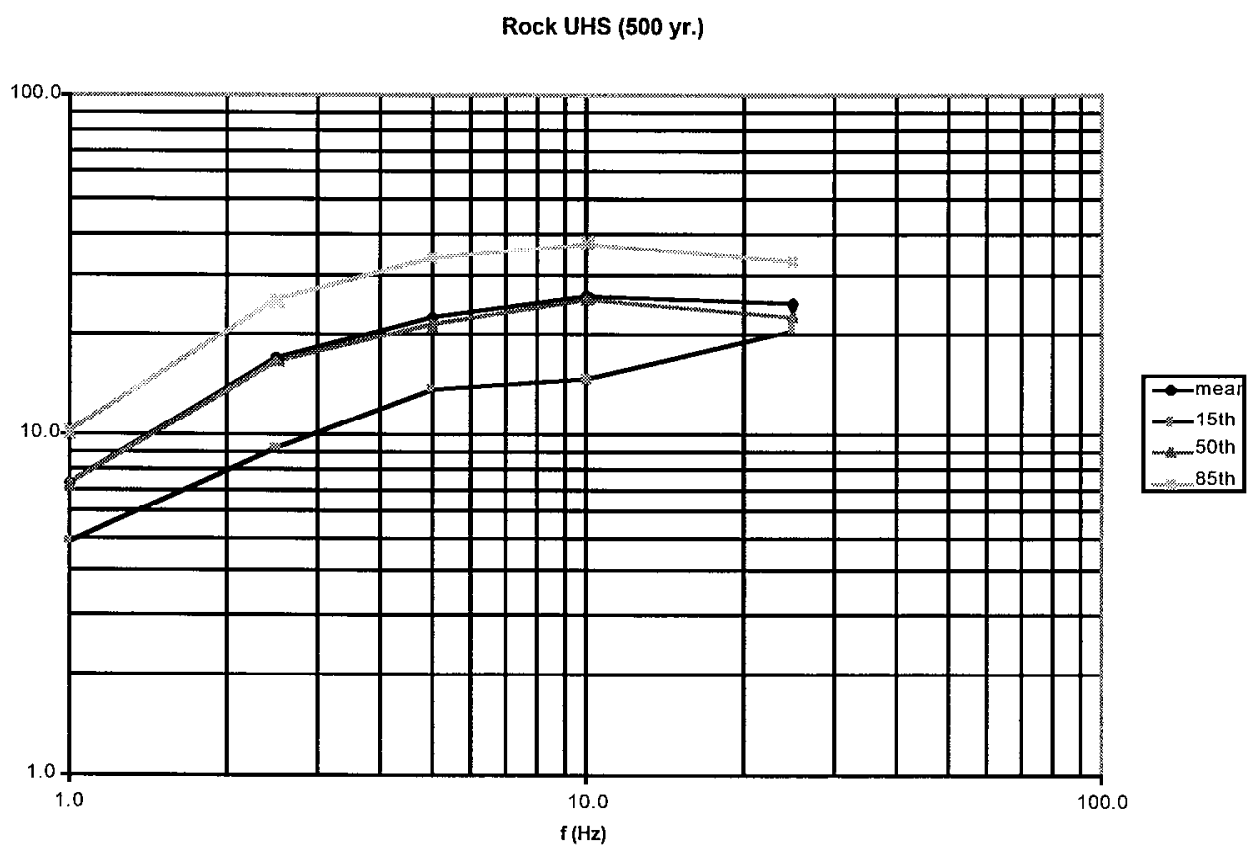

Figure 3.4-10 500-year return period 5\%-damped, mean, 15th, 50th and 85th percentiles UHS for Pantex rock site using the LLNL93 ground motion model. 


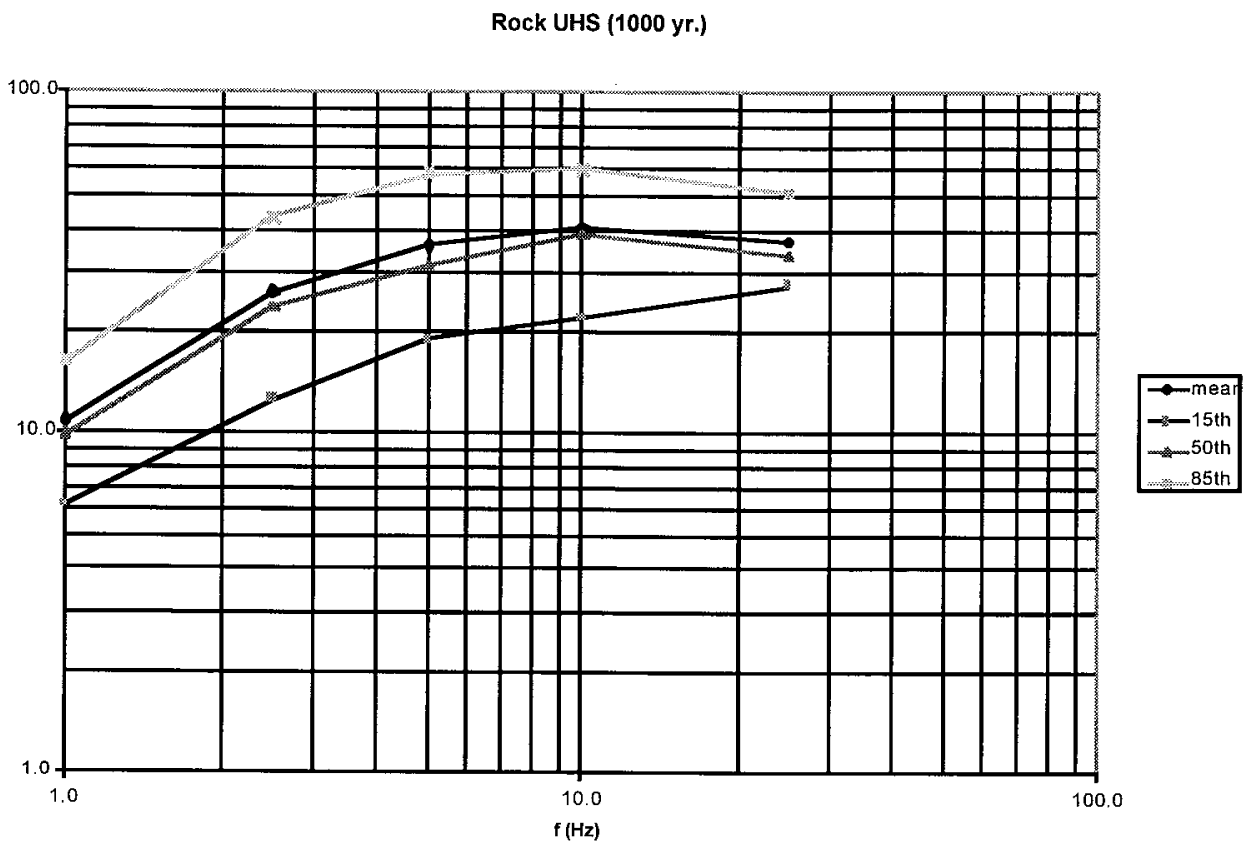

Figure 3.4-11 1,000-year return period 5\%-damped, mean, 15th, 50th and 85th percentiles UHS for Pantex rock site using the LLNL93 ground motion model.

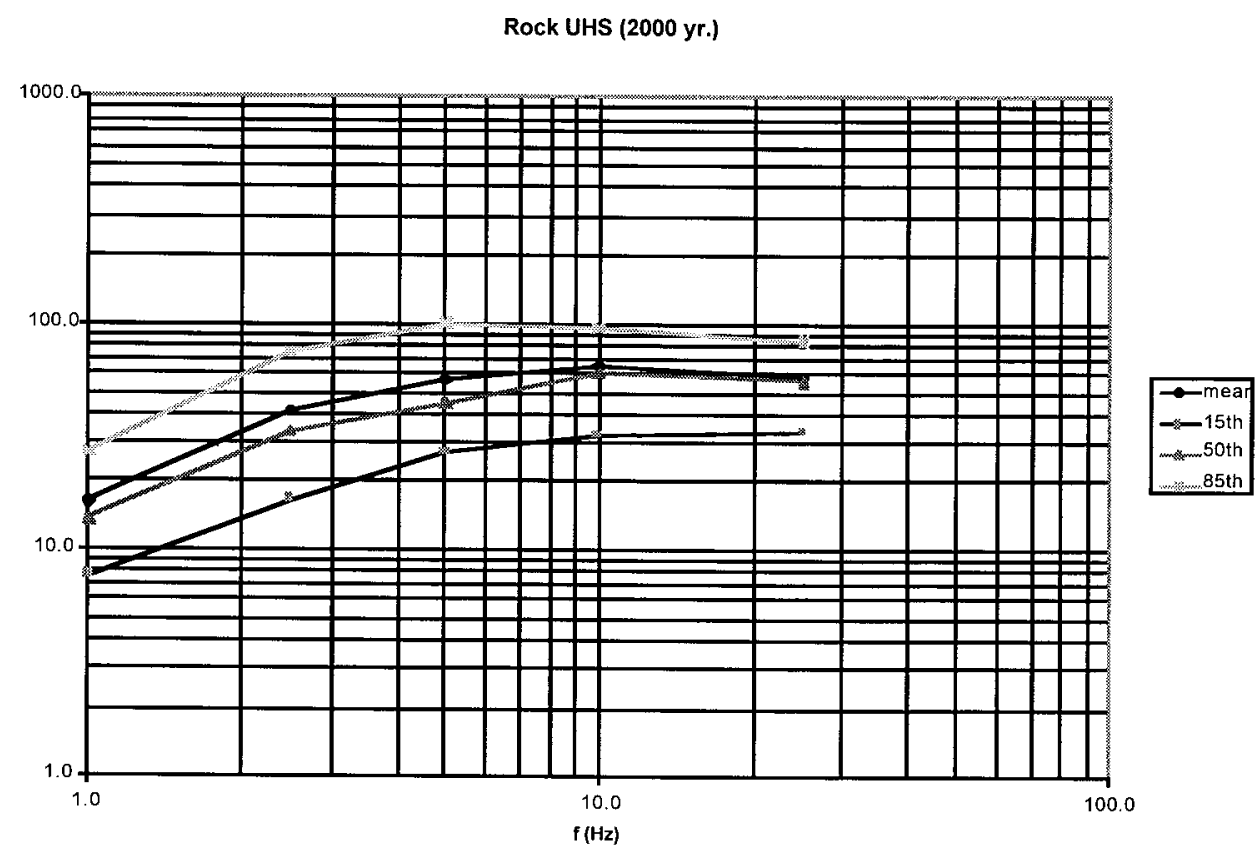

Figure 3.4-12 2,000-year return period 5\%-damped, mean, 15th, 50th and 85th percentiles UHS for Pantex rock site using the LLNL93 ground motion model. 
Rock UHS (10000 yr.)

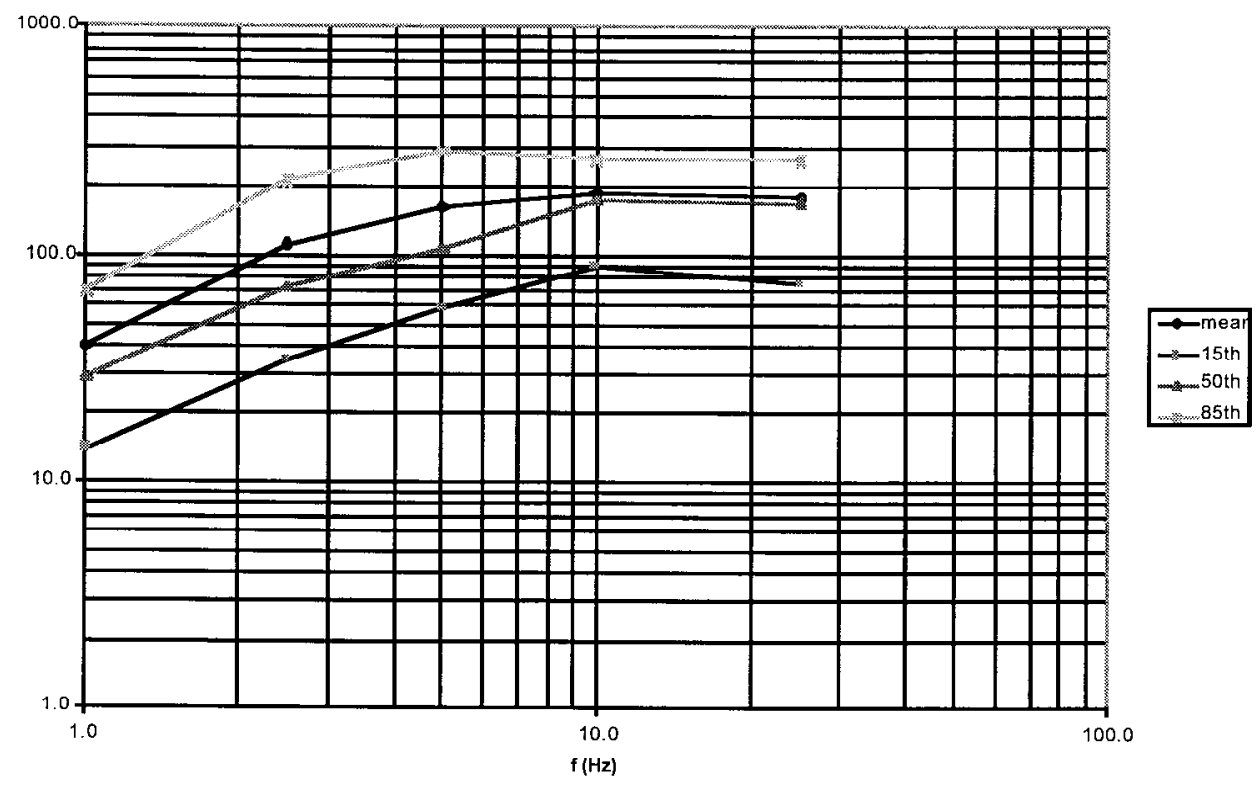

Figure 3.4-13 10,000-year return period 5\%-damped, mean, 15th, 50th and 85th percentiles UHS for Pantex rock site using the LLNL93 ground motion model

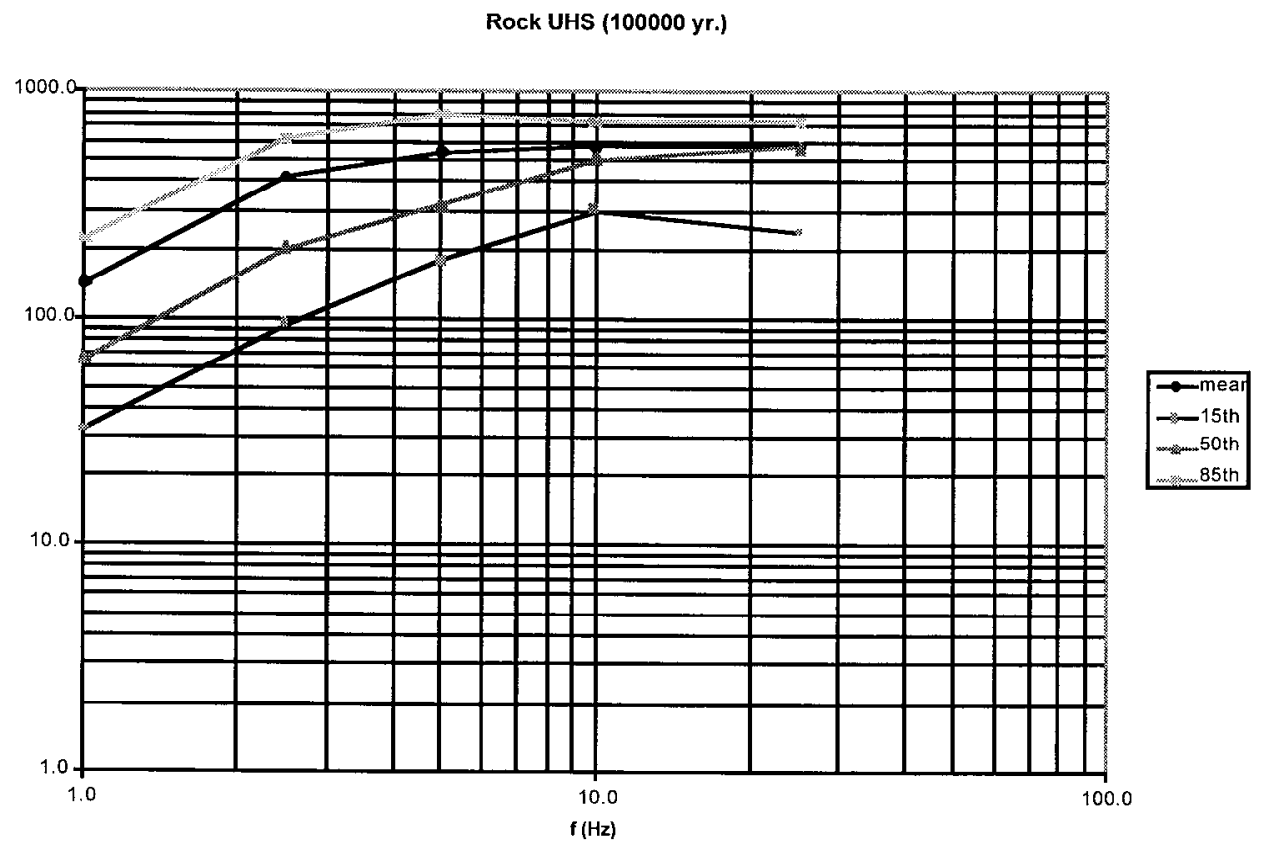

Figure 3.4-14 100,000-year return period 5\%-damped, mean, 15th, 50th and 85th percentiles UHS for Pantex rock site using the LLNL93 ground motion model 


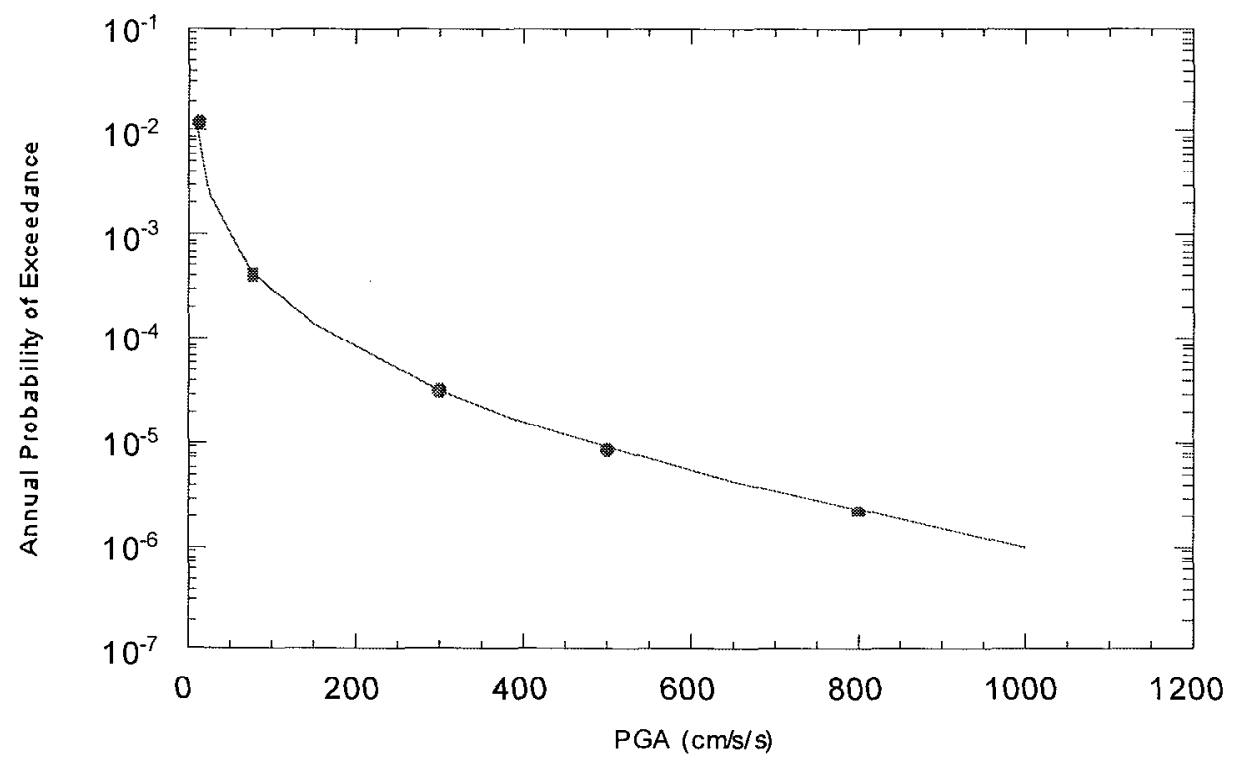

Figure 3.4-15 Total mean hazard curve with $\mathrm{A} / \mathrm{B95}$ ground motion rock model and USGS $B / C$ boundary soil correction

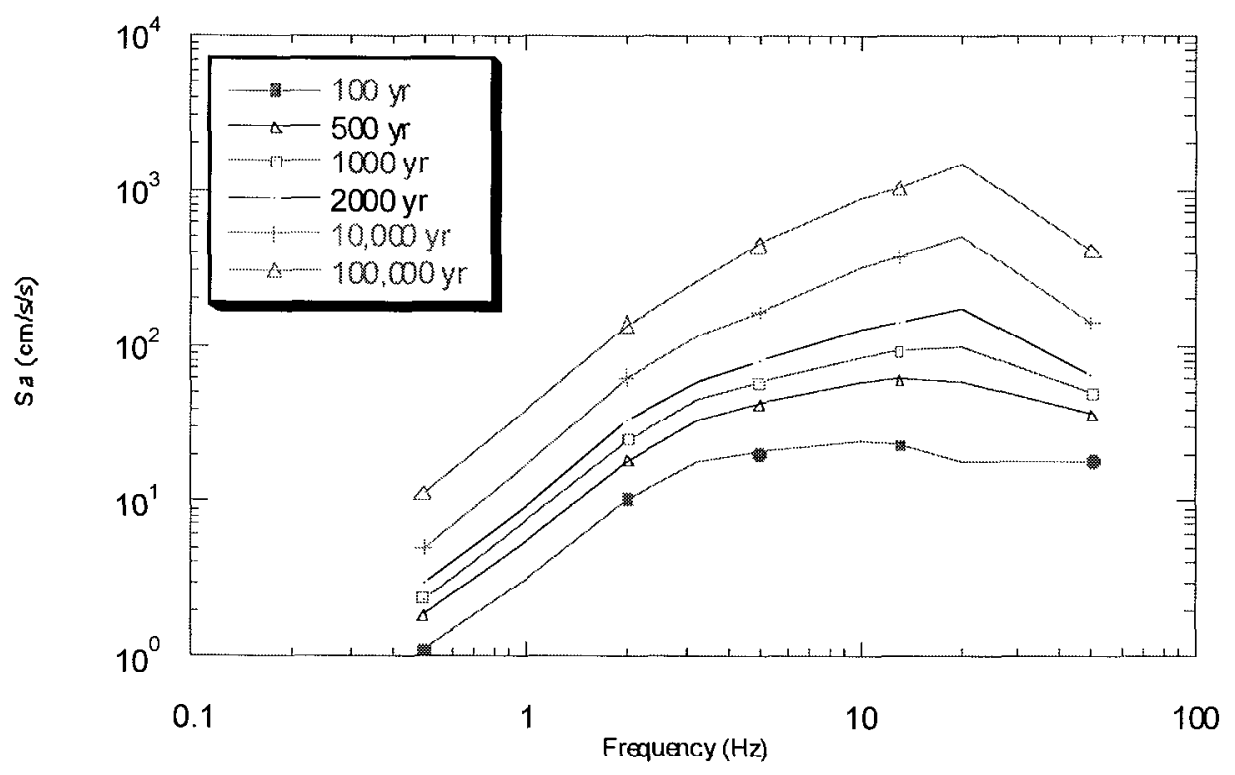

Figure 3.4-16 Mean UHS 5\%-damped response spectra with A/B95 ground motion model and USGS B/C boundary soil correction 


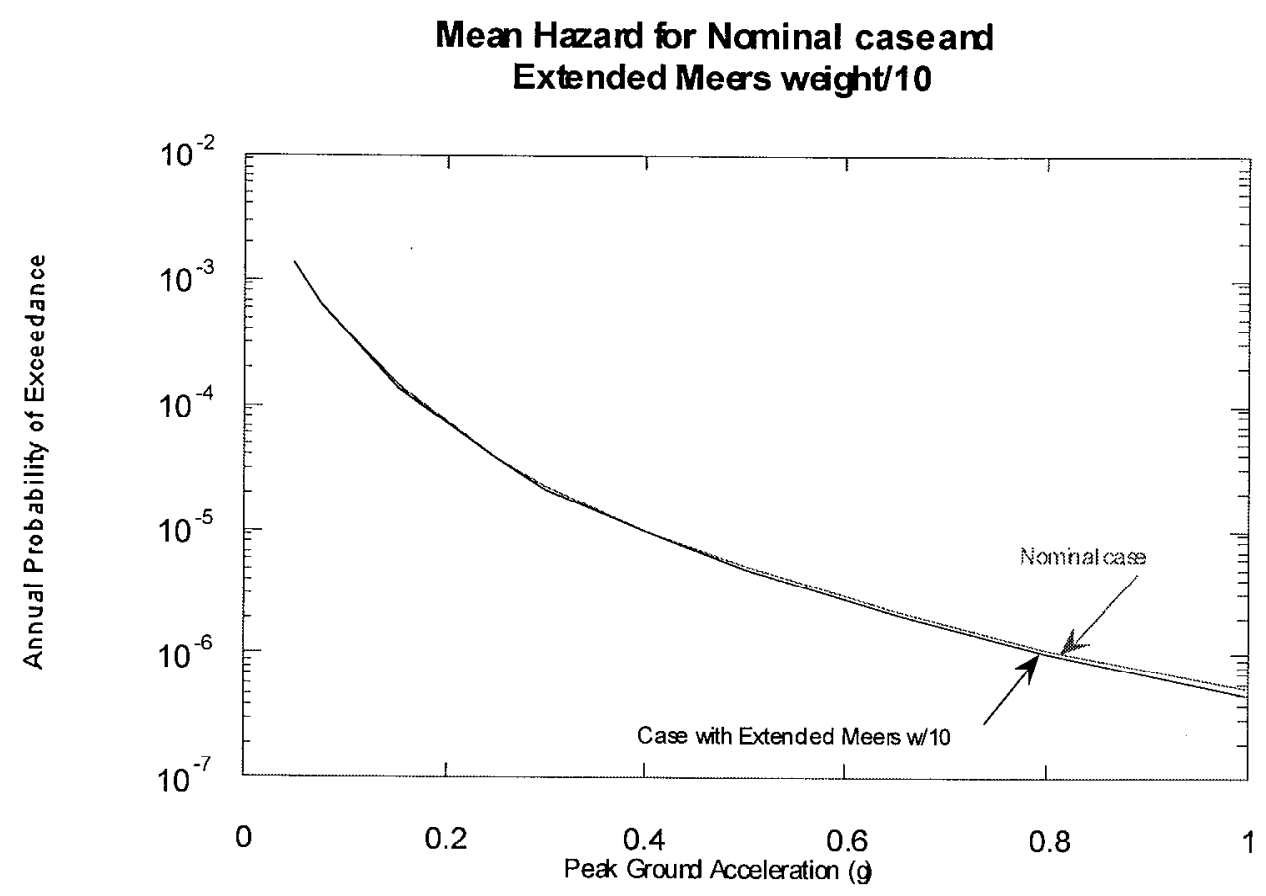

Figure 3.4-17 Mean hazard for nominal case and extended Meers weight/10

Comparison of the Mean Hazard for Nominal case, ates $/ 5$ in AWU and rate $\times 5$ inlmer Grid

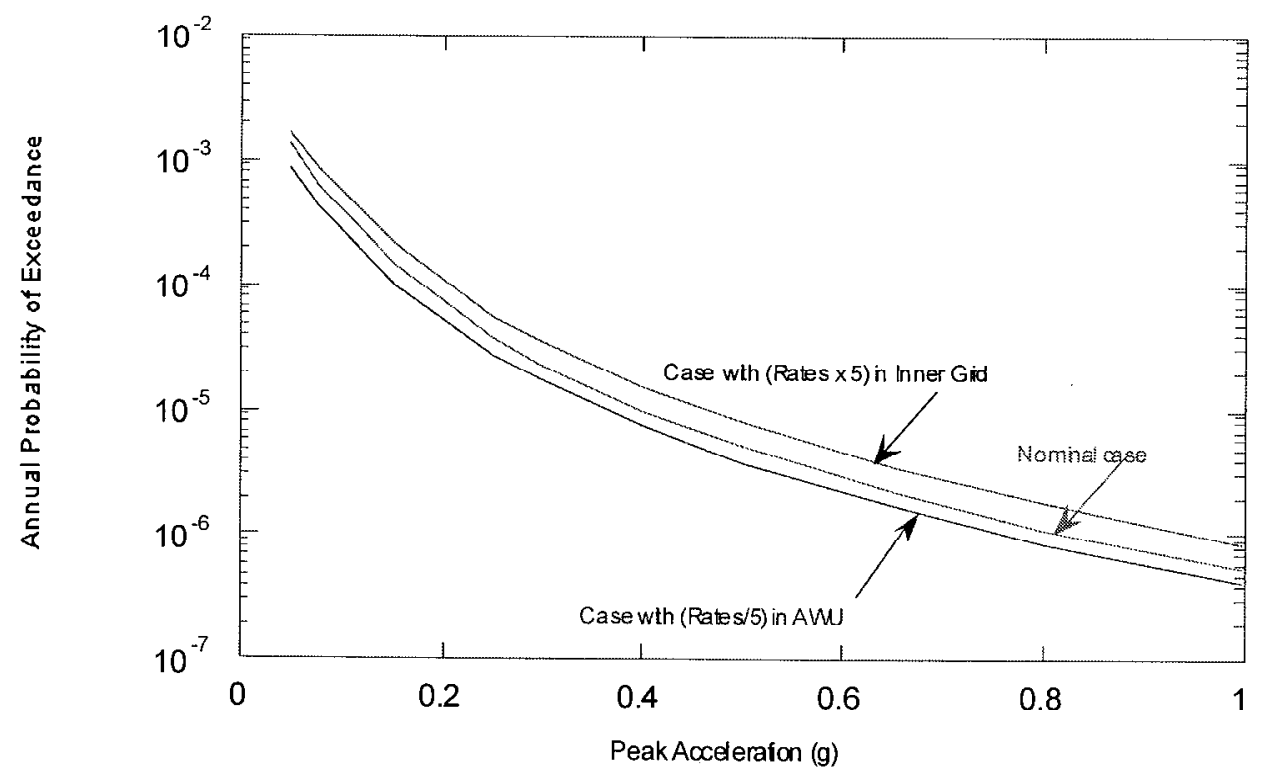

Figure 3.4-18 Comparison of the mean hazard for nominal case, rates $/ 5$ in $\mathrm{AWU}$ and rate $\times 5$ in inner grid 


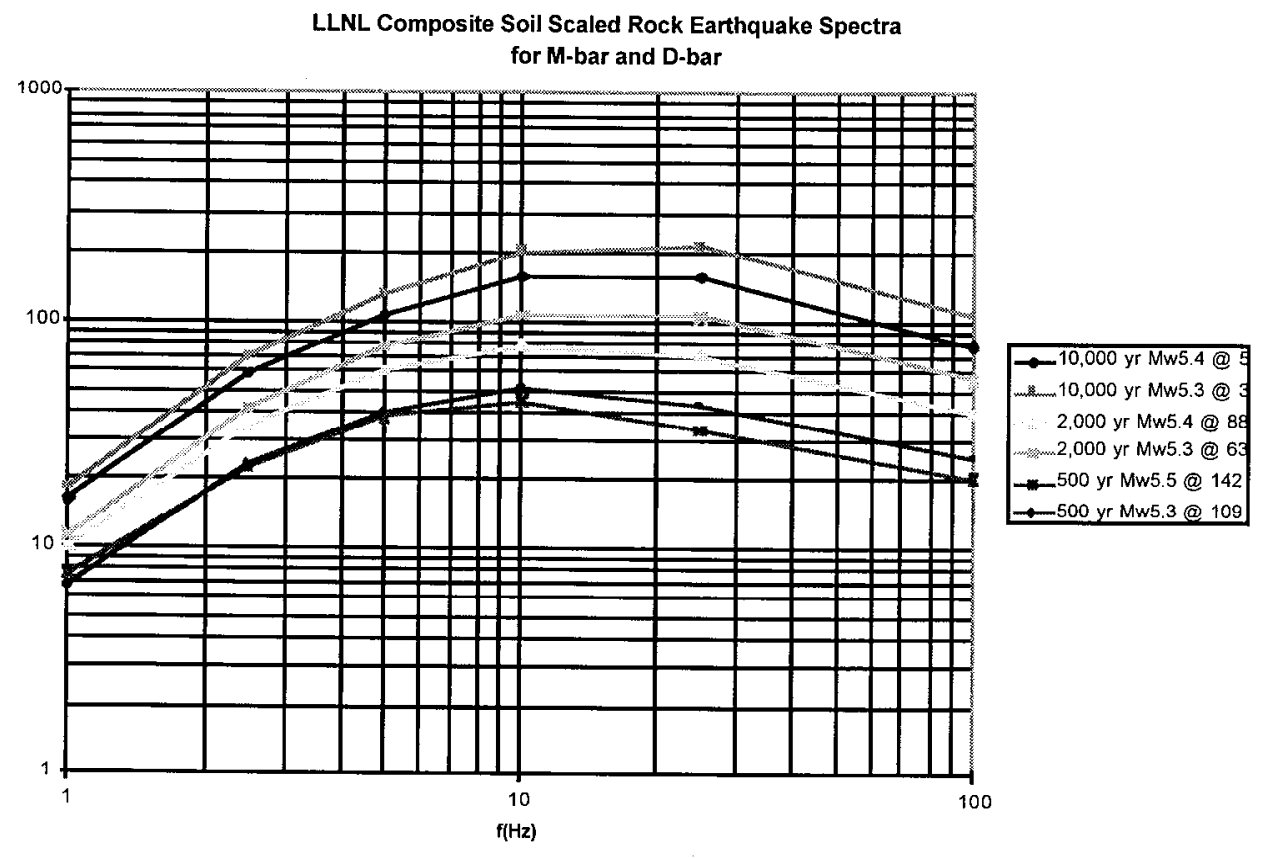

Figure 3.4-19 Median soil site response spectrum for each of the six controlling earthquakes (LLNL93 ground motion model and the EPRI93 amplification factors)

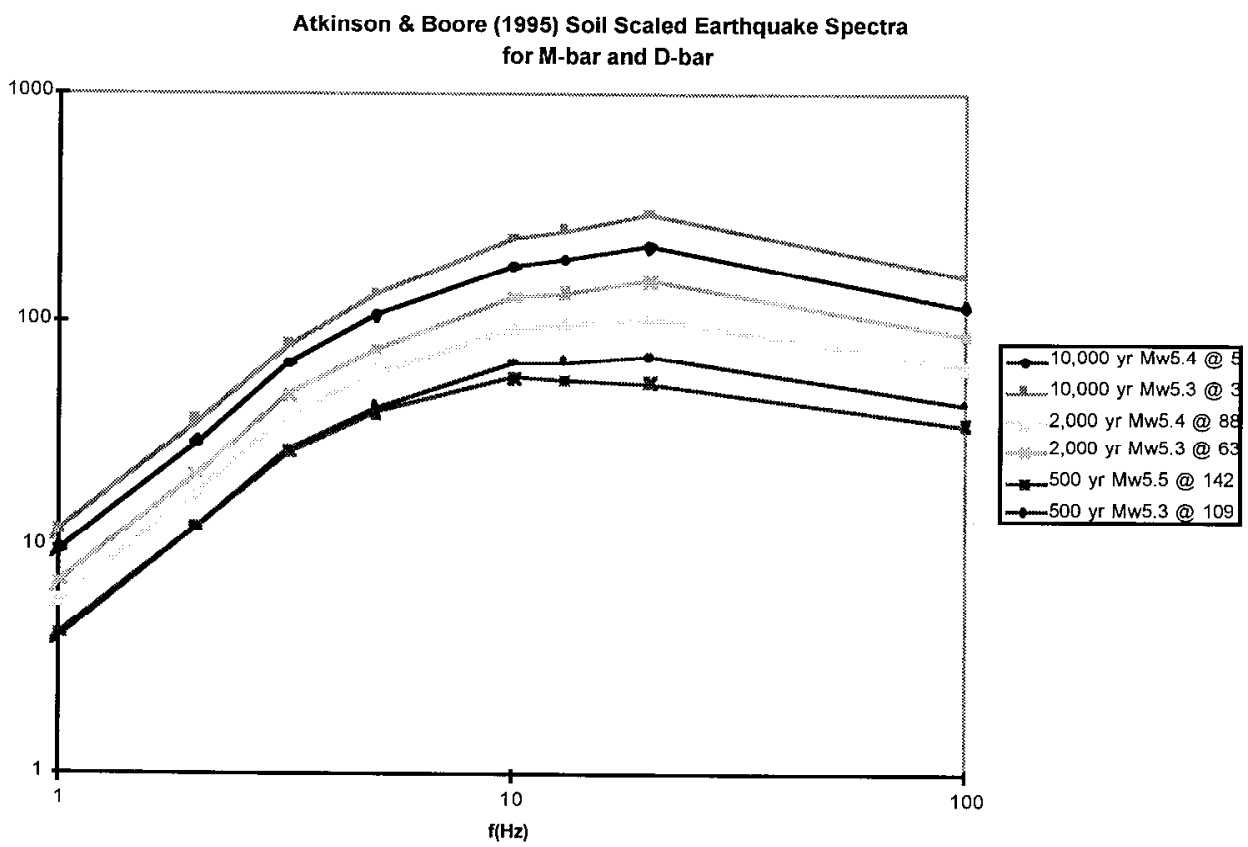

Figure 3.4-20 Median soil site response spectrum for each of the six controlling earthquakes (A/B95 ground motion model and the EPRI93 amplification factors) 
LLNL Composite Rock Earthquake Spectra for M-bar and D-bar

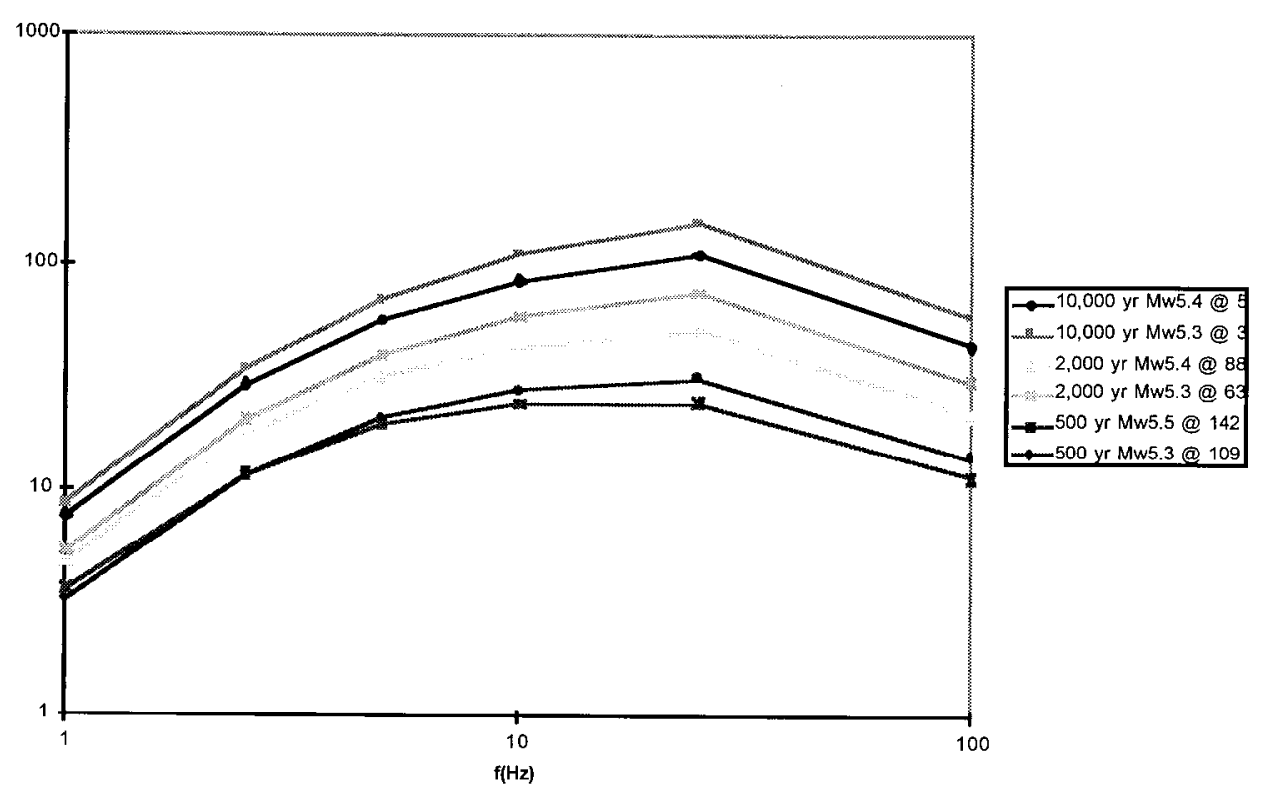

Figure 3.4-21 Median rock site response spectrum for each of the six controlling earthquakes (LLNL93 ground motion model)

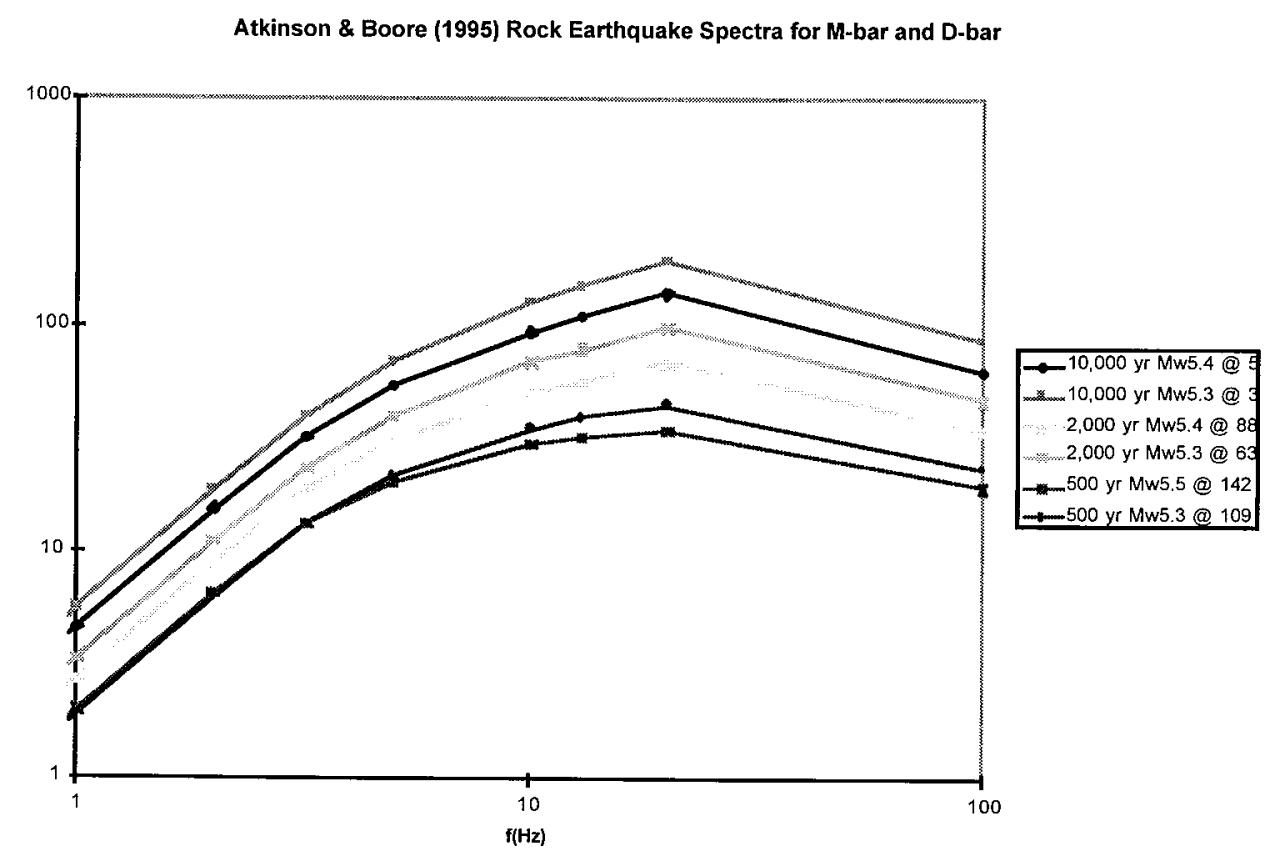

Figure 3.4-22 Median rock site response spectrum for each of the six controlling earthquakes (A/B95 ground motion model) 


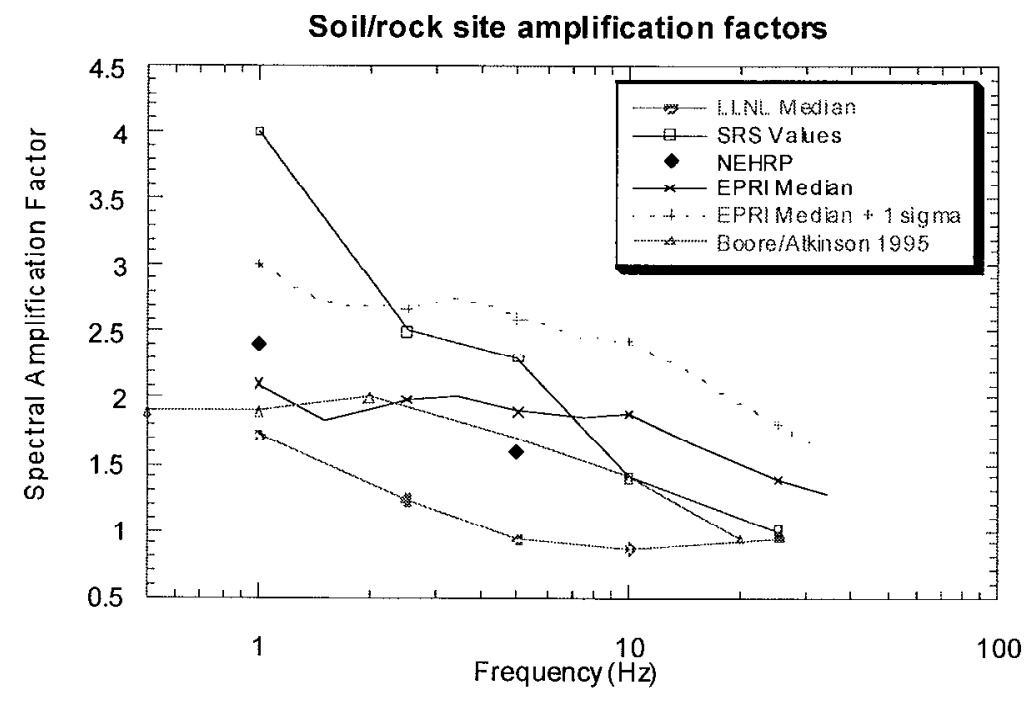

Figure 3.4-23 Comparison of site amplification factors considered in this study for Pantex site.

Soil UHS (500 yr.)

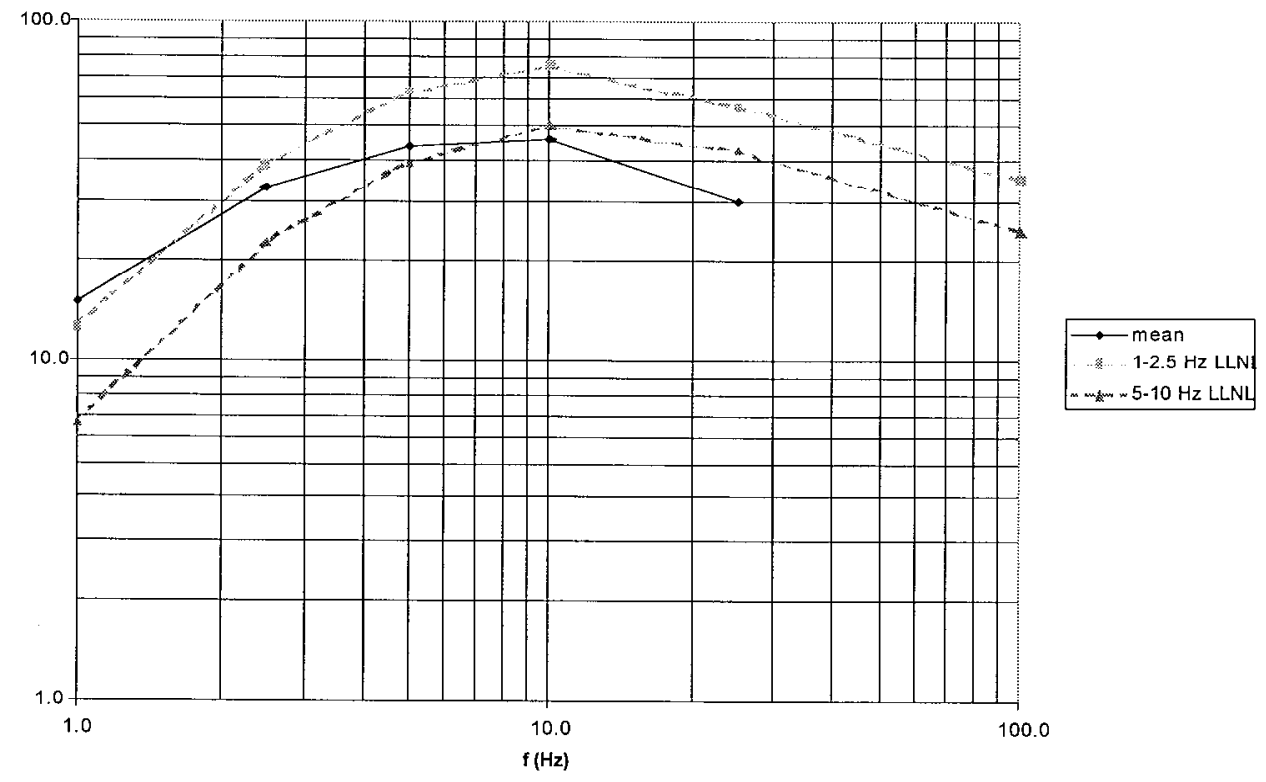

Figure 3.4-24 Scaling of the LLNL93 controlling earthquakes response spectral shape to the spectral values of the 500-year return period UHS at $(1-2.5 \mathrm{~Hz})$ and $(5-10 \mathrm{~Hz})$. 
Soil UHS (1000 yr.)

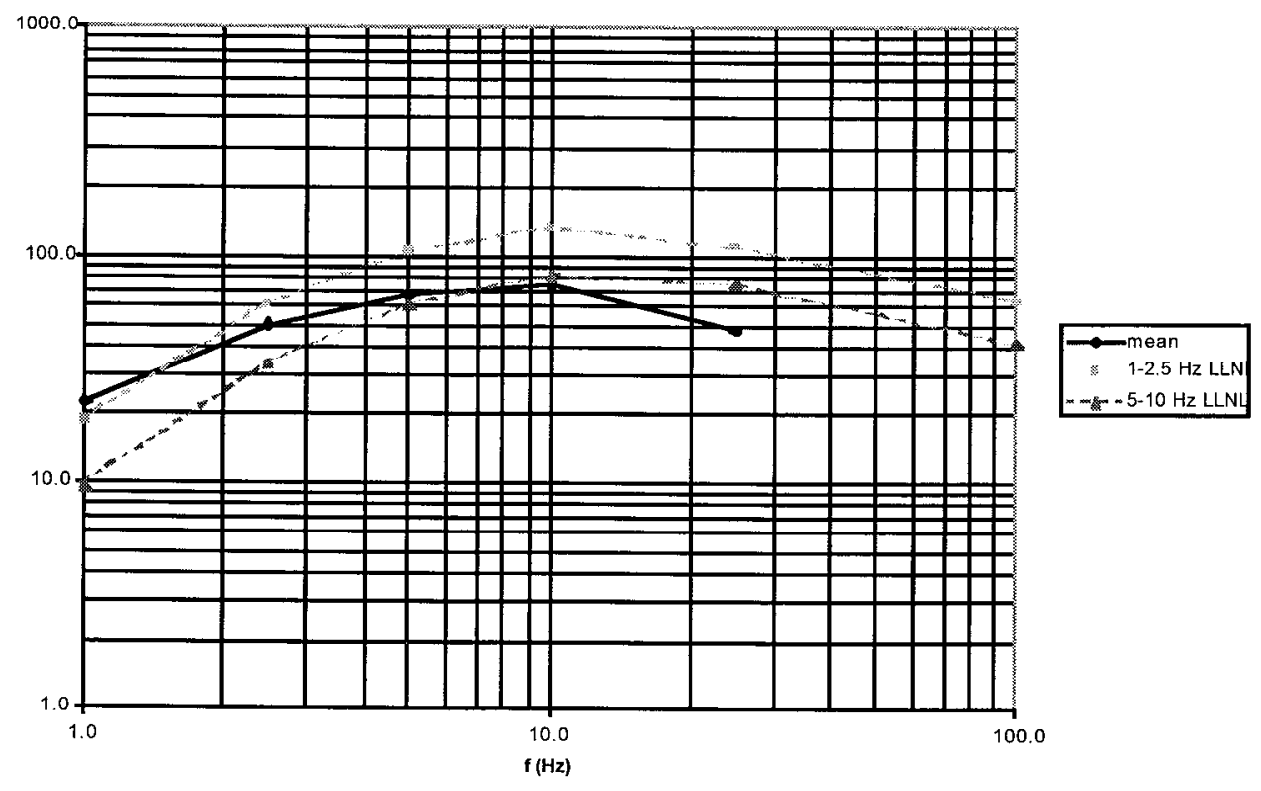

Figure 3.4-25 Scaling of the LLNL93 controlling earthquakes response spectral shape to the spectral acceleration values of the 1,000-year return period UHS at $(1-2.5 \mathrm{~Hz})$ and $(5-10 \mathrm{~Hz})$.

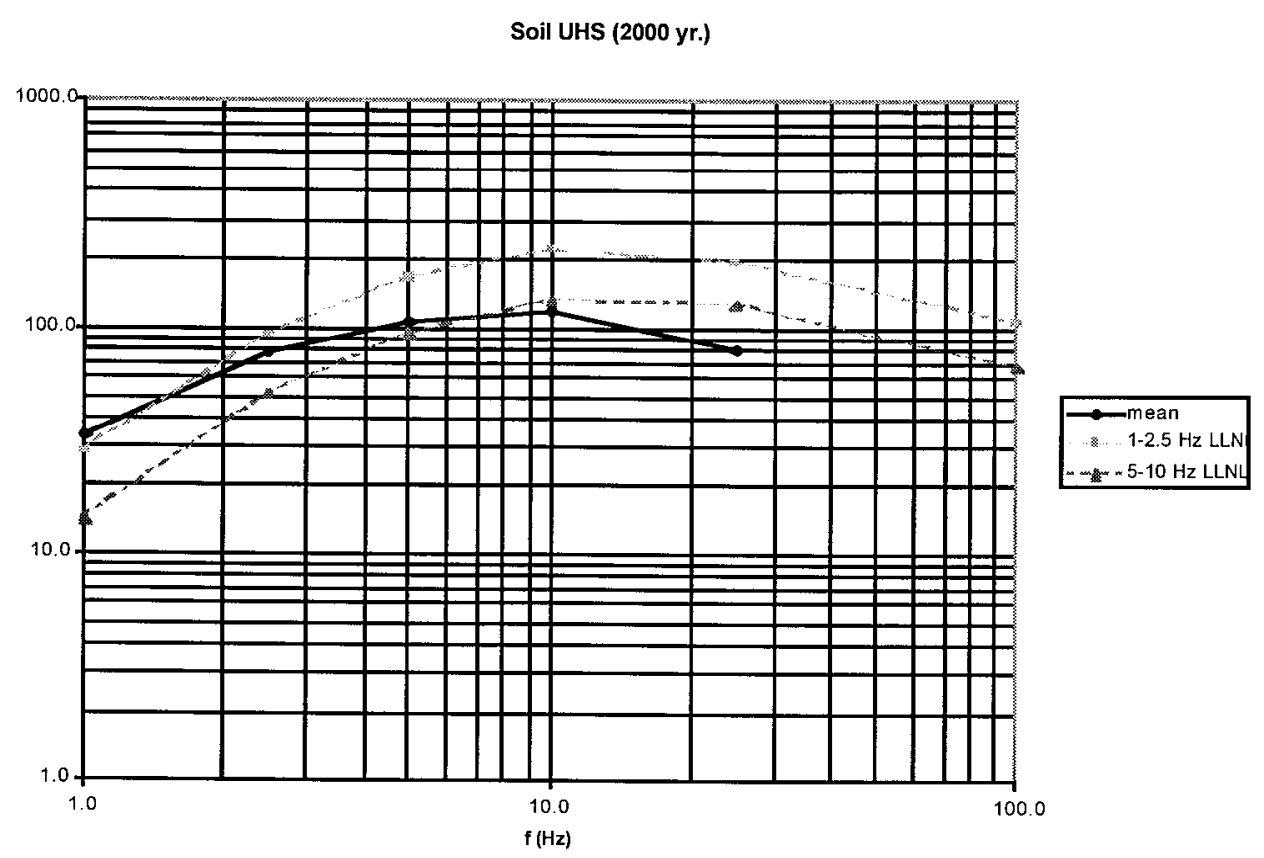

Figure 3.4-26 Scaling of the LLNL93 controlling earthquakes response spectral acceleration shape to the spectral values of the 2,000-year return period UHS at $(1-2.5 \mathrm{~Hz})$ and

$(5-10 \mathrm{~Hz})$. 
Soil UHS (10000 yr.)

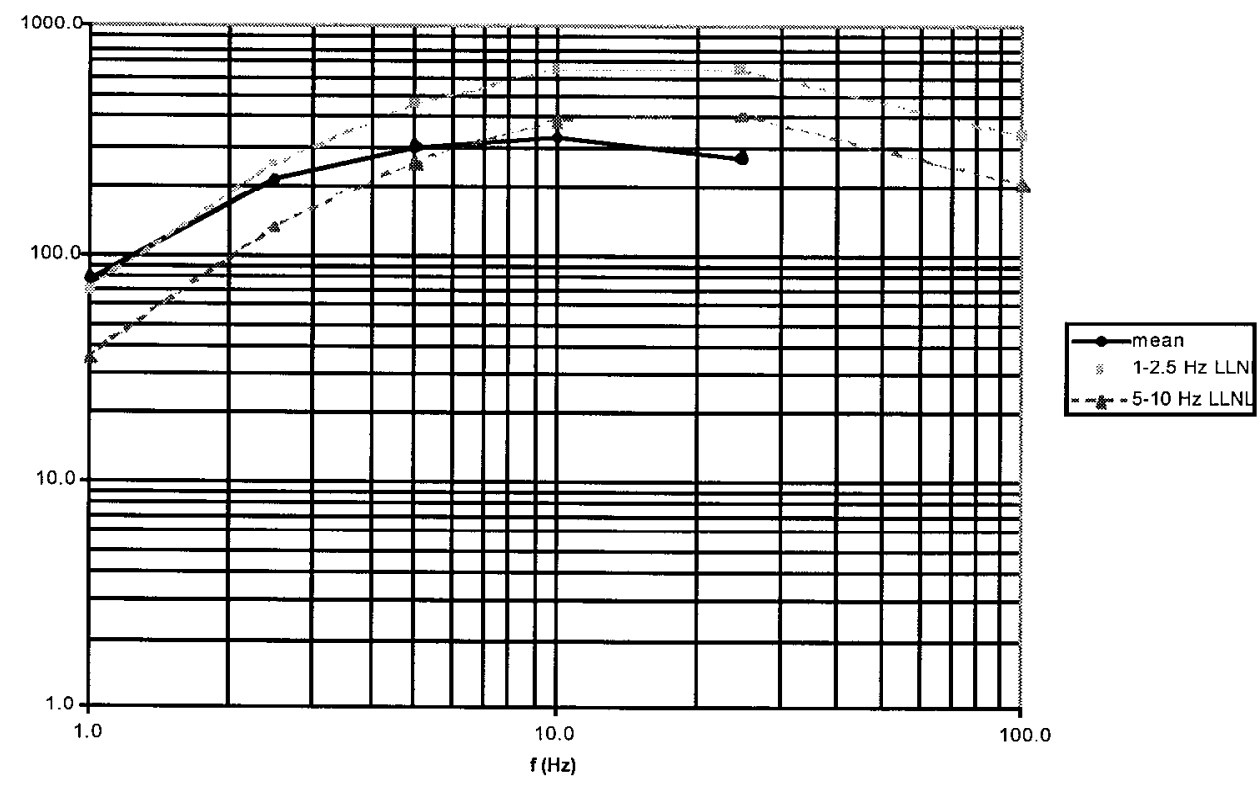

Figure 3.4-27 Scaling of the LLNL93 controlling earthquakes response spectral acceleration shapes to the spectral values of the 10,000-year return period UHS at $(1-2.5 \mathrm{~Hz})$ and $(5-10 \mathrm{~Hz})$.

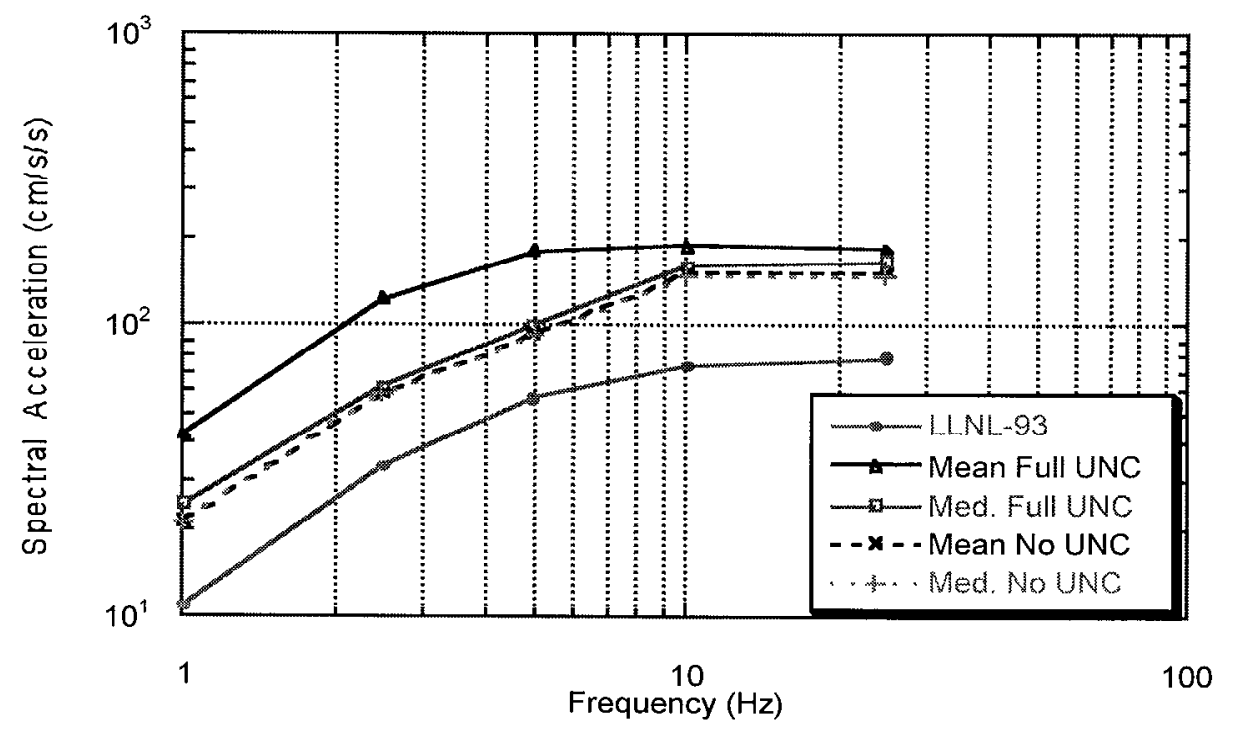

Figure 3.4-28 Comparison of spectral shapes between the LLNL93, $M_{w} 6,100-\mathrm{km}$ distance model and the 10,000-year return period UHS shapes with full uncertainty labeled "Full UNC" and with no epistemic uncertainty in the ground motion models labeled "No UNC". 


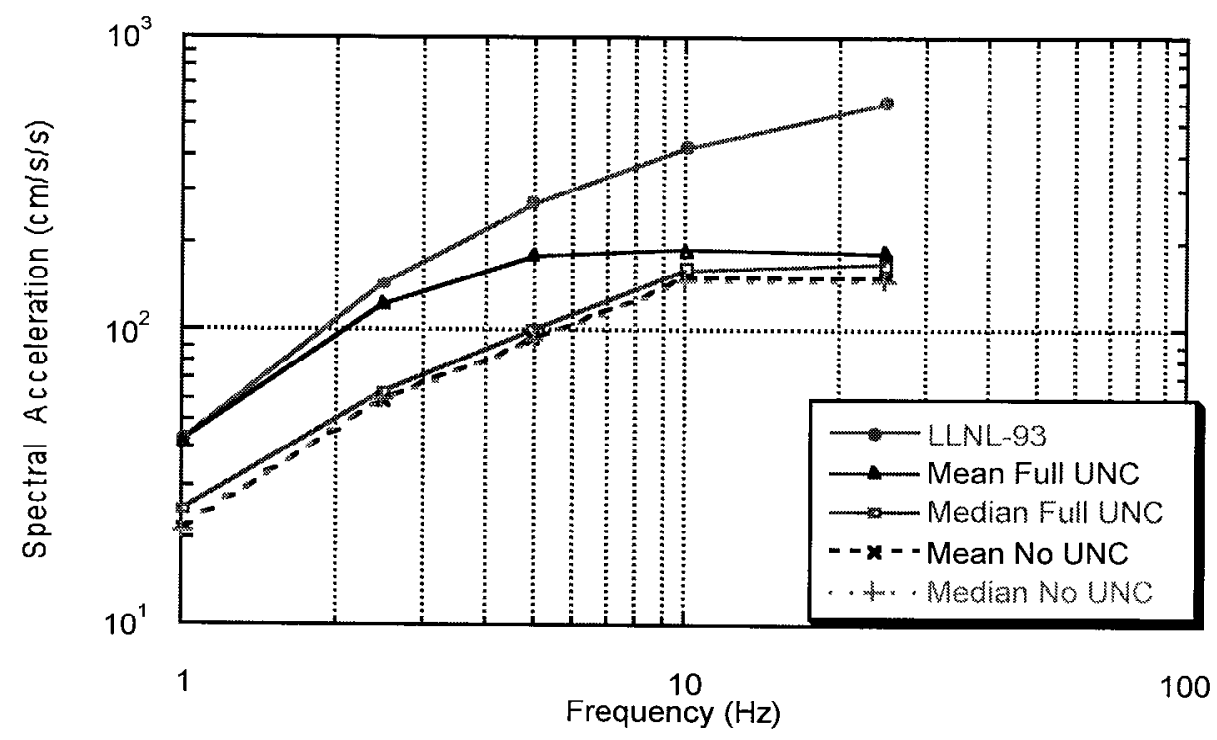

Figure 3.4-29 Comparison of spectral shapes between the LLNL93, $M_{w} 6,20-\mathrm{km}$ distance model and the 10,000-year return period UHS shapes with full uncertainty labeled "Full UNC" and with no epistemic uncertainty in the ground motion model labeled "No UNC".

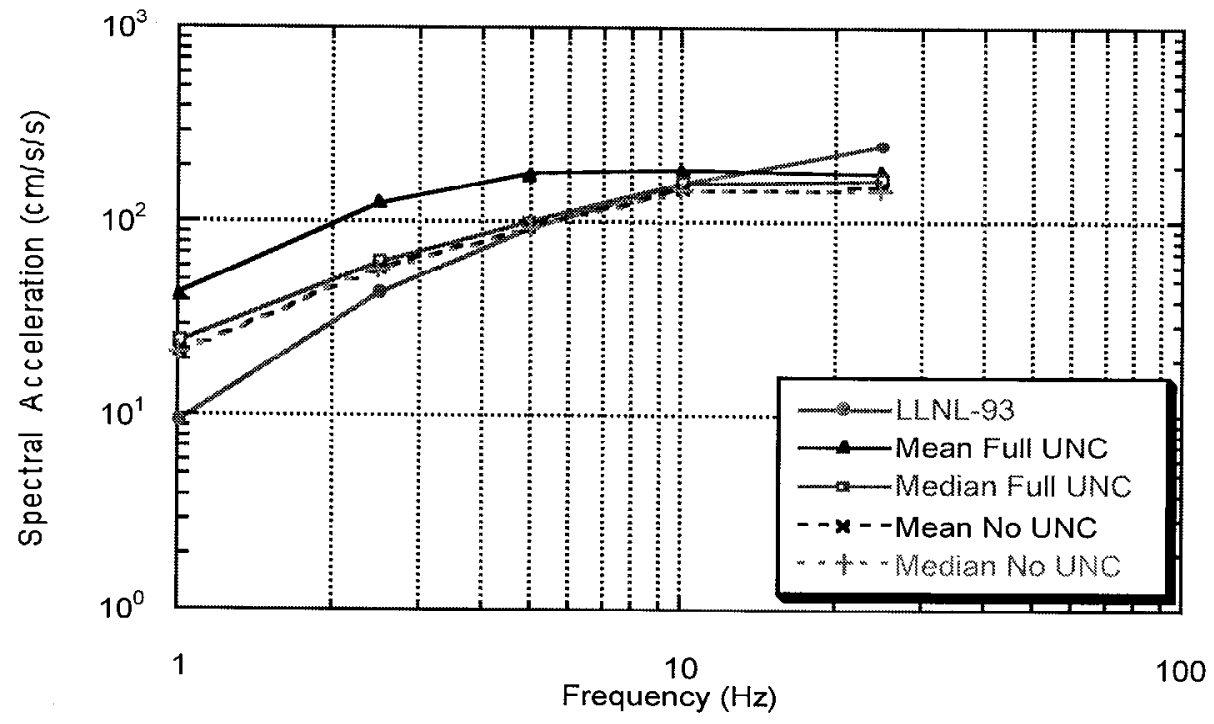

Figure 3.4-30 Comparison of spectral shapes between the LLNL93, $M_{w} 5,20-\mathrm{km}$ distance model and the 10,000-year return period UHS shapes with full uncertainty labeled "Full UNC" and with no epistemic uncertainty in the ground motion model labeled "No UNC" 


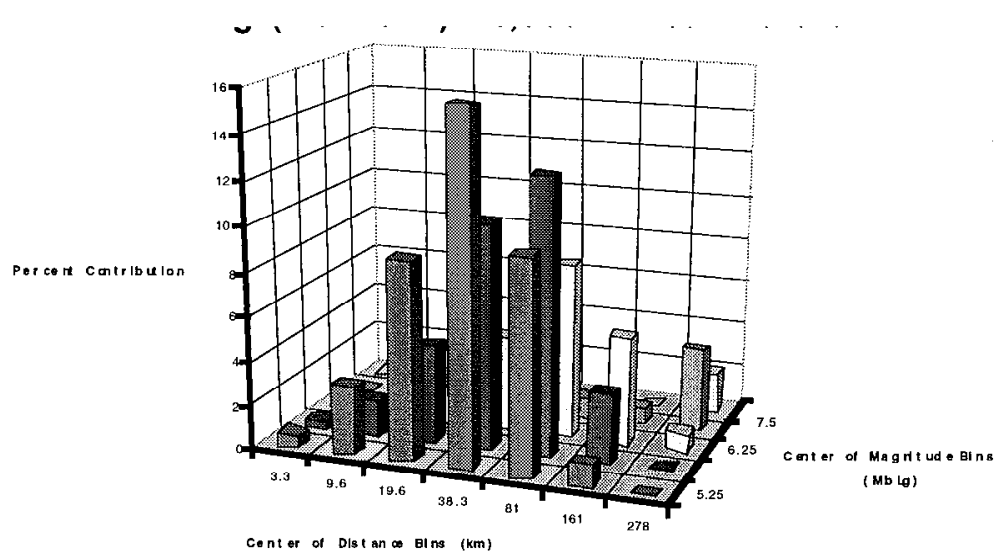

Figure 4.1-1 Contributions of magnitude and distance bins to the avg. (1.0-2.5 Hz) 10,00-yr. mean hazard

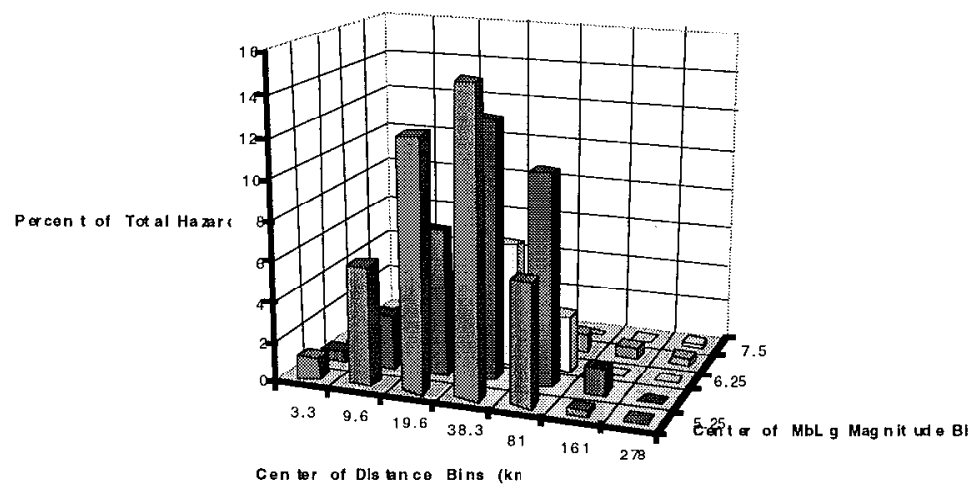

Figure 4.1-2 Contribution of the distance and magnitude bins to the avg. $(5.0-10.0 \mathrm{~Hz}) 10,000-\mathrm{yr}$. mean hazard

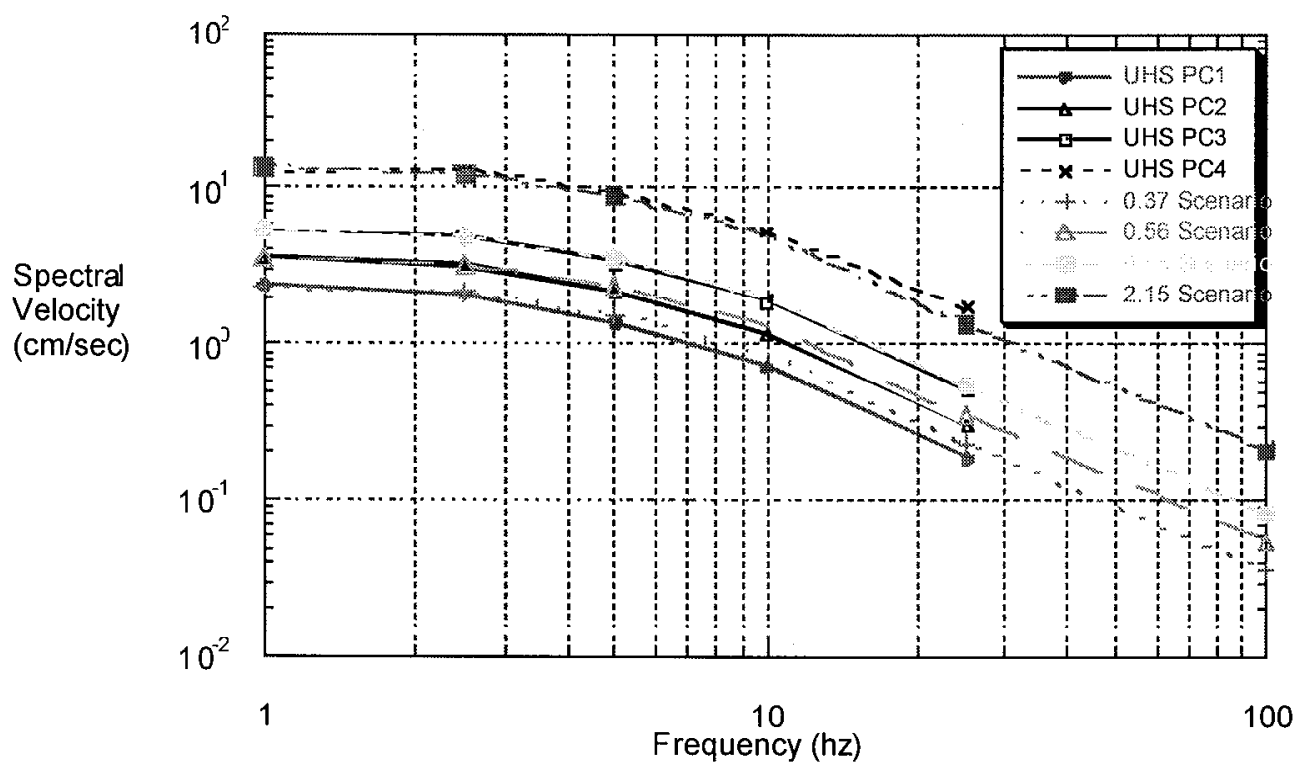

Figure 4.1-3 Comparison of the UHS spectra and the (1-2.5Hz) scaled low-frequency scenario earthquake shapes $\left(\mathrm{m}_{\mathrm{bLg}} 6.8,151 \mathrm{~km}\right)$ 


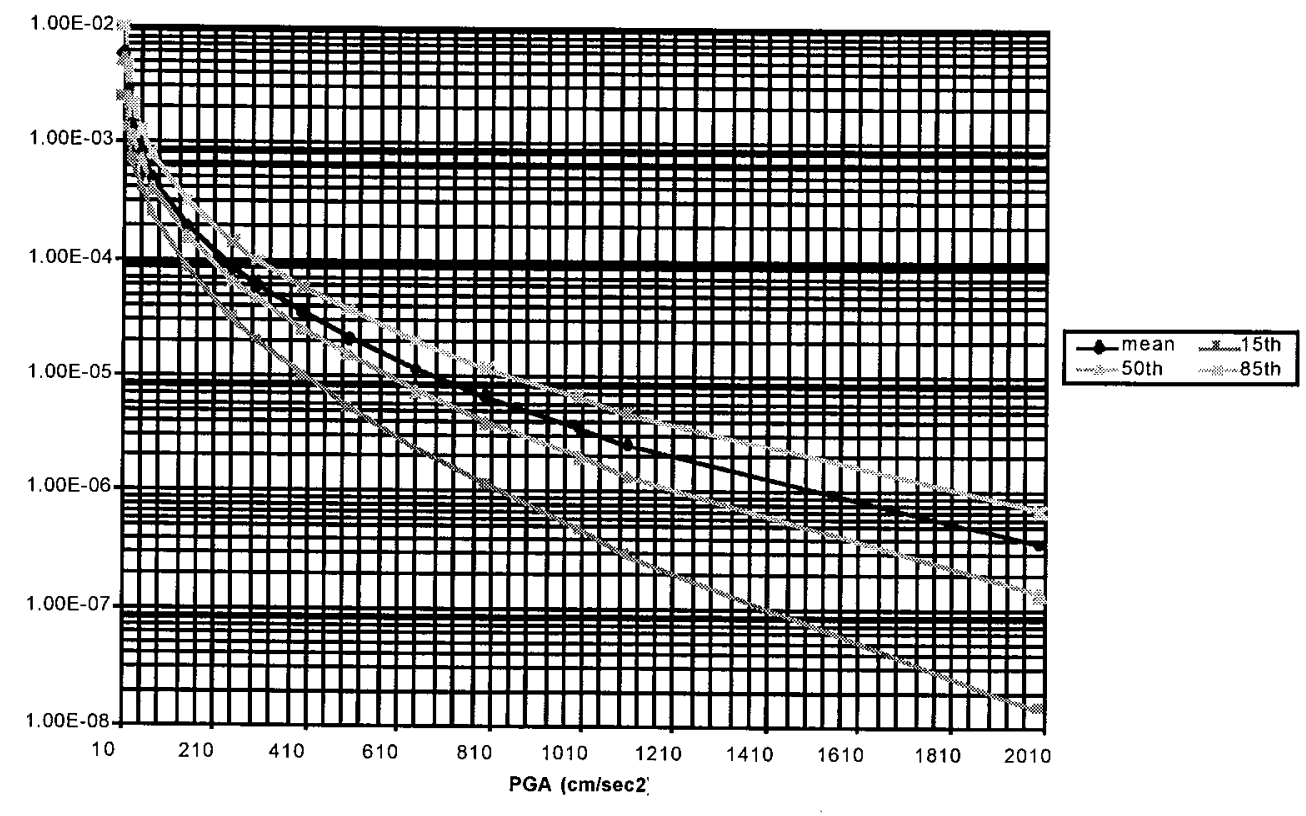

Figure 4.2-1 Final estimate of the mean, 15th, 50th, and 85th percentile hazard (annual probability of exceedance) at the Pantex soil site, with a linear PGA axis

LLNL Composite Soil PGA Hazard

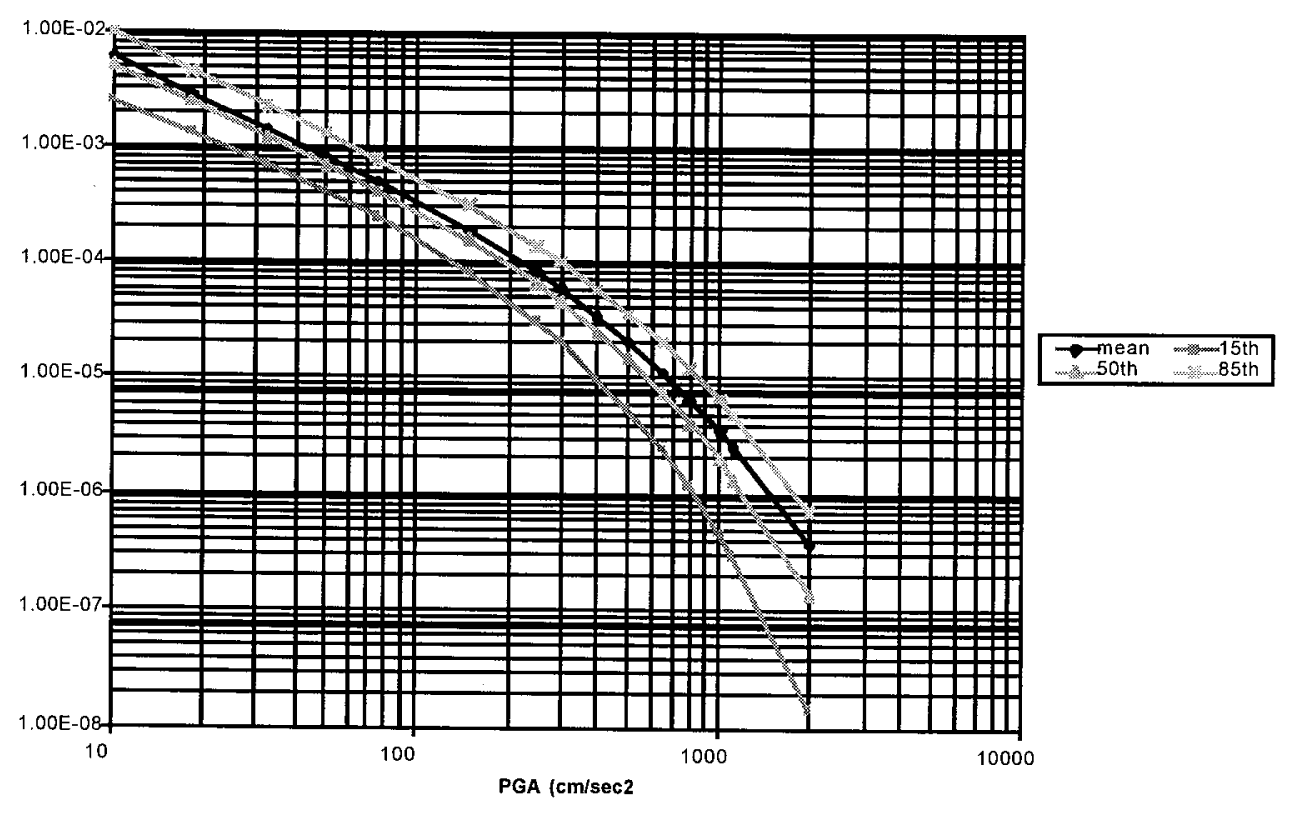

Figure 4.2-2 Final estimate of the mean, 15th, 50th, and 85th percentile hazard (annual probability of exceedance) at the Pantex soil site, with a log linear PGA axis 


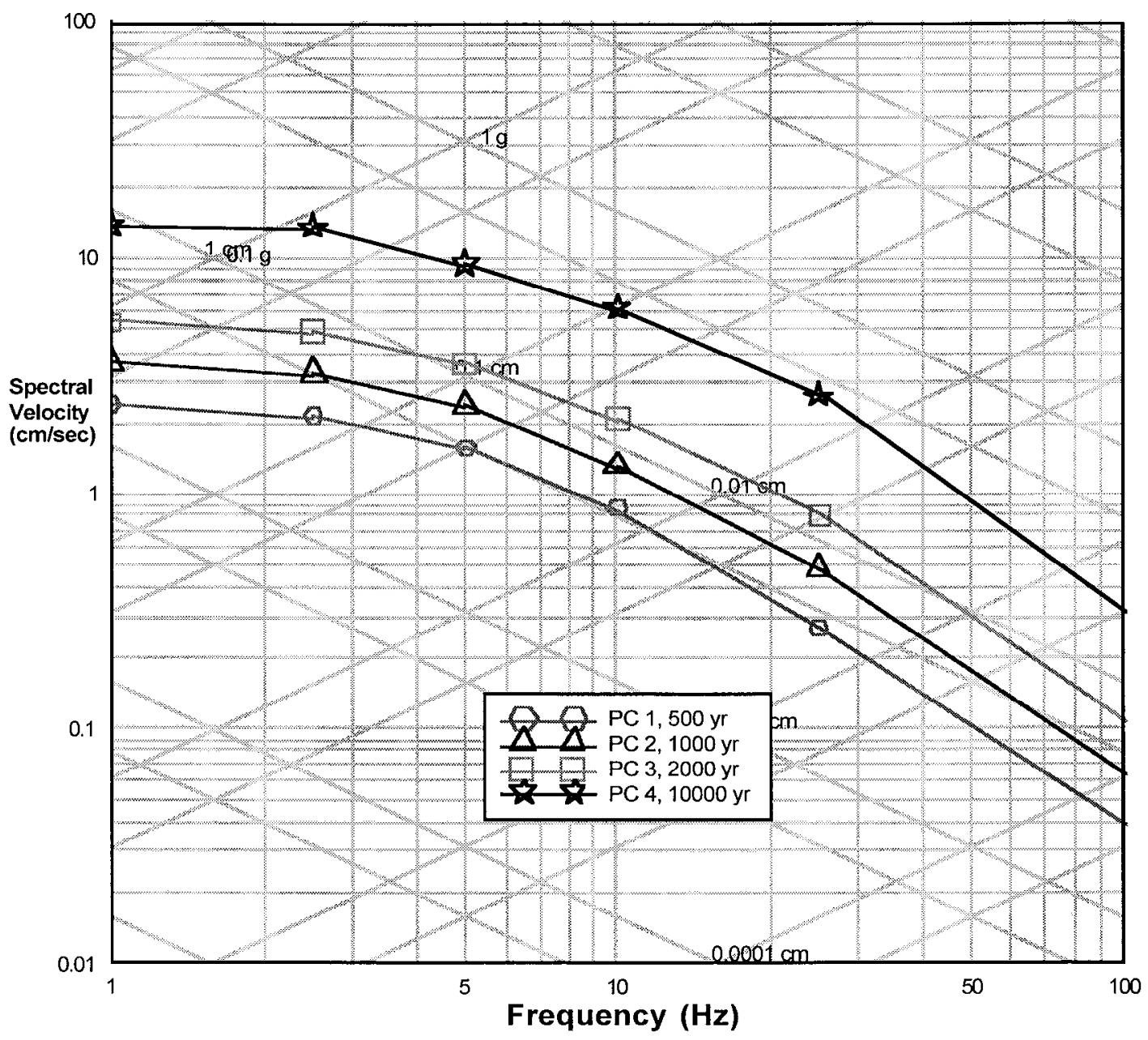

Figure 4.2-3 Design basis for Pantex 5\%-damping response spectra 


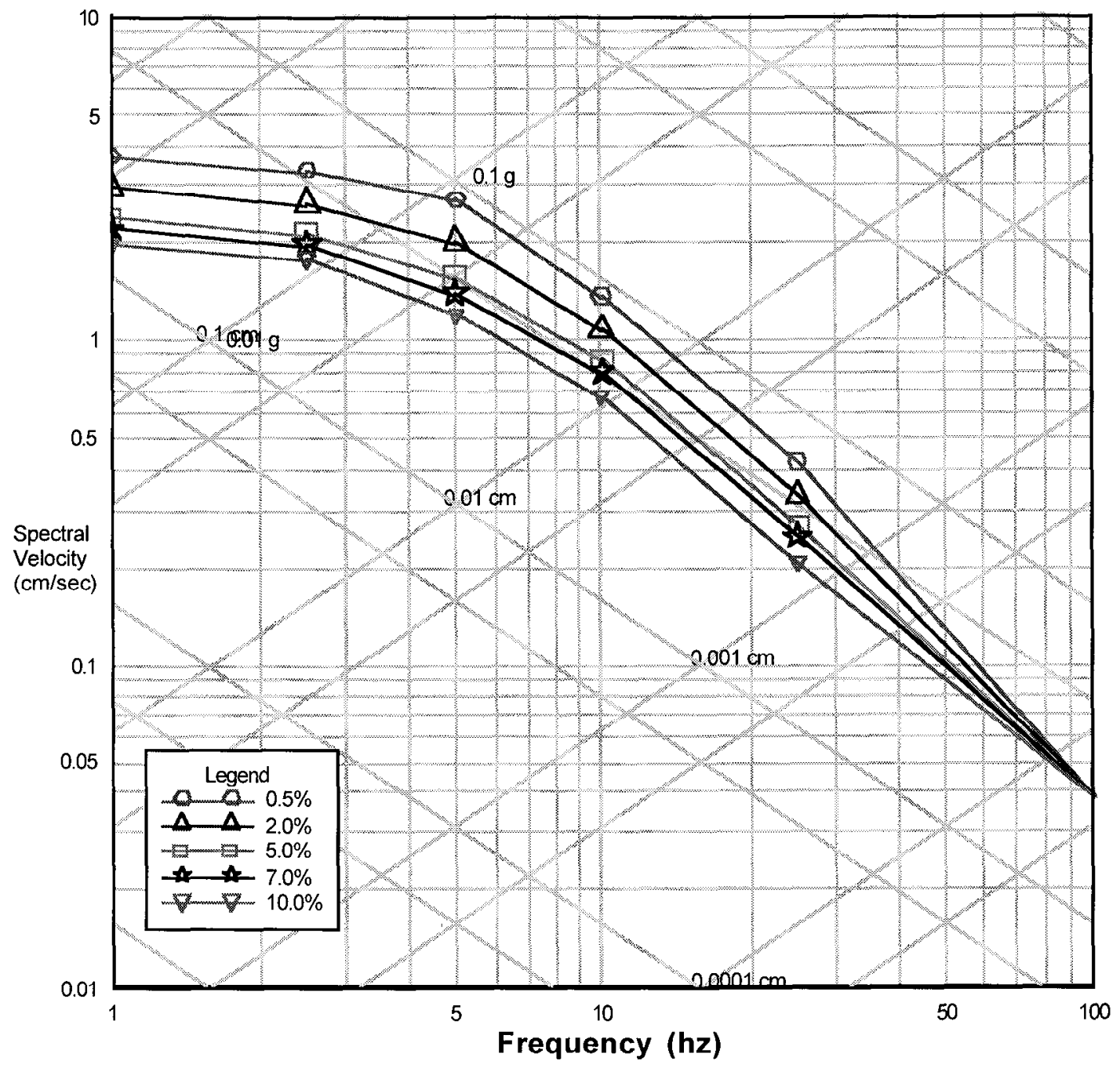

Figure 4.2-4 DBE response spectra for Pantex PC 1 (500 yr.) 0.5, 2.0, 5.0, 7.0 and 10.0\% damping 


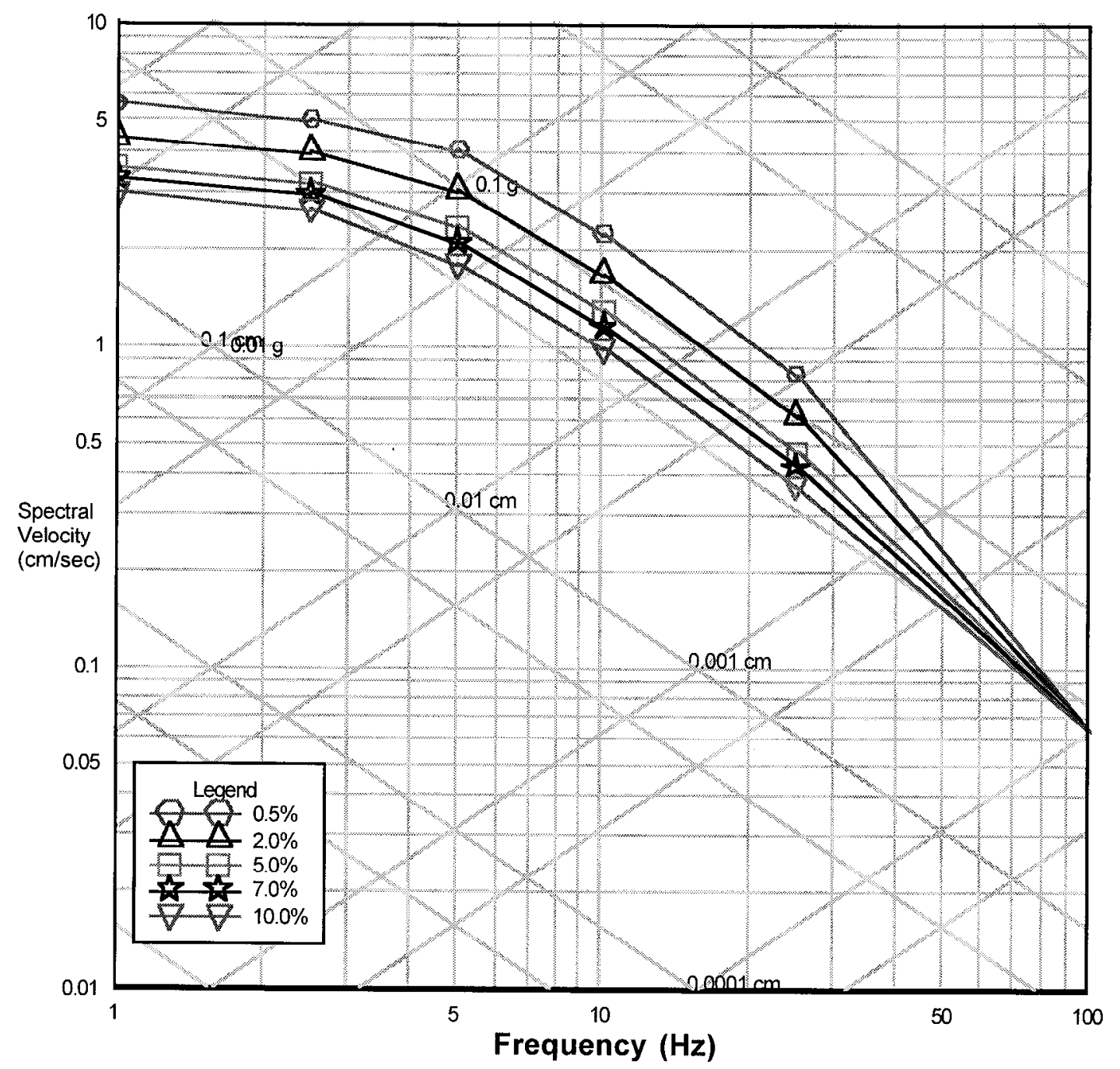

Figure 4.2-5 DBE response spectra for Pantex PC 2 (1000 yr.) 0.5, 2.0, 5.0, 7.0 and 10.0\% damping 


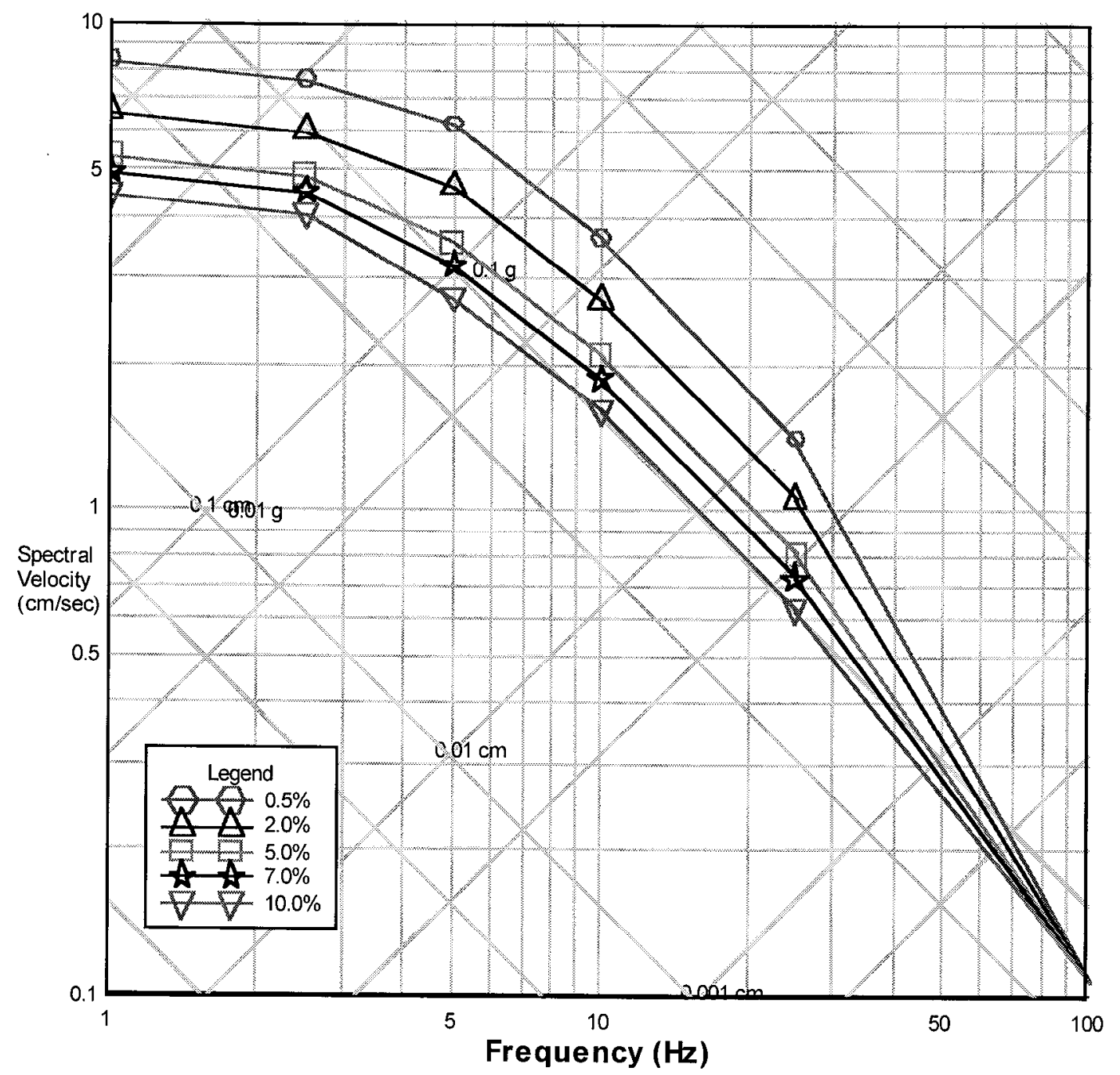

Figure 4.2-6 DBE response spectra for Pantex PC 3 (2000 yr.) 0.5, 2.0, 5.0, 7.0 and 10.0\% damping 


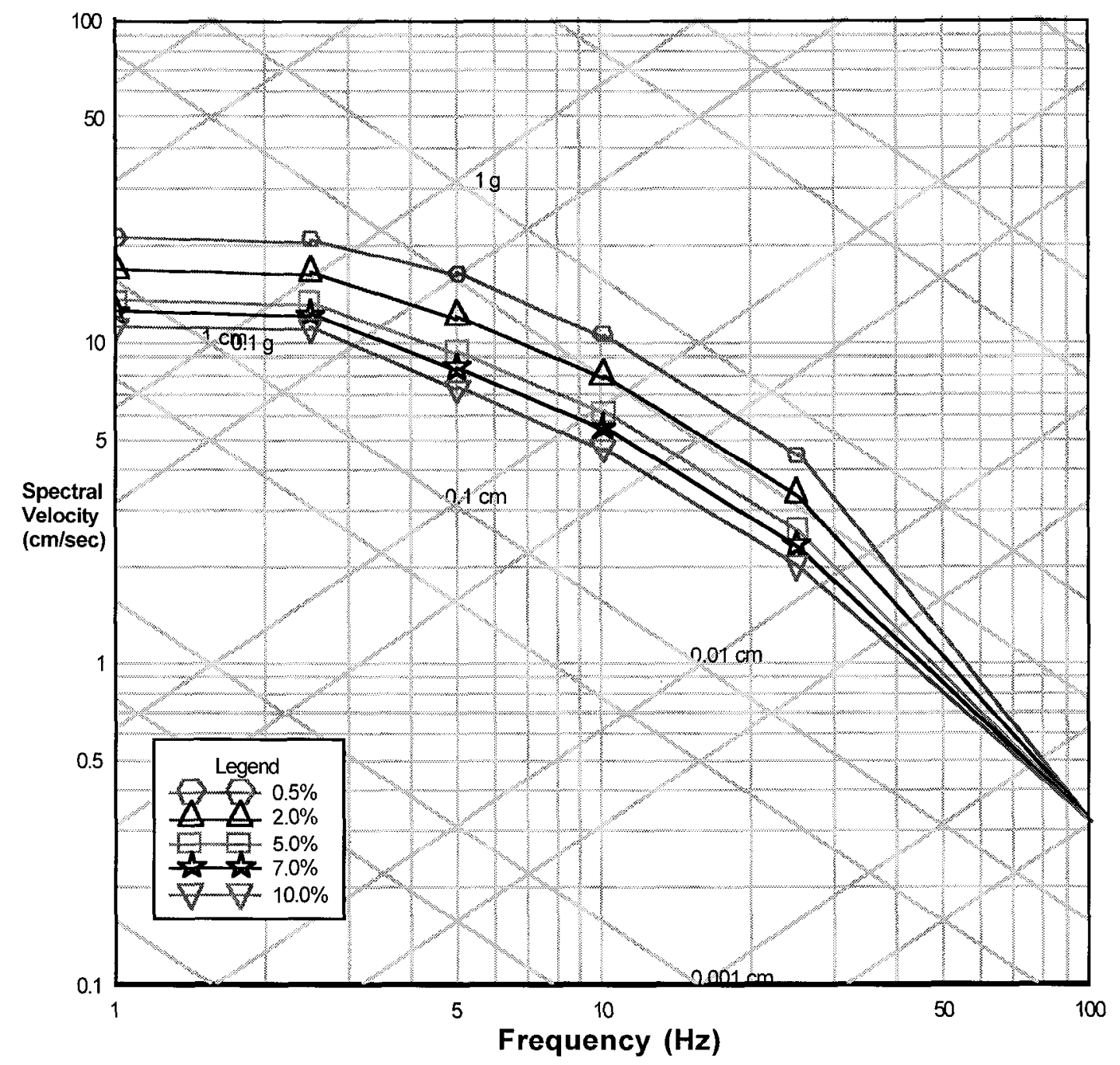

Figure 4.2-7 DBE response spectra for Pantex PC 4 (10,000 yr.) 0.5, 2.0, 5.0, 7.0 and 10.0\% damping 